\title{
Exploring Macroporosity of Additively Manufactured Titanium Metamaterials for Bone Regeneration with Quality by Design: A Systematic Literature Review
}

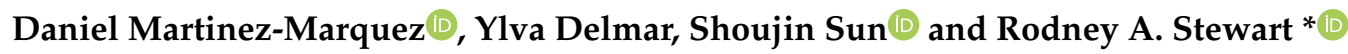 \\ School of Engineering and Built Environment, Griffith University, Gold Coast, QLD 4222, Australia; \\ daniel.martinezmarquez@griffithuni.edu.au (D.M.-M.); ylvadelmar@hotmail.com (Y.D.); \\ shoujin.sun@griffith.edu.au (S.S.) \\ * Correspondence: r.stewart@griffith.edu.au
}

Received: 23 September 2020; Accepted: 23 October 2020; Published: 27 October 2020

check for updates

\begin{abstract}
Additive manufacturing facilitates the design of porous metal implants with detailed internal architecture. A rationally designed porous structure can provide to biocompatible titanium alloys biomimetic mechanical and biological properties for bone regeneration. However, increased porosity results in decreased material strength. The porosity and pore sizes that are ideal for porous implants are still controversial in the literature, complicating the justification of a design decision. Recently, metallic porous biomaterials have been proposed for load-bearing applications beyond surface coatings. This recent science lacks standards, but the Quality by Design (QbD) system can assist the design process in a systematic way. This study used the QbD system to explore the Quality Target Product Profile and Ideal Quality Attributes of additively manufactured titanium porous scaffolds for bone regeneration with a biomimetic approach. For this purpose, a total of 807 experimental results extracted from 50 different studies were benchmarked against proposed target values based on bone properties, governmental regulations, and scientific research relevant to bone implants. The scaffold properties such as unit cell geometry, pore size, porosity, compressive strength, and fatigue strength were studied. The results of this study may help future research to effectively direct the design process under the $\mathrm{QbD}$ system.
\end{abstract}

Keywords: porous implants; bone implants; metamaterials; titanium; mechanical properties; pore size; unit cell; porosity; elastic modulus; compressive strength; additive manufacturing

\section{Introduction}

\subsection{Current Issues with Trational Bone Implants and Scaffolds}

Many physical conditions necessitate bone tissue replacements and joint implants. Some of these conditions are caused by degenerative diseases, birth defects, and orthopaedic traumas [1]. However, despite the tremendous progress in biomedical engineering, $20 \%$ of patients subjected to joint reconstructive surgery experience significant problems [2]. This situation is reflected in the fact that orthopaedic products, such as knee and hip prostheses, are the fifth most recalled medical products; of these recalls, $48 \%$ are due to manufacturing issues and 34\% to design flaws [3,4]. Some of the main flaws with orthopaedic implants are associated with their longevity, material properties, and mismatch with patient size and shape requirements $[5,6]$. Stress shielding is one of the main design flaws of load-bearing prostheses. This phenomenon occurs because bone is a self-healing material that requires load application to remodel itself, but a material with a higher modulus of elasticity $(E)$ absorbs all the stress generated, leading to bone reabsorption and subsequent loosening of the implant [7]. 
In the case of bone defects, they can be caused by tumour resection, infections, complex fractures, and non-unions [8]. The most common treatment for bone defects is surgical intervention, where an autograft (bone taken from the patient's body) is used to fill bone defect spaces [9]. However, due to their restricted availability, allografts (bone tissue from a deceased donor) are frequently used to treat critical-size defects [9]. Bone grafting is a common surgical procedure; it has been estimated that 2.2 million grafting procedures are performed worldwide each year [8]. However, late graft rupture has been reported to be as high as 60\% 10 years after the grafting procedure [10]. Allograft transplantation has a success rate of approximately $70 \%$. The low success rate of allografts is caused by the prevalence of infection, rejection by the host's immune system, fatigue fractures, delayed union, non-union, and incomplete graft resorption [11,12]. In the case of autografts, the disadvantages are increased post-operative morbidity, lack of available tissue, chronic pain, infection, nerve injury, and weakened bone donor graft sites $[12,13]$.

To solve these grafting problems, several scaffold traditional techniques have been used without much success: solvent-casting particulate-leaching, gas foaming, fibre meshes (fibre bonding), phase separation, melt moulding, emulsion freeze drying, solution casting, and freeze drying [14]. Some of the disadvantages of traditional scaffold fabrication techniques are their lack of control over porosity characteristics, such as pore size, pore distribution, and interconnectivity; the toxic by-products of scaffold degradation; and their lack of consistent mechanical properties [14]. Hence, traditional techniques for bone reconstruction including grafting and prostheses are not sufficiently effective, which represent a medical challenge that comes with several limitations and risks [9]. Moreover, no material yet exists with the ideal properties for bone tissue replacement [15-17]. To overcome these issues, tissue engineering has focused on additive manufacturing technologies to produce the next generation of bone implants and scaffolds.

\subsection{Additive Manufacturing}

Additive manufacturing (AM) technologies, supported by computer-aided design (CAD) software, progressively build 3D physical objects from a series of cross-sections, which are joined together to create a final shape [18]. With AM, it is possible to create complex interconnected and porous structures with controlled pore size, shape, and distribution and properties resembling bone mechanical properties, such as a modulus of elasticity to induce bone ingrowth $[19,20]$. This capability permits the fabrication of hierarchical structures at the microscale and the manipulation of material properties to create metamaterials. In terms of implant design, this advance means that products can be designed with a biomimetic approach according to the patient's anatomy and the bone tissue's mechanical properties [21]. The design freedom of AM allows its use in difficult clinical scenarios in which bone diseases, deformities, and trauma usually necessitate the reconstruction of bone defects with complex anatomical shapes, which is extremely difficult even for the most skilled surgeon [22]. The complex reconstruction of bone defects is possible through combining the advantages of AM with CAD and medical imaging technologies, such as computed tomography and magnetic resonance, to fabricate implants according to the patient's specific anatomy, thus achieving an exact adaptation to the region of implantation [23]. In the search of suitable materials for AM, bone regeneration, and implant application tissue engineering has focused on developing a variety of different types of synthetic and natural materials.

\subsection{Materials for Bone Regeneration and Implant Applications}

Materials appropriate for implantation within the human body require distinct biocompatible properties. Therefore, in the selection of appropriate materials for implant applications, several factors must be considered. First, the intended implant location must be considered to predict host response, which is governed by the biochemical and physical environments in contact with the medical device $[24,25]$. Second, the material should possess appropriate biological and mechanical properties for its specific purpose to prevent physical damage to the body. Third, from the perspective of 
tissue engineering, materials should mimic one or multiple characteristics of the natural region of repair. In the case of bone repair, the desired characteristics are osteoconductivity, osteoinductivity, and osseointegration. As a result, for an optimum scaffold and prosthesis design, material science may combine several technologies to create suitable materials that fulfil these needs.

\subsubsection{Polymers}

Polymers for AM and tissue engineering applications are biocompatible materials that offer several advantages over other materials, including biodegradability, cytocompatibility, easy processability, and flexibility in the tailoring of their properties [26]. Polymers can be classified as natural or synthetic and some of them already have regulatory approval [27].

Natural polymers are made from proteins such as alginate, gelatine, collagen, silk, chitosan, cellulose, and hyaluronic acid [28]. The advantages of natural polymers are their excellent biodegradability, low production costs, and superior chemical versatility, as well as their improved biological performance that allow better interactions with cells than other biomaterials, improving their attachment and differentiation [29]. However, natural polymers can be expensive to produce, due to the difficulty in controlling their mechanical properties, biodegradation rate, and quality consistency [30].

Due to the disadvantages of natural polymers, different synthetic polymers, such as polycaprolactone (PCL), polylactic acid (PLA), and poly Lactic-co-Glycolic Acid (PLGA), have been developed. Their advantages include low immunogenic potential, large scale low production cost, and good quality consistency [31]. Moreover, their mechanical properties, microstructure, and degradation rate can be tuned according to needs [27]. Despite the advantages of natural and synthetic polymers, they are unsuitable for load-bearing applications due to their lower modulus of elasticity compared to bone, unstable mechanical strength, and tendency to creep [32,33]. Hence, in recent years, a variety of polymers have been combined with different materials to such as bioceramics (e.g., bioglasses, tri-calcium phosphates, and carbon nanotubes) and metals to create composite materials with tunable mechanical properties as well as with the capacity to deliver drugs, exosomes, and growth factors, to name a few [34-37].

\subsubsection{Bioceramics}

Bioceramics are a large group of materials used for bone substitution and regeneration. Calcium phosphate $(\mathrm{CaP})$ ceramics is one of the main groups of bioceramics. Calcium phosphate ceramics are abundant in bone, constituting between $80 \%$ and $90 \%$ of bone's anorganic matter. This group of bioceramics is widely used as implant coating, bone grafting, and more recently have been fabricated for bone scaffolding applications with AM $[38,39]$. Hydroxyapatite HAP and $\beta$-tricalcium phosphate $(\beta-\mathrm{TCP})$, are the most-studied CaP bioceramics. The main advantages of calcium phosphate materials are their osteoinductive and osteoconductive properties, as well as their dissolution in body fluids [40]. For load-bearing applications, the major disadvantage of CaPs is their poor mechanical properties. Despite their good compressive strength, CaPs lack plastic deformation, making them brittle and prone to cracking. Consequently, these materials are not yet suitable for load-bearing applications [41]. Nevertheless, the lower wear rate of CaPs makes these materials the preferred choice for surface coating to reduce wear in joint prostheses [42]. They are also commonly used for spinal fusion, maxillofacial and cranio-maxillofacial reconstruction, as well as bone filler and bone cement due to their excellent biocompatibility and osteoconductivity [43].

Discovered in 1969 by Larry Hench, bioglasses are ceramic materials composed of calcium, phosphorus, and silicon dioxide [16]. Bioglasses are bioactive ceramic materials with strong osteointegrative and osteoconductive properties, as well as higher mechanical strength than calcium phosphate ceramics [44]. Hence, bioglasses have been intensely investigated with AM for bone tissue engineering applications $[45,46]$. The advantage of these materials is that by changing the proportions of their basic components, different forms with different properties can be obtained; for example, non-resorbable bioglasses can be transformed into resorbable bioglasses [44]. Moreover, they 
can be designed with controlled biodegradability and drug and cell delivery capabilities $[47,48]$. Their applications also include bioglass scaffolds produced using AM with controlled porosity architecture and improved mechanical properties for bone regeneration [49]. However, bioglasses are limited for use in practical load-bearing applications due to their low resistance to cyclic loading and their brittleness [50].

\subsubsection{Metals and Titanium as a Bio-Metamaterial}

Metals have been the common choice to replace hard tissue in load-bearing applications due to their mechanical properties, corrosion resistance, and biocompatibility. Most of these materials are alloys, such as 316L stainless steel (316LSS), cobalt chromium (Co-Cr), and titanium (Ti) alloys [5]. Among all metallic materials, the titanium alloy Ti-6Al-4V is the gold standard for orthopaedic applications [51,52] because of its high biocompatibility [53], high corrosion resistance, low modulus of elasticity [5], and high strength-to-weight ratio [19]. Furthermore, Ti is a reactive metal that naturally forms a thin layer of oxide, which blocks metal ions from reaching its surface, increasing its biocompatibility [54]. The biomedical applications of Ti-6Al-4V are quite broad and encompass dental implants; hip, shoulder, knee, spine, elbow, and wrist replacements; bone fixation components; and cardiovascular applications [5].

Nevertheless, the most common problems of metallic materials are wear and the stress-shielding effect caused by their high modulus of elasticity compared with bone [52,55-57]. Moreover, despite the excellent biocompatibility and mechanical properties of $\mathrm{Ti}$ and $\mathrm{Ti}$ alloys, they usually require long healing periods to create a stable interface with the surrounding bone [58], with insufficient implant osseointegration as a potential outcome [59]. Hence, to further augment the biological, mass transport, and mechanical performance of Ti and Ti alloys different metamaterials have been developed. For example, metallic bone implants with a modulus of elasticity similar to that of bone can drastically reduce wear, shear stress, and bone resorption and consequently prevent implant loosening and revision surgery [60]. This may translate into enhanced quality of life for the patient, reductions in hospital expenses and recovery time, and improvement in joint dynamic performance [61]. With porous $\mathrm{Ti}$ and Ti alloy bio-metamaterials, osseointegration is also improved, and superior results have been accomplished in relation to mechanical properties. Nonetheless, pores act as stress concentrators, reducing the material load capacity [23]. As a result, for the design of load-bearing prostheses, it is crucial to balance mechanical properties with biological stimulation. Consequently, there have been several efforts to find the optimal balance between pore size and porosity percentage in different materials. For example, Zaharin et al. [62] investigated the effect of pore variation on the porosity and mechanical properties of several Ti-6A-14V porous scaffolds. According to their results, scaffolds based on cube and gyroid unit cells with a pore size of $300 \mu \mathrm{m}$ provided similar properties to bone. Moreover, they concluded that increments in porosity decreased the scaffolds' elastic modulus and yield strength. In an earlier study Bobyn at al. [63] investigated the effects of pore size variation of cobalt-base alloy implants on the rate of bone growth. For this purpose, casted cobalt-base alloy implants were coated with powder particles and implanted into canine femurs for several weeks. The results indicated that pore sizes between 50 and $400 \mu \mathrm{m}$ provided the maximum bone ingrowth and fixation strength.

Despite the excellent biocompatibility and mechanical properties of Ti and Ti alloys, they usually require long healing periods to create a stable interface with the surrounding bone, frequently resulting in insufficient osseointegration [64]. Hence, to further augment Ti's bioactivity, corrosion resistance, and mechanical properties different mechanical, chemical, and physical surface modification methods have been developed [65-67]. Depending on the surface treatment used to modify Ti substrate, different topographic features can be achieved at the macroscale, microscale, and nanoscale. There is a large amount of evidence that rough Ti surfaces with topographic microfeatures better protein adsorption and provide higher osteoblasts attachment growth proliferation and activity than surface smooth surfaces [68]. Nonetheless, it has been demonstrated that nanoscale topography outperforms macro 
and micro-scale surface features towards augmenting cellular functions [69]. More recently, at has been proposed that a combination of different topographic features at the macro, micro, and nanoscale with local drug delivery functions can further enhance the biological, chemical, tribological, and mechanical performance of Ti bone implants [70-73].

\subsection{Purpose and Objectives}

The purpose of this research is to provide researchers and industry with an in-depth adaptation of the Quality by Design (QbD) system for the fabrication of additively manufactured porous Ti implants considering the QbD guidelines for 3D printed bone implants and scaffolds [74]. The QbD system is composed by eight main steps that need to be systematically followed to acquire a complete comprehension of the product and its manufacturing process, including the identification and control of all variables to achieve the desired quality. Specifically, the scope of this present study was limited to the first step of the QbD framework (Figure 1). Thus, the objectives of this study are:

1. Define the ideal mechanical, geometrical and dimensional characteristics of the internal architecture of $\mathrm{Ti}$ bone scaffolds from a biomimetic perspective.

2. Compare the results of different studies on fully porous Ti structures in relation to the ideal quality attributes of bone scaffolds.

3. Identify the studies on fully porous Ti structures that satisfies the critical quality attributes of Ti porous bone implants and scaffolds.

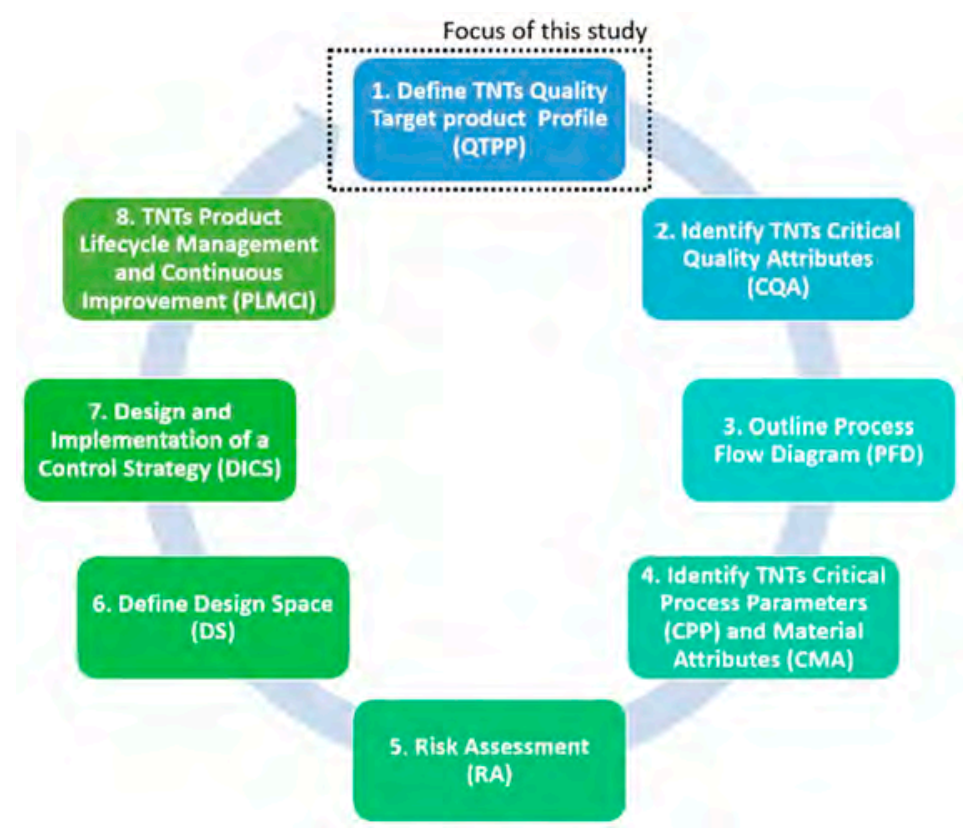

Figure 1. Schematic showing the focus of this study within the QbD system.

\section{Materials and Methods}

This systematic research study is part of the implementation of the QbD approach for porous metal implants. Therefore, a constructive research approach was used to further extend the $\mathrm{QbD}$ system for patient-specific bone implants and scaffolds produced by AM [75,76]. For an in-depth interpretation and synthesis the researchers immersed themselves in the contextual literature [77]. This was an exploratory qualitative study which requires the collection of secondary data from various datasets of peer-reviewed publications following the Preferred Reporting Items for Systematic Reviews and Meta-Analyses (PRISMA) statement [78]. 


\subsection{Data Collection}

A systematic search was conducted on 20 January 2020 in the Science Direct and Google Scholar databases according to objectives and the PRISMA statement. Relevant keywords were connected with the Boolean operators "OR" and "AND". Terms relevant to this research included the following: Titanium, Ti, additive manufacturing, 3D printing, rapid prototyping, bone tissue engineering, bone implant, implant, scaffold, prostheses, porous, porosity, and mechanical properties. To specify the search further, the terms were connected with Boolean operators (AND, OR): Implant(s); scaffold(s); prosthes(is, es); titanium; Ti; additive manufacturing; additively manufactured; 3D printing; and 3D printed.

The full phrase used was: (Implant* OR scaffold* OR prosthes?s) AND (titanium OR Ti) AND ("additive* manufactur" " OR "3D print" ${ }^{*}$ ") AND "mechanical properties" AND (porous OR porosity) AND "pore size" AND “elastic modulus" AND "fatigue".

\subsection{Study Selection}

Selected studies in the systematic literature search were limited to the following inclusion criteria: (1) peer-reviewed papers with full-text published within the last 20 years (2000 \pm 2020$)$; (2) empirical studies reporting the mechanical properties of $\mathrm{Ti}$ and Ti alloy porous scaffolds produced by AM for bone repair; (3) published in the English language; (4) the first 10 pages of the search results were assessed; and (5) the search results were sorted by relevance. From the systematic literature search in both the Science Direct and Google Scholar databases, a total of 5941 results were generated from which 83 articles were fully assessed, as presented in Table 1 and Figure 2.

Table 1. Search strategy, studies between 2000 and 2019.

\begin{tabular}{ccc}
\hline Database & Records Identified & Total \\
\hline Google Scholar & 3020 & 5941 \\
\hline Science Direct & 2921 & \\
\hline Duplicates & 80 & 5861 \\
\hline
\end{tabular}

\subsection{Data Extraction and Analysis}

The systematic literature search conducted in this study aimed to gather results of different studies regarding the characteristics of natural bone tissue, as well as the mechanical, geometrical, and dimensional properties of additively manufactured Ti porous implants with controlled porosity and/or pore size. The classification topics used in this study were pore size, pore shape, porosity, interconnectivity, multi-scaled, elastic modulus, compressive yield strength $\left(\sigma_{\mathrm{y}}\right)$, ultimate compressive strength $\left(\sigma_{\mathrm{tu}}\right)$, and fatigue strength. The references from the collected articles were systematically reviewed to identify further articles relevant to the subject. A full-text screening was performed by Y.D and D.M to avoid potential bias. A consensus meeting resolved any discrepancies between the reviewers.

Once all applicable literature had been identified, the extracted data were used to further extend the first step of the QbD system for fully porous Ti bone implants. Moreover, the data were also used to compare the different characteristics of Ti porous bone implants with natural bone tissue, and also to identify the most relevant characteristics that need to be imitated in the development of fully porous Ti bone implants. 


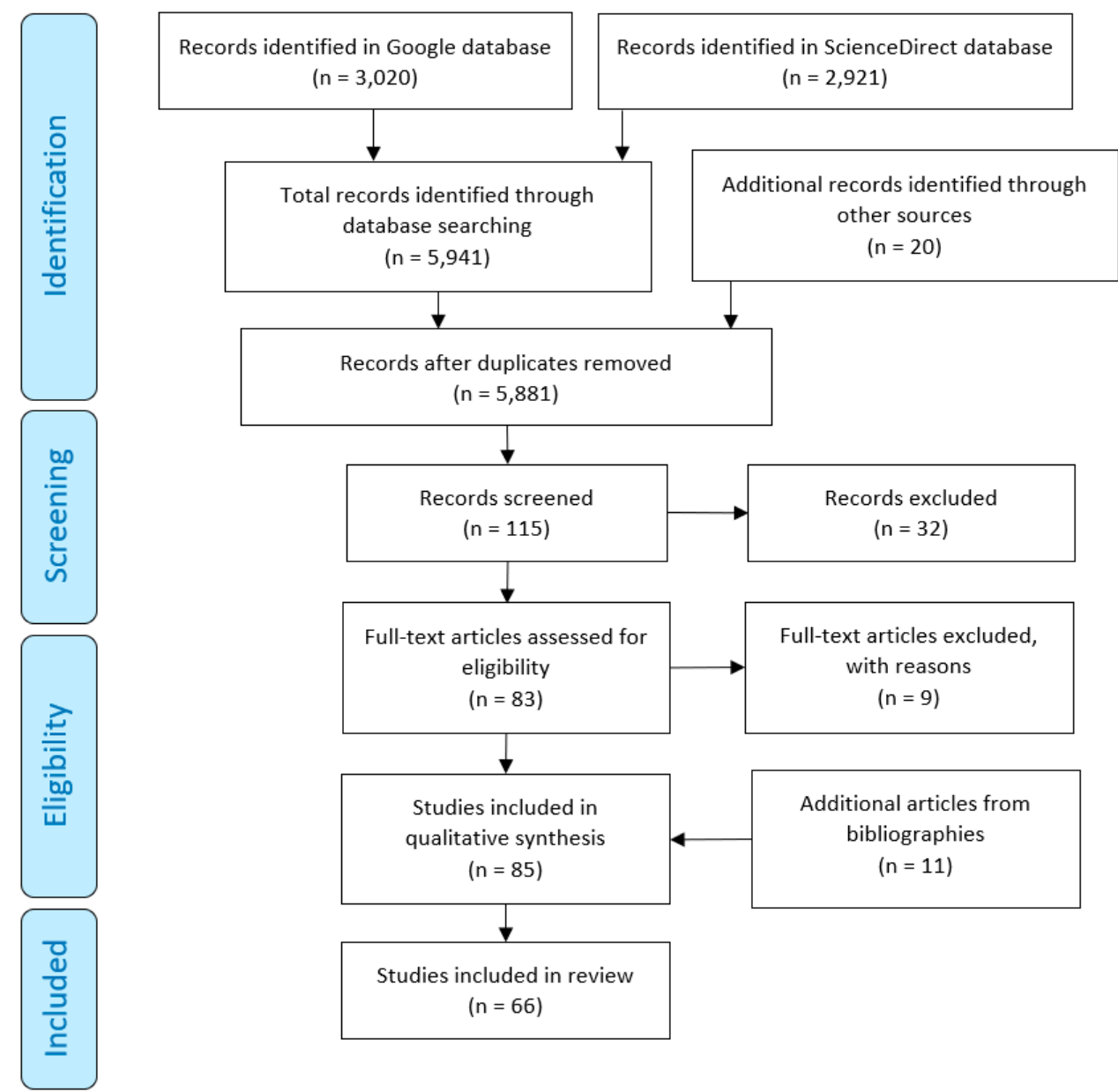

Figure 2. Search strategy and selection of studies in the Google Scholar and ScienceDirect databases.

\section{Results}

The systematic search identified a total of 64 different studies with data relevant to additively manufactured (AMd) porous Ti implants and scaffolds, as presented in Tables 2 and 3. From the 64 studies identified, 14 studies were used to extract information related to bone structure and mechanical properties (Table 2). The remaining 50 studies provided detailed information in relation to different characteristics of porous Ti scaffolds fabricated by AM for bone implant purposes. A total of 807 experimental data from these studies was extracted, analysed, and categorised in the following categories: pore size, pore shape, porosity, multi-scaled porosity, elastic modulus, interconnectivity, yield strength, ultimate compressive strength, and fatigue strength, as shown in Table 3. However, from these nine categories multi-scaled porosity was excluded from the analysis due to insufficient data for further analysis. Therefore, a total of eight different implant features were selected due to availability of recorded data in scientific research articles. The selected eight features are: unit cell, porosity, pore size, interconnectivity, elastic modulus, compressive yield strength, ultimate compressive strength, and fatigue strength. 
Table 2. Studies selected in the systematic search according to information related to bone properties.

\begin{tabular}{|c|c|c|c|c|c|c|c|c|}
\hline \multirow[b]{2}{*}{ Ref } & \multirow[b]{2}{*}{ Cod. } & \multicolumn{4}{|c|}{ Pore Characteristics } & \multicolumn{3}{|c|}{ Mechanical Properties } \\
\hline & & $\begin{array}{l}\text { Pore } \\
\text { Size }\end{array}$ & $\begin{array}{l}\text { Pore } \\
\text { Shape }\end{array}$ & Porosity & Interconnectivity & Young's Modulus & $\begin{array}{l}\text { Yield } \\
\text { Strength }\end{array}$ & $\begin{array}{l}\text { Compressive } \\
\text { Strength }\end{array}$ \\
\hline [79] & S51 & $\checkmark$ & $\checkmark$ & $\checkmark$ & $\checkmark$ & $\checkmark$ & $\checkmark$ & \\
\hline [80] & S52 & & & $\checkmark$ & & $\boldsymbol{v}$ & $\checkmark$ & $\checkmark$ \\
\hline [81] & S53 & $\checkmark$ & $\checkmark$ & $\checkmark$ & $\checkmark$ & $\checkmark$ & $\checkmark$ & $\checkmark$ \\
\hline [82] & S54 & & & $\checkmark$ & $\checkmark$ & $\checkmark$ & $\checkmark$ & $\checkmark$ \\
\hline [83] & S55 & & & & & $\checkmark$ & & \\
\hline [84] & S56 & & & & & & & $\checkmark$ \\
\hline [85] & S57 & & & $\checkmark$ & $\checkmark$ & $\checkmark$ & & \\
\hline [86] & S58 & & & $\checkmark$ & $\checkmark$ & & & \\
\hline [87] & S59 & $\checkmark$ & & & & & & \\
\hline [88] & S60 & $\checkmark$ & $\checkmark$ & $\checkmark$ & $\checkmark$ & & & \\
\hline [89] & S8 & $\checkmark$ & & $\checkmark$ & $\checkmark$ & $\checkmark$ & & \\
\hline [90] & S62 & & & $\checkmark$ & & $\checkmark$ & & \\
\hline [91] & S63 & & & & & $\checkmark$ & $\checkmark$ & $\checkmark$ \\
\hline [84] & S64 & $\checkmark$ & & $\checkmark$ & & $\checkmark$ & & \\
\hline [92] & S65 & $v$ & & & & & & \\
\hline [93] & S66 & & & & & $\checkmark$ & $\checkmark$ & $\checkmark$ \\
\hline
\end{tabular}


Table 3. Studies selected in the systematic search according to information related to additively manufactured (AMd) porous Ti structures' mechanical, geometrical, and dimensional properties.

\begin{tabular}{|c|c|c|c|c|c|c|c|c|c|c|}
\hline \multirow[b]{2}{*}{ Ref } & \multirow[b]{2}{*}{ Cod. } & \multicolumn{5}{|c|}{ Pore Characteristics } & \multicolumn{4}{|c|}{ Mechanical Properties } \\
\hline & & Size & $\begin{array}{l}\text { Unit } \\
\text { Cell I } \\
\text { Geometry }\end{array}$ & Porosity\% & Connectivity & Multi-scaled & $\begin{array}{l}\text { Young's } \\
\text { Modulus }\end{array}$ & $\begin{array}{l}\text { Compressive } \\
\text { Yield } \\
\text { Strength }\end{array}$ & $\begin{array}{l}\text { Ultimate } \\
\text { Compressive } \\
\text { Strength }\end{array}$ & Fatigue \\
\hline [19] & S1 & $\checkmark$ & $\sqrt{2}$ & 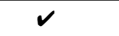 & $\sqrt{2}$ & & $v$ & & $v$ & \\
\hline [94] & S2 & $v$ & 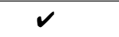 & $\sqrt{2}$ & & & 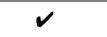 & 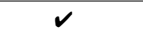 & & \\
\hline [82] & S3 & $\boldsymbol{v}$ & $v$ & $v$ & $v$ & & $v$ & $v$ & $v$ & \\
\hline [95] & S4 & $\boldsymbol{v}$ & $v$ & & & $v$ & $v$ & $v$ & & $v$ \\
\hline [62] & S5 & $\checkmark$ & $v$ & 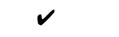 & $v$ & & $v$ & $v$ & & \\
\hline [96] & S6 & $\boldsymbol{v}$ & $v$ & $v$ & & & $v$ & & & \\
\hline [97] & S7 & & 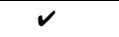 & $\sqrt{2}$ & & & $v$ & & $v$ & \\
\hline [98] & S8 & $\boldsymbol{v}$ & $v$ & $v$ & $v$ & & $v$ & & $v$ & \\
\hline [99] & S9 & 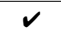 & 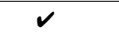 & $v$ & 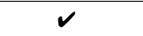 & & & & & \\
\hline [100] & $\mathrm{S} 10$ & $v$ & $v$ & $v$ & $v$ & $v$ & $v$ & $v$ & $v$ & \\
\hline [101] & S11 & $\boldsymbol{v}$ & $v$ & $v$ & & & $v$ & $v$ & & \\
\hline [102] & S12 & $\checkmark$ & $v$ & $v$ & $v$ & $v$ & $v$ & $v$ & & \\
\hline [103] & $\mathrm{S} 13$ & $v$ & $v$ & $v$ & $v$ & & $v$ & $v$ & $v$ & $v$ \\
\hline [104] & S14 & & $v$ & 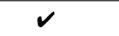 & $\checkmark$ & & $v$ & $v$ & $v$ & $v$ \\
\hline [105] & $\mathrm{S} 15$ & $v$ & $v$ & $v$ & & & & $v$ & & \\
\hline [106] & S16 & $\checkmark$ & $\checkmark$ & $\checkmark$ & $\checkmark$ & & & $\checkmark$ & $\checkmark$ & $v$ \\
\hline [107] & S17 & $v$ & $v$ & $v$ & $v$ & & & $v$ & $v$ & $v$ \\
\hline [108] & $\mathrm{S} 18$ & $v$ & $v$ & $v$ & $v$ & & $v$ & $v$ & $v$ & \\
\hline [109] & S19 & $v$ & $v$ & $v$ & $v$ & $v$ & & & & \\
\hline [110] & $\mathrm{S} 20$ & $v$ & $v$ & $v$ & & $v$ & $v$ & & $v$ & \\
\hline [111] & S21 & & $v$ & $v$ & $v$ & & $v$ & $v$ & $v$ & \\
\hline [112] & S22 & $v$ & $v$ & $v$ & & & $v$ & $v$ & & $v$ \\
\hline [113] & $\mathrm{S} 23$ & $v$ & $v$ & $v$ & $v$ & & $v$ & $v$ & & \\
\hline [114] & S24 & $v$ & $v$ & $v$ & $v$ & & & & $v$ & \\
\hline [115] & S25 & $v$ & $v$ & $v$ & & & $v$ & $v$ & & \\
\hline [116] & S26 & $v$ & $v$ & $v$ & $v$ & & $v$ & $v$ & & $v$ \\
\hline [117] & S27 & $\checkmark$ & $v$ & $v$ & & & $v$ & $v$ & & $v$ \\
\hline [118] & S28 & $v$ & $v$ & $v$ & & & $v$ & $v$ & & $v$ \\
\hline [119] & S29 & $v$ & $v$ & $v$ & & $v$ & $v$ & $v$ & & \\
\hline [120] & S30 & $v$ & $v$ & $v$ & & & $v$ & $v$ & $v$ & \\
\hline [121] & S31 & $v$ & $v$ & $v$ & $v$ & $v$ & $v$ & $v$ & $v$ & \\
\hline [122] & S32 & $v$ & $v$ & $v$ & $v$ & & $v$ & $v$ & & \\
\hline [123] & S33 & $v$ & $v$ & $v$ & $v$ & $v$ & $v$ & $v$ & & \\
\hline [124] & S34 & $v$ & $v$ & $v$ & $v$ & & $v$ & & $v$ & \\
\hline [125] & S35 & $v$ & $v$ & $v$ & & & $v$ & $v$ & $v$ & $v$ \\
\hline [126] & S36 & $v$ & $v$ & $v$ & & & $v$ & & $v$ & \\
\hline [127] & S37 & $\checkmark$ & $v$ & $v$ & & & $v$ & $v$ & & \\
\hline [128] & S38 & $v$ & $v$ & $v$ & $v$ & & $v$ & $v$ & $v$ & \\
\hline [79] & S39 & $v$ & $v$ & $v$ & & & $v$ & $v$ & & $v$ \\
\hline [129] & $S 40$ & $v$ & & $v$ & & & $v$ & & $v$ & \\
\hline [130] & S41 & $v$ & $v$ & $v$ & $v$ & & $v$ & & & \\
\hline [131] & $\mathrm{S} 42$ & $v$ & $v$ & $v$ & & & $v$ & $v$ & & \\
\hline [132] & S43 & $v$ & $v$ & $v$ & $v$ & & & $v$ & & \\
\hline [133] & S44 & $\checkmark$ & $v$ & $v$ & $v$ & & $v$ & $v$ & & \\
\hline [134] & S45 & $v$ & $v$ & $v$ & & & $v$ & & $v$ & \\
\hline [135] & S46 & & $v$ & $v$ & & & & & & $v$ \\
\hline [136] & S47 & $v$ & $v$ & $v$ & $v$ & $v$ & $v$ & $v$ & & \\
\hline [137] & S48 & & $v$ & $v$ & & & $v$ & $v$ & & $v$ \\
\hline [138] & S49 & $v$ & $v$ & $v$ & & & $v$ & $v$ & & \\
\hline [139] & S50 & $v$ & $v$ & $v$ & & & $v$ & $v$ & & \\
\hline
\end{tabular}

Through the systematic research performed in this study and by reviewing the medical device regulations from the Food and Drug Administration (FDA), a Quality Target Product Profile has been established including proposed values for the Ideal Quality Attributes for mechanical and dimensional 
properties of porous bone implants. These target properties are aimed for porous metal implant structures designed for load bearing implant applications. Following this, the results of the selected studies were compared and discussed, from a biomimetic point of view, with the characteristics of natural human bone to identify implants with properties similar or superior to human bone and current medical standards.

\subsection{QbD Step 1: Ideal Quality Target Product Profile}

The Quality Target Product Profile (QTPP) is critical for formulating the ideal features of a product considering both performance and safety. To direct the product development process, it is vital to understand user needs. Using QTPP, design failures can be identified early in the product development process to reduce costs and time. According to Martinez-Marquez et al. [36], the quality of bone implants should be defined from three perspectives: product-based, manufacturing-based, and user-based. In the context of fully porous Ti microstructures, the dimensions of quality considered most relevant are performance, features, reliability, conformance, durability, and perceived quality. The requirements relating to bone implants corresponding to these quality dimensions have been identified through studies of existing scientific research results.

\subsection{Bone Implant Requirements}

An additively manufactured bone implant must act as a stable scaffold that is biocompatible without causing inflammation or leaching material toxins into surrounding tissue. It requires a suitable surface that promotes cell adhesion and differentiation as well as provides a constant flow of cell nutrients and metabolic waste. This allows for bone tissue formation [81]. The scaffold material must have mechanical properties matching those of the surrounding tissues to avoid stress shielding and mechanical failure [81,82]. The bone pore size, geometry, interconnectivity, and porosity are microscopic features that make for the foundation of bone regeneration, cell growth, osteoconduction, and cell proliferation [74]. Designing implants with adequate pore dimensions allows for a constant flow of cell nutrients and waste. It also allows for sufficient connections to establish between the local bone area and the scaffold [74]. If the right attributes are chosen for the implant microstructure, it can mimic human bone's natural characteristics, which is the end goal of biomimetic implant design $[79,80]$. Vasireddi and Basu [140] completed a list of general requirements for 3D printed implants:

- “A 3D, highly porous structure to support cell attachment, proliferation and extracellular matrix production;

- An interconnected pore network to promote oxygen, nutrient and waste exchange;

- A biocompatible and bioresorbable substrate with suitable degradation rates;

- An appropriate surface chemistry for cell attachment, proliferation and differentiation;

- Mechanical properties to support, or match, those of the tissues at the site of implantation; an architecture which promotes formation of the native anisotropic tissue structure; and

- An adapted geometry of clinically relevant size and shape."

In similar research, Jabir et al. [141] described the main fundamental requirements for implants as biocompatibility, good manufacturability, geometric precision, appropriate design, biomechanical stability, resistance to implant wear, corrosion and aseptic loosening, bioactivity, and osteoconduction. Since the environment in the human body is highly corrosive and biomaterials are usually bioactive, the implant will interact with its environment after implantation [140]. The implant must therefore be designed with both useful functions and biological safety, providing utmost biocompatibility. The implant design must have a high degree of reproducibility, which will ensure faster and cheaper manufacturing as well as predictability and reliability.

Furthermore, the implant must be durable and of initial strength for safe handling during sterilisation, transport, and surgery, and to survive physical forces in vivo after implantation [142]. The implant will be subjected to constant load in the body, from walking and further strenuous 
movements [127]. Its mechanical strength is vital for its viability, where the implant must last the entirety of its expected lifetime without defects or failure [127].

Taking all the above into consideration in conjunction with the ideal eight quality dimensions of AMd bone implants proposed by Martinez-Marquez at al. [74], we proposed seven ideal quality dimensions of porous internal architecture of Ti bone implants. These quality dimensions are based on three quality perspectives, namely product, manufacturing, and user-based, as presented in Table 4 .

Table 4. The ideal quality dimensions of porous internal architecture of Ti bone implants.

\begin{tabular}{|c|c|c|}
\hline Quality Approach & Dimension & Description \\
\hline \multirow{3}{*}{ Product-based approach } & Performance & $\begin{array}{l}\text { The porous microstructure should } \\
\text { provide an environment ideal for } \\
\text { bone ingrowth and endow the } \\
\text { implant with a stiffness similar to } \\
\text { natural human bone while } \\
\text { maintaining sufficient strength. }\end{array}$ \\
\hline & Features & $\begin{array}{l}\text { Tailored internal architecture with } \\
\text { specific properties, including but } \\
\text { not limited to pore size, unit cell, } \\
\text { porosity, elastic modulus, } \\
\text { interconnectivity, compressive } \\
\text { yield, and ultimate strength, as } \\
\text { well as fatigue strength. }\end{array}$ \\
\hline & Reliability & $\begin{array}{l}\text { Optimised fabrication of porous Ti } \\
\text { structures with high mechanical } \\
\text { strength as well as a high degree } \\
\text { of reproducibility, minimal defects, } \\
\text { and zero failure rates (within their } \\
\text { life expectancy). }\end{array}$ \\
\hline \multirow{3}{*}{ Manufacturing-based approach } & Manufacturability & $\begin{array}{l}\text { The scaffold's micro-geometry } \\
\text { should be designed in such a way } \\
\text { that it is easy to manufacture with } \\
\text { high accuracy and definition. }\end{array}$ \\
\hline & Conformance & $\begin{array}{l}\text { The mechanical, geometrical, and } \\
\text { dimensional characteristics should } \\
\text { comply with medical regulations } \\
\text { and quality standards. }\end{array}$ \\
\hline & Durability & $\begin{array}{l}\text { Porous Ti structures should } \\
\text { withstand mechanical forces } \\
\text { experienced during handling, } \\
\text { implantation surgery, and } \\
\text { operation thereafter in a } \\
\text { traumatised bone } \\
\text { microenvironment constantly } \\
\text { under load. }\end{array}$ \\
\hline User-based approach & Perceived quality & $\begin{array}{l}\text { Clinicians should have access to } \\
\text { relevant characteristics through } \\
\text { medical reports and statistical data } \\
\text { where implant performance can be } \\
\text { seen. }\end{array}$ \\
\hline
\end{tabular}

\subsection{QbD Step 1.1: Ideal Quality Attributes}

The Ideal Quality Attributes (IQA) are the tissue or biological construct characteristics that must be mimicked to imitate the desired tissue biological architecture and functions. The IQA can be dimensional, physicochemical, mechanical, biological, or functional. However, if any technological and regulatory limitations exist it is important to consider that these IQA serve just as 'ideal models' to imitate even if it is not possible to achieve them. Therefore, the IQA can provide an ideal goal for the product development process in any tissue engineering project. 
By studying the properties of natural human bone, we can find the different IQAs for bone implants $[79,80]$. As mentioned in Section 3.1, the implant must be of adequate strength while the elastic modulus must be similar to that of surrounding tissue to avoid damage [81]. The structure must be porous, using unit cells that allow for fluid movement and bone ingrowth, and the right porosity will reduce the implant stiffness. Interconnectivity completes the flow within the structure and facilitates bone ingrowth [82]. A combination of cancellous and cortical bone properties applied on bone implants can allow the implant to function like a natural bone, yet stronger without impairing surrounding native tissue. Another specific property of bone is its ability to heal itself when fractured $[90,143]$. The process involves cell migration, differentiation, and cellular proliferation [125]. The ability of natural bone to selfheal must be considered when designing a Ti implant, since the structure will not be able to do the same.

\subsubsection{Structure and Composition of Bone}

To fully understand the microstructure requirements of fully porous Ti implants, one must first understand the properties of human bone. Bone is essentially an open-cell composite material of fibrous protein, collagen, and calcium phosphate crystals, with an intricate vascular system forming various structures and systems in a five-level hierarchically organised structure [84,144]. According to Rho, et al. [145], these five hierarchical levels are dimensional scales ranging from the macro to the sub-nano levels (Figure 3).

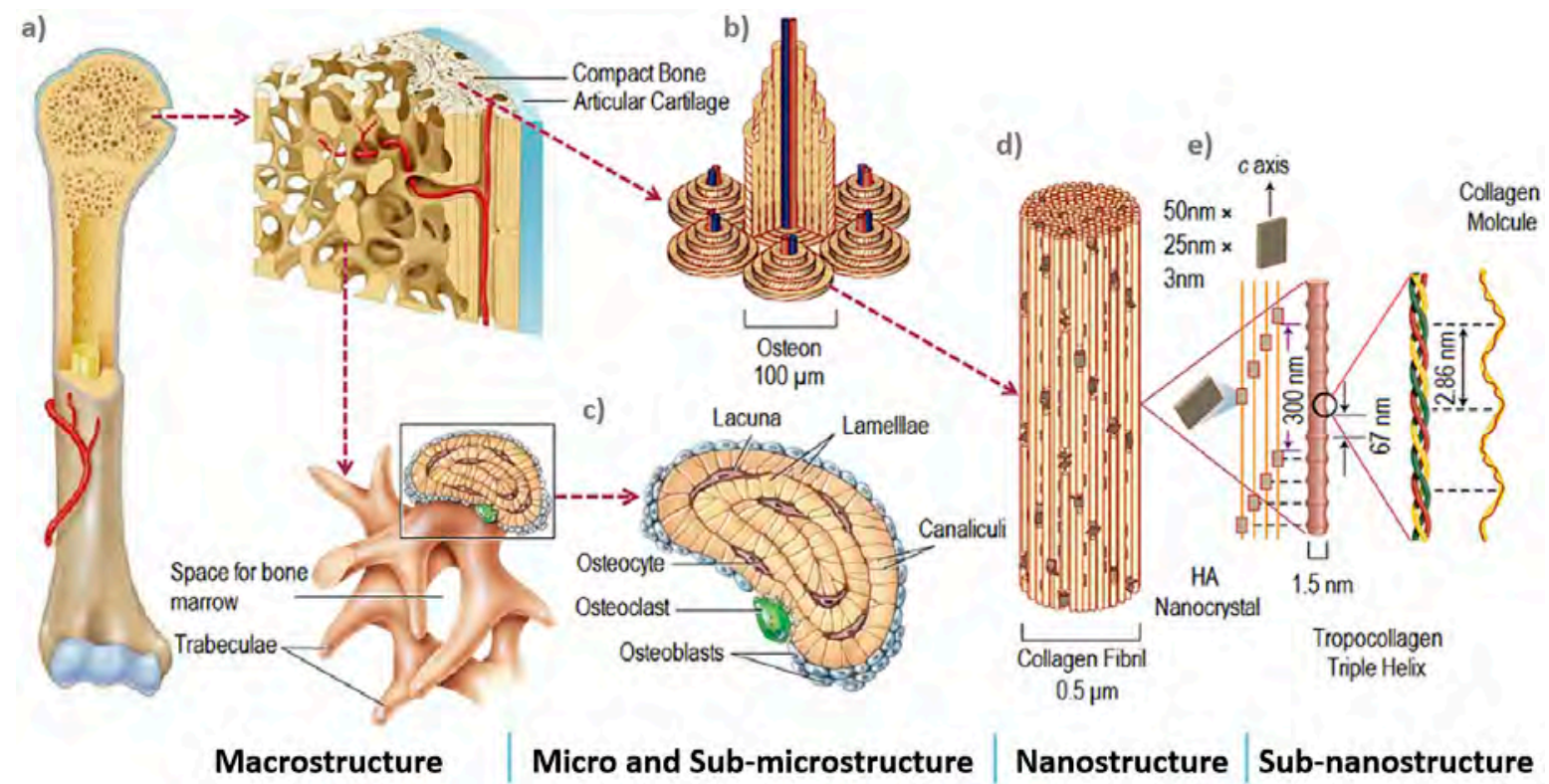

Figure 3. Hierarchical structural organization of bone: (a) cortical and cancellous bone; (b) osteons with Haversian systems; (c) lamellae; (d) collagen fiber assemblies of collagen fibrils; (e) bone mineral crystals, collagen molecules, and non-collagenous proteins. Image reproduced from Ref [81].

Bone's macrostructure is composed of cancellous and cortical bone, which are two different regions of bone with different density. Cortical bone forms the outside layer of the bone providing a strong, compact structure, leaving only $3-10 \%$ of the volume for its biological elements, such as blood vessels, osteocytes, erosion cavities, and canaliculi [81]. Cancellous bone forms the inside of the bone and is spacious and highly porous [81]. The pores are filled with bone marrow and the spacious architecture allows space for metabolic waste and nutrients to flow. Cancellous bone has an active metabolism and regenerates quicker compared with cortical bone [146]. By changing its density, cancellous bone can reorganise its structure depending on the stress direction [107]. These features cause cancellous bone mechanical properties to vary from bone to bone and change longitudinally [144]. 
The microstructure of bone ranges from 10 to $500 \mu \mathrm{m}$ and it contains three major cavities. These are Haversian canals, osteocyte, lacunae, and canaliculi [88]. Cortical bone microstructure is composed of cylindrical structures called osteons with diameters ranging between 70 to $140 \mu \mathrm{m}[81,87,92]$. Along osteons' central axis are pores called haversian systems, with diameters ranging between 20 to 50 $\mu \mathrm{m}$, containing blood vessels and nerves [92]. Cancellous bone micro-architecture is composed of irregular units called trabeculae which create its porous structure. The pore geometry and pore size of cancellous bone porous structure is critical for cell distribution and cell migration [81]. Cancellous bone is naturally stochastic, with random pore distribution of pores of different size.

The pores in cancellous bone are ellipsoidal in the natural direction of loading and are usually $300-600 \mu \mathrm{m}$ wide [147]. The interconnectivity between the pores of cancellous bone is essential for nutrient and waste diffusion.

At the micro level are also located the three types of differentiated bone cells osteoclasts, osteoblasts, and osteocytes, as shown in Figure 4. Osteoclasts and osteoblasts are vital for the functions of developing and healing bone tissue [86]. Osteoclasts (Figure 4a) are the main cells responsible for resorption of old bone tissue. Osteoblasts (Figure $4 \mathrm{~b}$ ) are bone cells responsible for bone formation, remodelling, fracture healing (for which they are critical), and bone development [148]. Osteocytes (Figure 4c) are osteoblasts cells present inside mature bone and serve as mechanosensory cells to control the activity of osteoclasts and osteoblasts [149].

Bone's sub-microstructure, from 1 to $10 \mu \mathrm{m}$, is composed of lamellae which in cortical bone compromise the concentric layers of osteons and in cancellous bone lamellae forms the trabeculae volume $[150,151]$. The sub-nanostructure of bone, below a few hundred nanometres, is composed molecular constituent elements, such as collagen, non-collagenous organic proteins, and mineral. From a few hundred nanometres to $1 \mu \mathrm{m}$ is bone's nanostructure comprising fibrillar collagen with embedded hydroxyapatite nanocrystals [152].

\subsubsection{Bone Mechanical Properties}

Most bones in the body are load bearing and require high mechanical strength. Bone tissue is anisotropic and stronger in compression than in tension. The mechanical properties must be measured in two orthogonal directions: longitudinal, which is the natural loading direction, and transverse [86]. The mechanical strength of bone is complex to measure as it varies with age, health, activity, and position in the body [86]. Bone becomes stiffer and less ductile with age and its ability to heal decreases [155]. It is also likely to weaken with immobilisation, such as for a person with movement disabilities or limited physical activity.

The two different types of bone, cortical and cancellous, have completely different mechanical properties; therefore to specify the properties of bone as one material, both bone types must be considered. Cortical bone is highly dense an act like a shell that provides the greatest stiffness and resistance to bending. In contrast, the mechanical properties of cancellous bone are determined by its apparent density and trabecular architecture. The trabecular structure of cancellous bone is arranged accordingly to the stress distribution of load, as shown in Figure 5. As a result, the least material is used in the most strategic locations to carry the greatest loads with the least strain [156]. 
a)

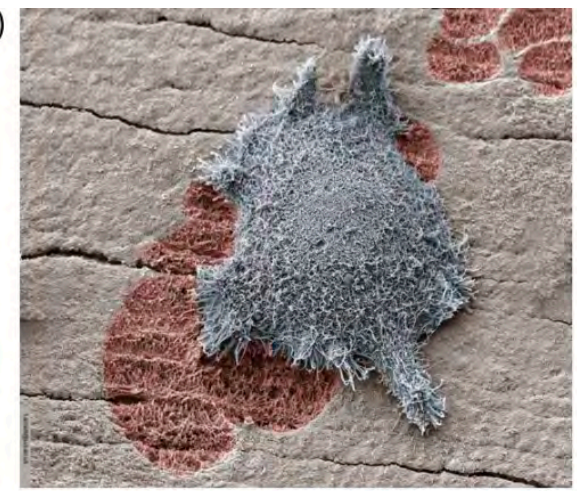

b)

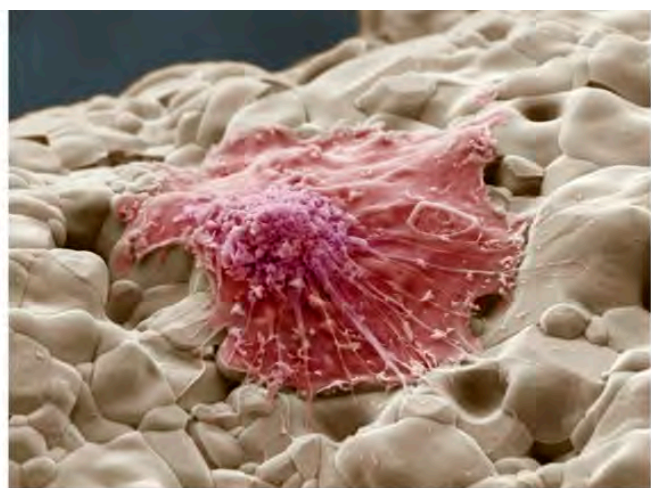

c)

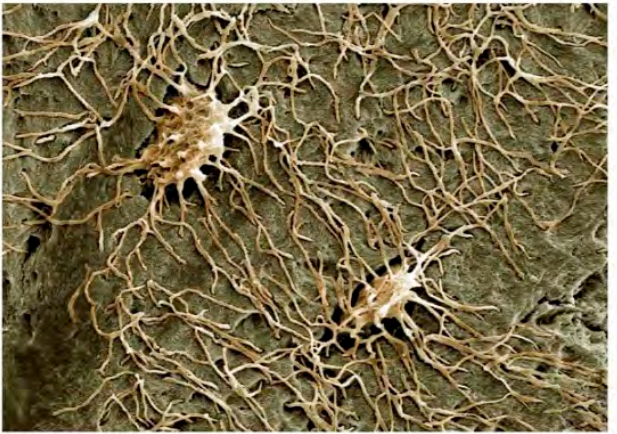

Figure 4. Coloured scanning electron micrographs of bone cells: (a) Activated osteoclast and resorption pit by kind permission of Timothy Arnett Ref [153]; (b) Osteoblast growing on a bone scaffold made of calcium oxide and silicon dioxide with added strontium and zinc by kind permission of Guocheng Wang from [154]; (c) Osteocytes embedded in the bone matrix with long cytoplasmic extensions reaching into the bone tissue, by kind permission of Kevin Mackenzie. Here, the minerals in the bone have been removed by embedding in resin and etching with perchloric acid. This reveals the spaces in the bone and the shape of the osteocyte cells.

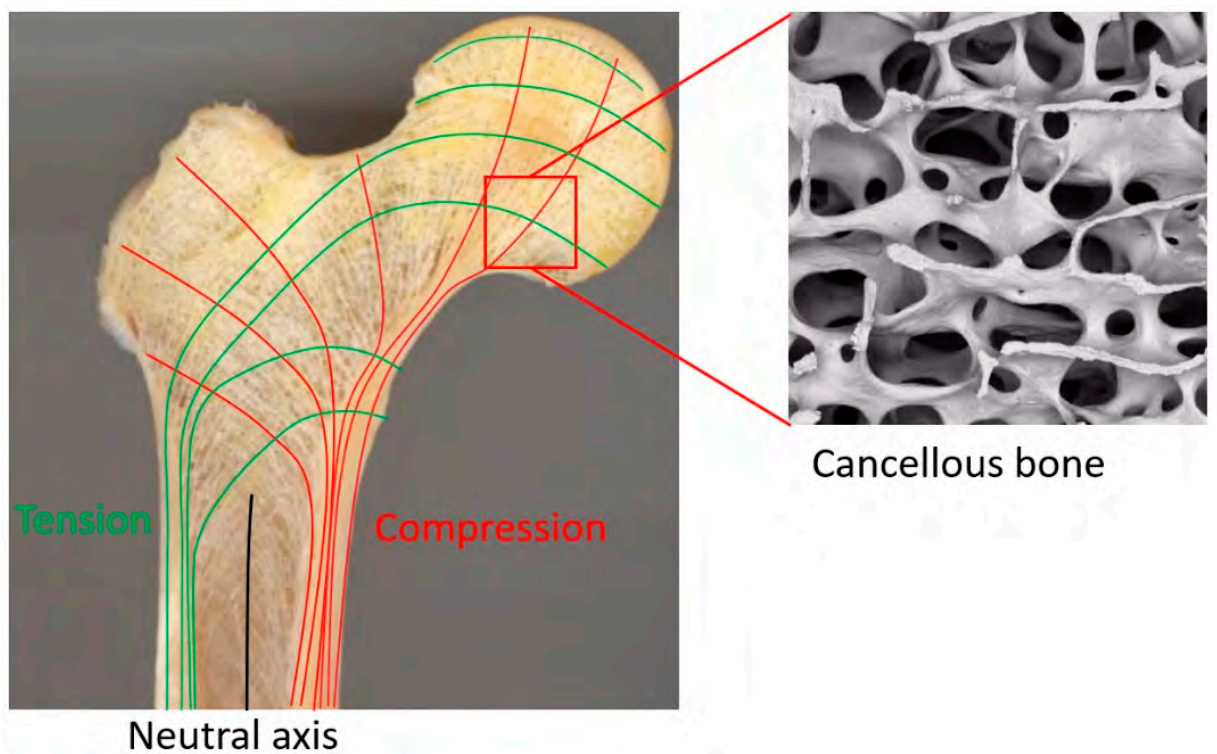

Figure 5. Cortical and cancellous bone; image adapted from $[157,158]$ by kind permission of Alan Boyde.

The mechanical properties of cortical and cancellous bone are difficult to measure, and tend to vary depending on bone orientation, test methods, mathematical formulas, and assumptions [146,151,159]. According to Chen and Thouas [57], the elastic modulus of cortical bone is approximately 11-21 GPa in the longitudinal direction and 5-13 GPa in the transverse direction. Another study suggested 
18-22 GPa [147], whereas Wang et al. [81] suggested a range of 3-30 GPa. Cortical bone has a porosity of less than $10 \%$ [85]. The elastic modulus of cancellous bone is estimated to be $0.02-6$ GPA and it has a high porosity of $50-90 \%[85,86]$.

To achieve adequate strength in bone implant design, one must understand the strength requirement of bone. Especially cortical bone must be considered, because the strength of such tissue is the minimum strength required by the implant. The compressive yield point of bone represents the threshold from where the structure accumulates irreversible deformation. Unlike metals such as steel, the yield point cannot be clearly distinguished, and it is rather associated with a continuous transition zone [160]. Furthermore, it has been proven that the compressive yield strength of bone varies depending on the anatomic site [161]. The challenges in determining the yield strength of cortical bone results in varying values in the literature. Researchers have estimated cortical bone to have a compressive yield strength of $133.6 \pm 34.1 \mathrm{MPa}$ [162]. The same characteristic was estimated to be 108-117 MPa by Yeni and Fyhrie [163]. Further studies have tested compressive yield strain using uniaxial compression and achieved $141.0 \pm 5.0$ [164], $111.0 \pm 18.6$ [165], $112.5 \pm 9.5$ [166], and $115.1 \pm$ 16.4 MPa [167].

If the loading surpasses the yield point for bone, it will eventually reach the ultimate point. This point represents the ultimate compressive strength the bone can withstand until irreversible strains and damage occur. Past this point, macrocracks are formed and fracture occurs [160]. Unlike yield strength, the ultimate compressive strength of cortical bone can be exactly determined, using a stressstrain experiment [160]. However, due to bone properties differentiating, values vary in the literature. For example, Wang et al. [84] suggested that cortical bone has an ultimate compressive strength of 180-200 MPa, whereas Calori et al. [8] suggested a wider range of 130-290 MPa and Henkel et al. suggested 100-230 MPa [168]. Tables 5 and 6 summarise the mechanical and dimensional properties of natural bone considered in this study.

Table 5. Summary of dimensional properties of natural human bone.

\begin{tabular}{cccccc}
\hline Material & Pore Size & Pore Shape & Porosity & Interconnectivity & Ref \\
\hline $\begin{array}{c}\text { Cancellous } \\
\text { bone }\end{array}$ & $300-600 \mu \mathrm{m}$ & $\begin{array}{c}\text { Spongy, } \\
\text { ellipsoidal } \\
\text { pores }\end{array}$ & $50-90 \%$ & $55-70 \%$ & $\begin{array}{c}{[82,84,89,91,} \\
169]\end{array}$ \\
\hline Cortical bone & $10-50 \mu \mathrm{m}$ & $\begin{array}{c}\text { Cylindrical } \\
\text { canals }\end{array}$ & $3-10 \%$ & - & \\
\hline
\end{tabular}

Table 6. Summary of mechanical properties of natural human bone.

\begin{tabular}{|c|c|c|c|c|c|}
\hline Material & $\begin{array}{l}\text { Young's } \\
\text { Modulus }\end{array}$ & $\begin{array}{l}\text { Compressive } \\
\text { Yield Strength }\end{array}$ & $\begin{array}{c}\text { Ultimate } \\
\text { Compressive } \\
\text { Strength }\end{array}$ & $\begin{array}{c}\text { Compression } \\
\text { Fatigue } \\
\text { Strength } \\
\end{array}$ & Ref \\
\hline $\begin{array}{c}\text { Cancellous } \\
\text { bone }\end{array}$ & $0.02-6 \mathrm{GPa}$ & 7.2-23.2 MPa & 17-33 MPa & $\begin{array}{c}72.6-124 \mathrm{MPa} \\
\text { at } 10^{6} \text { cycles }\end{array}$ & \multirow{2}{*}{$\begin{array}{c}{[8,82,84,89,91} \\
93,162,165,168- \\
171]\end{array}$} \\
\hline Cortical bone & 3-30 GPa & $92.4-167.7 \mathrm{MPa}$ & $100-290 \mathrm{MPa}$ & $\begin{array}{c}137 \mathrm{MPa} \text { at } 10^{6} \\
\text { cycles }\end{array}$ & \\
\hline
\end{tabular}

\subsection{Comparison of Properties of Porous Ti Scaffolds Fabricated by AM and Ideal Quality Attributes}

\subsubsection{Unit Cell Geometry}

Metamaterials can be rationally designed by changing their geometry at the microscale of the constituting unit cells of the porous structure. In this systematic search, a total of 169 porous scaffolds were identified as a rationally designed and fabricated for bone implant applications. It was found that there are three preferred strategies for fabricating bio-metamaterials: beam-based, sheet-based, and including irregular porous structures [172]. 
According to Figure 6, the preferred design approach was beam-based, which represent $74.6 \%$ of the total scaffolds produced in the selected studies. The beam-based bio-metamaterials' micro-architecture is composed of a lattice structure created using unit cells based on platonic solids, Archimedean solids, prisms and anti-prisms, and Archimedean duals [173-177] to mimic bone porous macro structure and mechanical properties such as modulus of elasticity. Nevertheless, the biological performance of bio-metamaterials created with beam-based geometries is limited by their inaccurate description of complex natural shapes due to their straight edges and sharp turns [109].

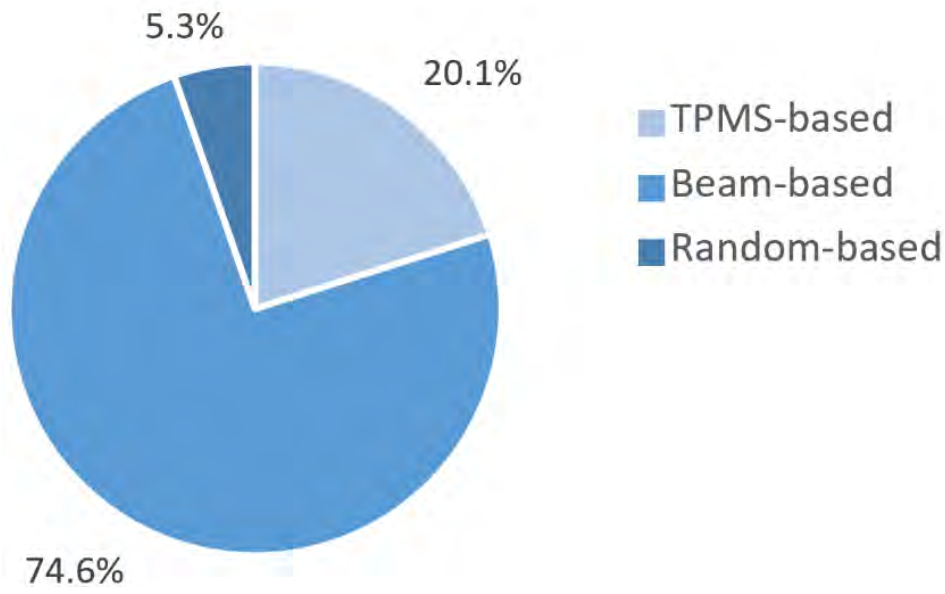

Figure 6. Distribution of experimental studies on beam-based, triply periodic minimal surfaces (TPMS), and random based geometries for bone implant applications.

The unit cells of sheet-based geometries, on the other hand, are based on triply periodic minimal surfaces (TPMS), which are present in different organisms and cellular structures [178]. Therefore, it is no surprising that the second most used design strategy identified in this systematic search was sheet-based representing $20.1 \%$ of the total scaffolds produced, from which all used a TPMS as unit cell. Bio-metamaterials based on TPMS can mimic the various properties of bone to an unprecedented level of multi-physics detail in terms of mechanical properties and transport properties [79,172]. Moreover, the bone-mimicking mean surface curvature of zero of TPMS eliminates the effect of stress concentrators at nodal points [120].

In the case of irregular porous structures, are created in a random way to generate irregular porous structures that mimic trabecular bone geometry and mechanical properties [179]. These irregular structures are generated using the Voronoi and Delaunay tessellation methods. Irregular structures have been found to further enhance scaffold's permeability and bone ingrowth compared with porous structures designed with regular unit cells [180]. According to our results only $5.3 \%$ of the studies used a randomised design approach to create irregular porous structures to mimic trabecular bone. This result was surprising considering that irregular porous structures were the first additively manufactured coatings used for orthopaedic implants in the medical industry. However, unlike random porous scaffolds, the great advantage of using regular repeating arrays of unit cells made of beam or sheet-based geometries is that they allow the creation of metamaterials with properties that can accurately be predicted [181]. This explain why these design strategies are preferred in research.

From all the different possible unit cells that can be used to produce metamaterials, a total of 17 types of unit cell were used by the selected studies, as presented in Figure 7. According to Figure 7, the beam-based diamond unit cell (59 studies) was the most used, followed by the cubic (18 studies), and the gyroid TPMS (17 studies). These results correlate with the opinion of different experts who have stated that the diamond unit cell is the most studied for the development of metamaterials due to its biomimetic mechanical properties [121,182]. The high mechanical properties and self-supporting properties of the diamond unit cell are due to its unique geometrical arrangement, where one node is tetrahedrally surrounded by four other nodes coming from the crystal structure of the diamond 
crystal [113], as shown in Figure 8a. Moreover, this arrangement gives 48 symmetry elements to the diamond structure, making this unit cell invariant to different symmetry operations such as translations, reflections, rotations, and inversion [183]. Similarly, extensive research for bone regeneration has been performed to study the cubic unit cell (Figure $8 \mathrm{~b}$ ). The research interest in the cubic unit cell is because it is based on one of the simplest and easy-to-manufacture platonic solids thanks to its struts at an angle of $90^{\circ}$ [62]. In the case of porous metamaterials based on the gyroid TPMS (Figure 8c), they have been found to exhibit similar topology to human trabecular bone, and also superior mechanical properties compared with metamaterials based on other types of TPMS [120]. For example, according to Yang et al. [184] metamaterials based on the gyroid TPMS have a more homogeneous stress distribution, which can provide equal mechanical stimulation to bone cells.

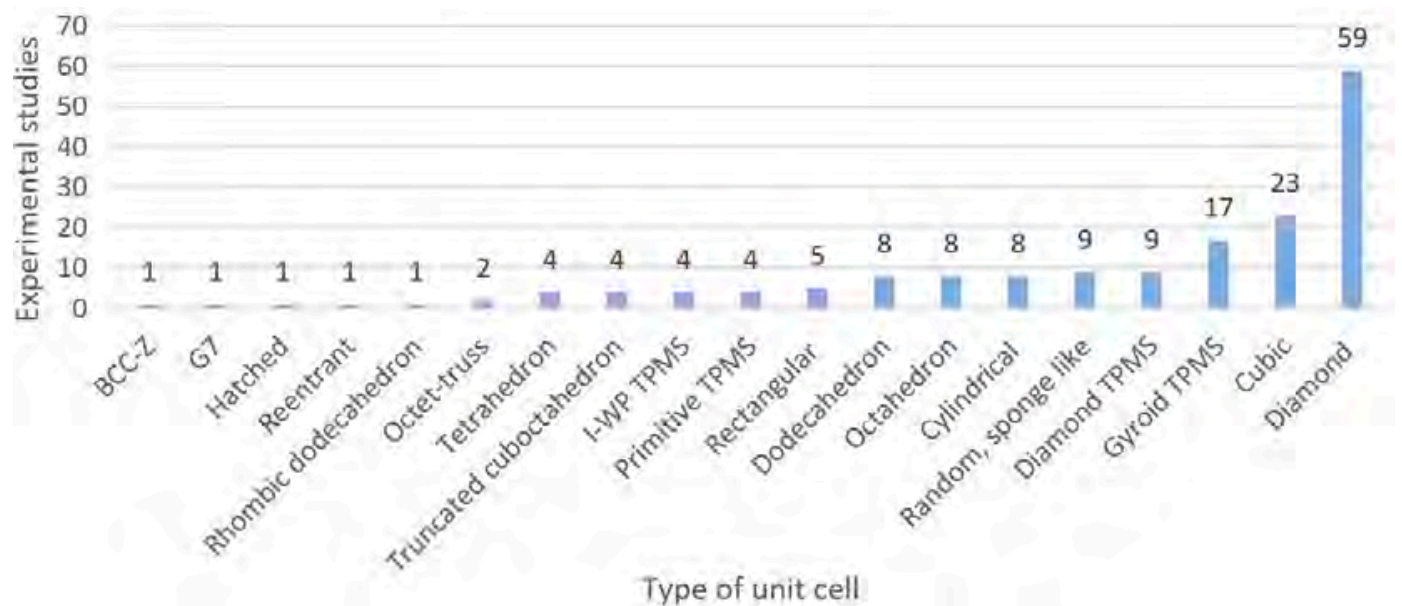

Figure 7. Comparison of the number of experimental studies of each unit used for bone regeneration identified in the reviewed articles.

a)
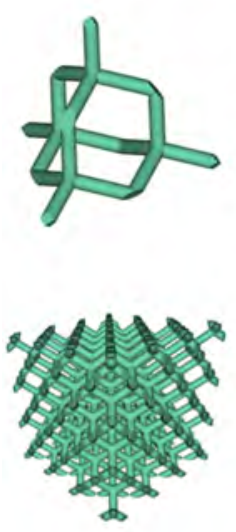

Beam-based b)

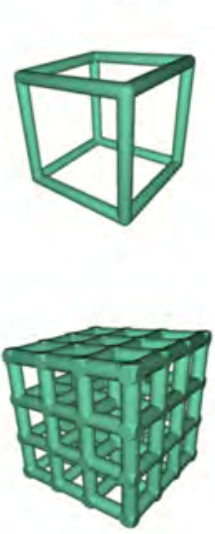

c)

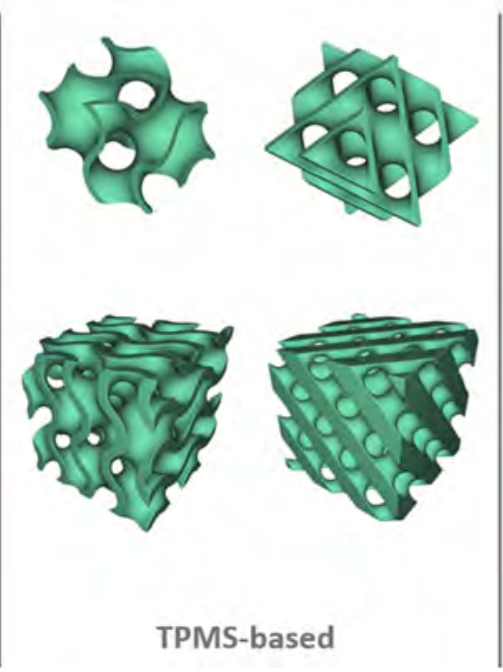

e)

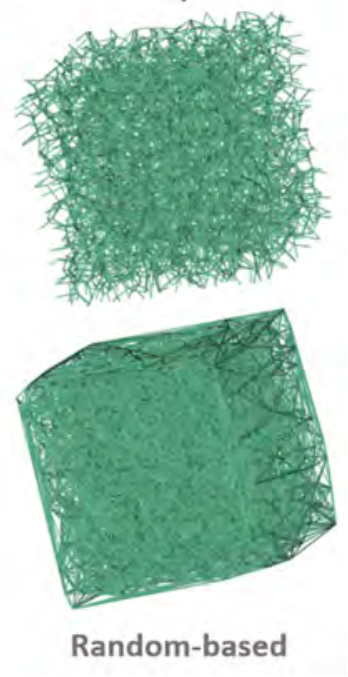

Figure 8. Some examples of unit cells with their corresponding meta-biomaterial scaffold below: (a) diamond beam-based unit cell; (b) cubic beam-based unit cell; (c) Gyroid triply periodic minimal surface based (TPMS-based) unit cell; (d) Diamond TPMS-based unit cell; and (e) Voronoi (top) and Delaunay (bottom) irregular porous structures.

In the case of random or stochastic structures, Kou et al. [185] suggested that scaffolds based on this structures are more realistic; that is, they look more like natural bone with random non-uniform pore distribution and pore size [185]. Such structures are believed to provide benefits such as improved mechanical properties, including strength, fluid dynamics, surface area, and surface-to-weight ratio. 
They combine advantages of small and large pores without necessarily decreasing the mechanical strength or reducing the bone in-growth to levels that are inappropriate in application [186]. Figure 8 presents the five most representative unit cells identified in this study.

\subsubsection{Porosity}

It is known that the degree of micro-porosity in bone implants directly affects their biological and mechanical properties. The porosity of natural bone is crucial for vascularisation, diffusion of cell nutrients and metabolic waste, and cell migration [187], and in a similar way it is important for metal bone implants. Moreover, several studies have considered porosity as the main parameter affecting stiffness and strength of porous biomaterials. Increased porosity reduces the strength of the implant $[187,188]$. As a result, porous metallic biomaterials are used as coatings in many medical applications, but more recently porous biomaterials have been proposed for load-bearing applications beyond surface coatings [138,142]. Ti and Ti alloys are commonly used for load-bearing implant applications due to their relatively low elastic modulus fatigue resistance, high strength to weight ratio, and corrosion resistance [82,94]. However, bulk $\mathrm{Ti}$ and $\mathrm{Ti}$ alloys do not completely match all the mechanical properties of natural bone such as modulus of elasticity. Therefore, it is a need of the hour to accomplish specific mechanical properties for Ti or Ti-based alloys by controlling the porosity and pore characteristics for customised implants [131]. However, the ideal porosity for medical implants seems controversial in the literature [181].

In this systematic review a total of 49 articles out of 50 recorded porosity of various degrees, as shown in Figure 9. For example, Stamp et al. [186] recommend using a porosity above 65\% in medical implants whereas Ghanaati et al. [189] found that vascularisation increased in vivo when reducing the porosity from 80 to $40 \%$. Sarhadi et al. [190] and Schiefer et al. [191] have recommended using a porosity of approximately 50\%. According to Will et al. [192], the porosity that best promotes vascularization in porous scaffolds is $40-60 \%$. Pattanayak et al. [193] manufactured porous Ti implants and reported an increase in compressive strength from $35 \mathrm{MPa}$ to $120 \mathrm{MPa}$ when reducing the porosity from 75 to $55 \%$. Murr et al. reduced the porosity from 88 to 59\% with an increase in stiffness from $0.58 \mathrm{GPa}$ to $1.03 \mathrm{GPa}$ [131]. As mentioned, natural cancellous bone has a porosity of 50-90\% [85,86].

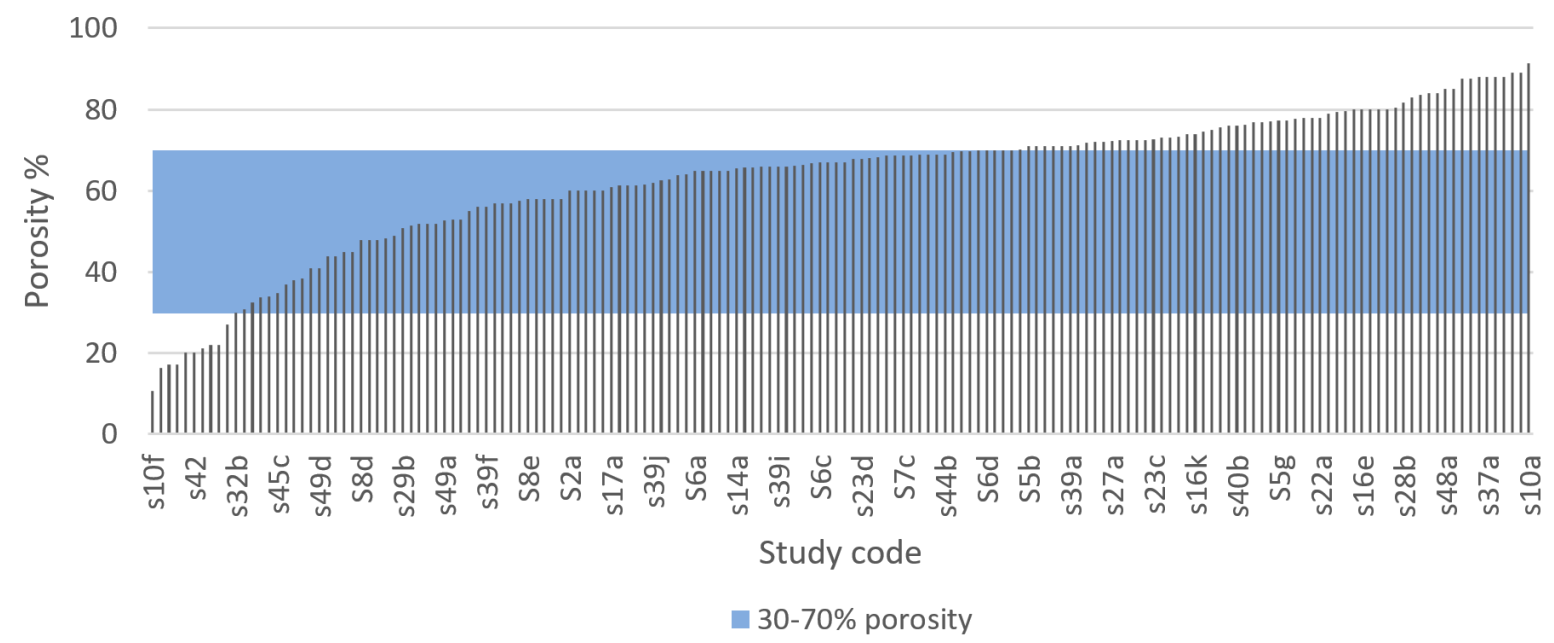

Figure 9. Porosity of implant specimens in the reviewed articles, compared with the Ideal Quality Attribute (IQA) target zone.

Zou et al. [102] designed three implants with similar pore size and shape. By reducing the porosity from 72 to $53 \%$ they achieved a compressive strength of $200 \mathrm{MPa}$ and Young's modulus of $4.3 \mathrm{GPa}$, instead of a compressive strength of $60 \mathrm{MPa}$ and Young's modulus of $2 \mathrm{GPa}$. Even though both implants achieved a stiffness close to that of human bone, only the implant with 53\% porosity achieved a compressive strength greater than human bone. Hence, the implant with $72 \%$ porosity would not 
qualify as a load-bearing bone implant. These results, along with previous research by Pattanyak et al. and Murr et al., confirm the influence of porosity on mechanical properties [193]. They also show that the implant porosity may be adjusted within limits to increase strength and adjust bone stiffness, which varies for each patient's characteristics.

From a medical regulatory perspective, the U.S Food and Drug Administration (FDA) only approves implant porosities of 30-70\% for porous coatings on solid Ti implants [194]. The range is relatively large but can be used to one's advantage since both the elastic modulus and strength of the implant can be adjusted by adjusting the porosity. Implants with porosity outside of this range do not comply with FDA regulations and cannot enter the market. It is known that medical regulations, especially for implantable medical devices, are based on strong scientific evidence. Therefore, it is vital to adhere to these regulations when designing bone implants.

Taking into consideration the medical regulations for porous implants, we selected a porosity range of $30-70 \%$ as the IQA for porous metal implants to identify studies in the systematic search that fabricated Ti scaffolds with porosity values within this range. From the 49 articles that recorded porosity of various degrees, a total of 167 results were extracted and compared with the selected IQA porosity range. The results of this comparison are presented in Figure 9. According to our results, 56.6\% of the porous scaffolds studied in the 49 selected articles had porosity values within the acceptable porosity range (30-70\%) required to satisfy medical regulations such as the FDA. By contrast, a total of 26 studies explored the properties of porous scaffolds with porosity values above the acceptable porosity range representing $37.3 \%$ of the total results extracted in this systematic literature review. There were several reasons for these studies to explore porosity levels higher than 70\%. For example, Zhang et al. [100] and Amin Yavari et al. [106] fabricated different porous structures with various porosities to explore their mechanical properties and deformation mechanisms. Moreover, porous Ti scaffolds with high levels of porosity can serve as storage for mesenchymal stem cells to facilitate bone tissue regrowth, and also to improve cell oxygenation and nutrition [100]. On the other hand, Ti porous scaffolds with porosity levels lower than $30 \%$ can provide similar mechanical properties to cortical bone $[98,100]$.

\subsubsection{Macropore Size}

Since macro pore size is directly related to the strength, porosity, and stiffness of the implant, it is an important property for implant design [195]. Pore size has a profound effect on the behaviour of osteogenic cells even in an organ culture system [196]. The implant's macro porosity determines whether bone cells can successfully penetrate and grow within the structure, and many studies have discussed the influence of pore size on the biological properties of implants [197]. Furthermore, several studies have shown that a minimum pore size of $100 \mu \mathrm{m}$ is required for vascularization and bone ingrowth, but pores larger than $100 \mu \mathrm{m}$ increase bone in-growth by allowing improved vascularization and oxygenation [86,91,193]. A minimum macropore size limit of $100 \mu \mathrm{m}$ is supported by further research as vascular penetration has been found to be restricted in smaller pore interconnections $[85,168,188,192]$.

Studies have found that pores greater than $300 \mu \mathrm{m}$ are required for vascularisation and bone ingrowth [86,168]. Tang et al. [188] found that 200-350 $\mu \mathrm{m}$ is the optimal macropore size, and various studies have found that bone ingrowth is less likely to occur beyond $400 \mu \mathrm{m}[90,195,198]$. However, research that used pore sizes of 300,600, and $900 \mu \mathrm{m}$ in porous Ti scaffolds found that those with macropores sizes of 600 and $900 \mu \mathrm{m}$ had much higher bone ingrowth compared with the scaffolds with $300 \mu \mathrm{m}$ pores [101]. Bose et al. [85] suggested that all macropore sizes between 100 and $600 \mu \mathrm{m}$ are osteoconductive. Fukuda et al. [199] experienced greater results in 500 and $600 \mu \mathrm{m}$ pores compared with 900 and $1200 \mu \mathrm{m}$ pores. Xue et al.'s [98] results showed that macropore sizes in the range of 100-600 $\mu \mathrm{m}$ possess the optimum ability for cell growth into the pore structure of porous titanium.

According to the FDA regulations, macropore sizes of 100-1000 um are approved for coatings for Ti implants [194]. Large macropores have a smaller surface area than do small pores, decreasing the cell attachment on the implant [86]. However, large macropores increase scaffold vascularisation, 
which is vital for supplying oxygen and nutrients to the tissue as well as osteoblast proliferation and migration [80], but they decrease the mechanical strength of the material. The limit of how much the macropore size can be increased while maintaining sufficient mechanical strength depends on both the material and the processing conditions. Therefore, regulatory guidelines for surface coating may be misleading for fully macroporous implants, since the strength-to-weight ratio differs between a porous and solid structure. Since the porosity decreases the strength of the implant, and large pore sizes decrease the strength of the internal architecture, large pore sizes must be avoided to increase the structure's strength. A more defined pore size range is therefore sought [86].

In this study, the macroporosity used in different studies was explored. It was found that no consensus currently exists on what upper limit to macropore size that is ideal, but somewhat of a consensus on the lower limit exists $(100 \mu \mathrm{m})$. According to FDA regulations, porous implants should have macropore sizes between 100 and $1000 \mu \mathrm{m}$ [194]. It has further been found that macropores start to lose their osteogenic functionality when larger than 500-600 $\mu \mathrm{m}[8,16,85,98,199]$. Considering that a fully porous structure is weaker than a solid structure, and that high strength is vital for implants, it can be assumed that there is no need to design a structure with pores larger than what is needed to cater for all functions within the implant.

These findings made us choose a macropore size range of 100-600 $\mu \mathrm{m}$ as the IQA for porous metal implants to identify the studies in the systematic search that fabricated Ti scaffolds with pore size values within this range. From the 42 articles that recorded pore size of various degrees, a total of 144 results were extracted and compared with the selected IQA pore size range, as seen in Figure 10. According to our results, $51.4 \%$ of the results of all studies had a macropore size within 100-600 $\mu \mathrm{m}$. It was further noted that $86.8 \%$ of the experimental results of all studies had a macropore size within the FDA recommended range of 100-1000 $\mu \mathrm{m}$. From these results, we could infer that most of the research studies identified through the systematic search somewhat considered the macroporosity range required to satisfy medical regulations.

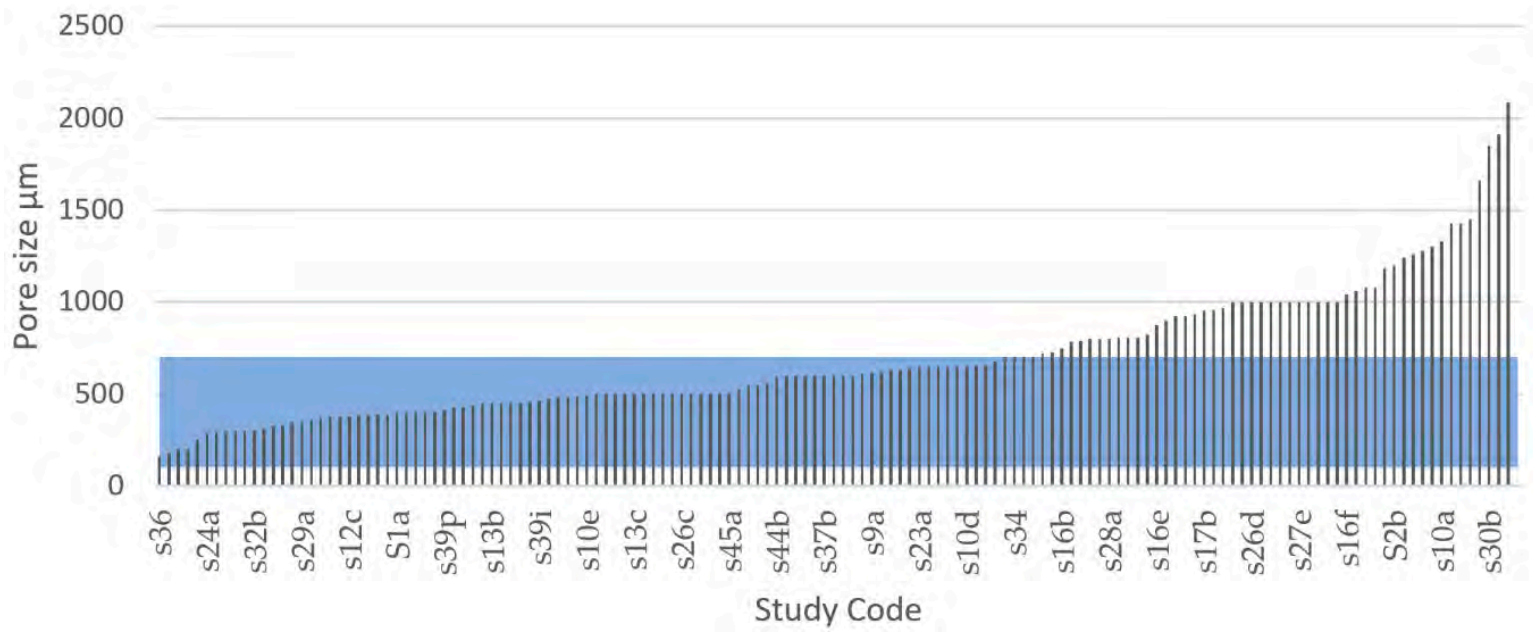

Figure 10. The pore sizes recorded in the reviewed articles, compared with the Ideal Quality Attribute IQA target zone.

By contrast, a total of 68 results out 144 showed pore size values above the acceptable macropore size range representing $48.6 \%$ of the total results extracted in this systematic literature review. There were several reasons for these studies to explore pore sizes above $600 \mu \mathrm{m}$. For example, the FDA approves macropore sizes between 100 and $1000 \mu \mathrm{m}$ [194]. Hara et al. [96] tested four porous structures with different macropore size to explore their mechanical properties. Taniguchi tested 300, 600, and $900 \mu \mathrm{m}$ pore sizes and found that the structures with 600 and $900 \mu \mathrm{m}$ pore size exhibited higher bone ingrowth. Large macropores increase scaffold vascularisation, which is vital for supplying oxygen and nutrients to the tissue as well as osteoblast proliferation and migration [80]; however, larger pores also have a 
smaller surface area compared with small pores, decreasing the cell attachment on the implant [86]. Larger macropores also result in higher porosity, and this reduces the strength of the implant $[187,188]$.

The ideal macropore size for bone implants is controversial and undefined, and according to Otsuki et al., a reason for the varied pore size data may be that the interconnectivity of pores was not considered [198]. Macropore size regulations have been developed for the first generation of porous implants, which use a single-scaled porous network with repeated, equally sized, and shaped pores. However, bone grows in a naturally random structure with pores of different sizes, shapes, and directions similar to the structure of a sponge $[130,155]$. The use of a multiscale porous scaffold that combines smaller and larger pore sizes within the same structure is a recent strategy to optimise the internal architecture of implants $[142,188]$. This method combines advantages of both small and large macropores without decreasing the strength or reducing the bone in-growth to levels that are inappropriate in application [188]. According to our results, a total of 8 out of 50 studies used some sort of multiscale pore approach, but it was observed that the design method varied, and that the researchers failed to provide the percentage of the total structure that used each pore size. It was further observed that a multiscale porous structure occurred in some implants where the manufacturing of a single-scaled structure resulted in varying pore sizes due to unprecise manufacturing tolerances.

\subsubsection{Pore Inter Connectivity}

According to our results, $46 \%$ of the collected studies registered pore interconnectivity. Interestingly, all of these studies designed their porous scaffolds with an interconnectivity of $100 \%$. The pores in a porous bone implant must be interconnected to ensure movement and the supply of necessary nutrients through ingrowth of tissue and bone [200]. Interconnected pores tend to facilitate the flow of fluids and biological cells through the structure which is essential for bone tissue formation [185]. According to Nyberg et al. [201] the integration of artificial material tissue with native tissue can be improved by interconnected pores. Tang et al. [188] suggested that an increased pore interconnectivity increases the number and size of blood vessels formed in scaffolds. The interconnectivity is also a critical factor for ensuring that all cells within the structure are within a $200 \mu \mathrm{m}$ range from a blood supply to provide transfer of nutrients and oxygen [202]. According to the FDA's recommendations for porous metal coatings, pores in such structures must be interconnected [194]. Although this requirement is for surface coatings, it also indicates the importance of an interconnected porosity for fully porous implants. In the systematic review, it appears as though a vast majority of studies had indicated the importance of an interconnected porosity. Therefore, to guarantee all processes and fluid movements necessary for tissue and bone ingrowth, the selected IQA for pore interconnectivity would ideally be $100 \%$.

\subsubsection{Elastic Modulus}

It was observed in this systematic review that an elastic modulus is a property commonly reported in AM porous scaffolds studies (by $89 \%$ of all studies). A controlled modulus of elasticity has proved to be critical in prostheses and scaffolds to avoid stress shielding [81,82]. Stress shielding occurs when there is a stiffness mismatch between the implant and surrounding bone, and it can cause inflammation and the need for revision surgery [197]. Ti and common implant Ti alloys have an elastic modulus of roughly 100-120 GPa $[81,84,138,197]$. A reduced modulus is necessary to avoid stress shielding and can be achieved by designing implants with a porous structure [90].

Defining an ideal specific modulus of elasticity for porous bone implants is not practical because Since the mechanical properties of human bone, especially the elastic modulus, change drastically with factors, such as age, physical activity, and health. For example, femoral bone specimens from patients aged 3, 5, and 35 years had an elastic modulus of 7, 12.8, and $16.7 \mathrm{GPa}$, respectively, indicating a dramatic change with age [90]. As previously shown in Table 6, the elastic modulus of human bone varies in the literature. Chen and Thouas [57] estimated the elastic modulus of cortical bone to be approximately 11-21 GPa in the longitudinal direction, whereas Lee et al. [147] suggested 18-22 GPa. 
Wang et al. [81] suggested a wider range of 3-30 GPa. These findings indicate that the stiffness of an implant may need to be adjusted specifically for the person it is intended for, and that the target value for the elastic modulus may be specific to each patient. Therefore, it is more practical to think that for the design of porous scaffolds, an ideal target area exists for the modulus of elasticity. Based on this, the IQA for elastic modulus is proposed to be 3-30 GPa for fully porous Ti implants.

Figures 11 and 12 show the elastic modulus that was reported in the reviewed articles and these values were compared with the proposed IQA. From the extracted of elastic modulus results, $55.5 \%$ reached the target area of 3-30 GPa. These implants achieved an elastic modulus within the range of natural bone and would therefore eliminate risk of stress shielding. By contrast, $40 \%$ of the results exhibited an elastic modulus below $3 \mathrm{GPa}$, and only $3.6 \%$ of the results reported an elastic modulus higher than $30 \mathrm{GPa}$. These results clearly demonstrated that most studies are aiming towards a modulus of elasticity closer to the bone modulus.

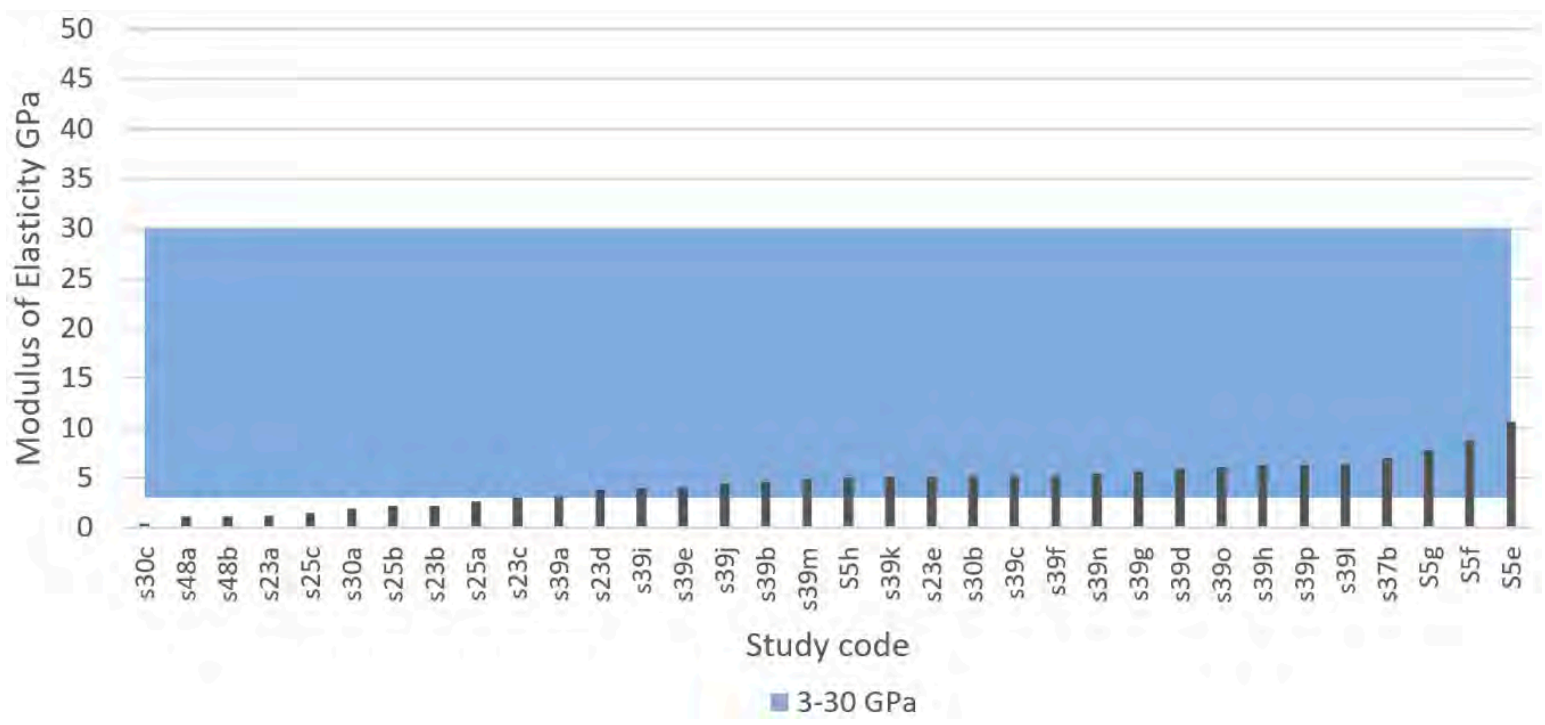

Figure 11. Elastic modulus of porous metamaterials based on triply periodic minimal surfaces (TPMS) compared with the Ideal Quality Attribute (IQA) target zone.

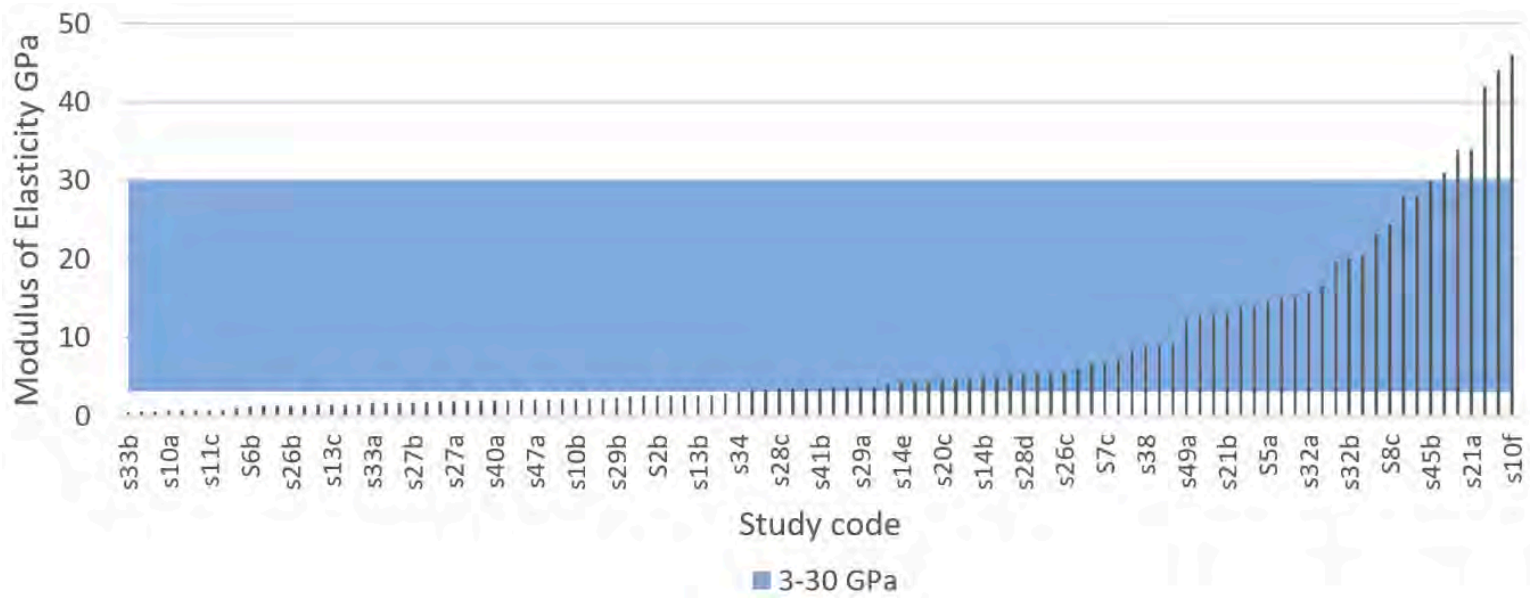

Figure 12. Elastic modulus of porous beam-based metamaterials compared with the Ideal Quality Attribute (IQA) target zone.

The elastic modulus of metals such as titanium and its alloys naturally have a much higher elastic modulus compared with bone [81]. However, research shows that the elastic modulus of metals can be readily adjusted by modifying their porosity. Porous metals with a low modulus of elasticity correspond to high levels of porosity. For example, Wang et al. [84] explored five types of porous 
structures using the same material $(\mathrm{TiNbZr})$ and pore size $(550 \mu \mathrm{m})$ but ranging porosity. His results revealed that four of the implants with porosities ranging from $42 \%$ to $69 \%$ all achieved an elastic modulus within the approved range of 3-30 GPa; however, the implant with the highest porosity (74\%) achieved the lowest elastic modulus of 1.6 GPa. Similarly, Li et al. [203] used a porosity of 91\% resulting in a low elastic modulus of $0.8 \mathrm{GPa}$. Furthermore, Chen et al. [204] received an elastic modulus of 44.4 GPa for a porous titanium structure using $30 \%$ porosity but by increasing the porosity to $40 \%$ the elastic modulus was reduced to $24.7 \mathrm{GPa}$.

Using the data obtained through the systematic literature search we calculated two multiple linear regressions to predict the modulus of elasticity of beam and TPMS-based AMd Ti scaffolds. The regression model used the independent variables of pore size, relative density (porosity), and the interaction of pore size-porosity. According to our results, a regression equation was found for beam-based AMd Ti scaffolds $(\mathrm{F}(3,75)=54.139, p<0.0001)$, with an $\mathrm{R}^{2}$ adj of 0.671 , as shown in Figure 13a. The residuals of the multiple linear regression are randomly scattered around the centre line of zero with no obvious pattern. The predicted compressive yield strength of beam-based scaffolds is equal to $27.738-0.078$ (pore size) -27.417 (porosity) +0.0689 (pore size porosity), where pore size is coded or measured in $\mu \mathrm{m}$, and relative density expressed as porosity as a percentage. The beam-based scaffolds' modulus of elasticity decreased $0.078 \mathrm{MPa}$ for each $\mu \mathrm{m}, 27.417 \mathrm{MPa}$ per $1 \%$ of porosity increment, and increased $0.0689 \mathrm{MPa}$ for the interaction pore size* porosity. Both pore size $(p<0.0005)$ and porosity $(p<0.0001)$ were significant predictors of beam-based scaffolds' modulus of elasticity, including the interaction between pore size and porosity $(p<0.0001)$.

a)

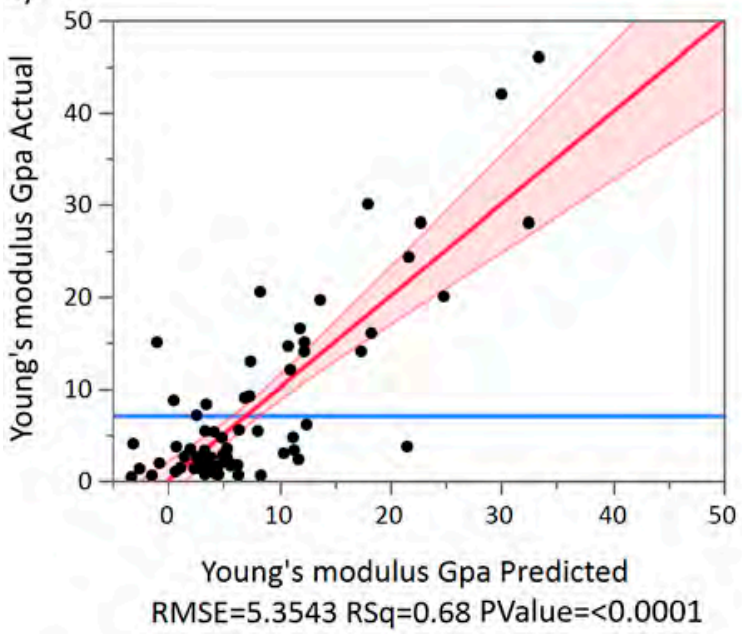

b)

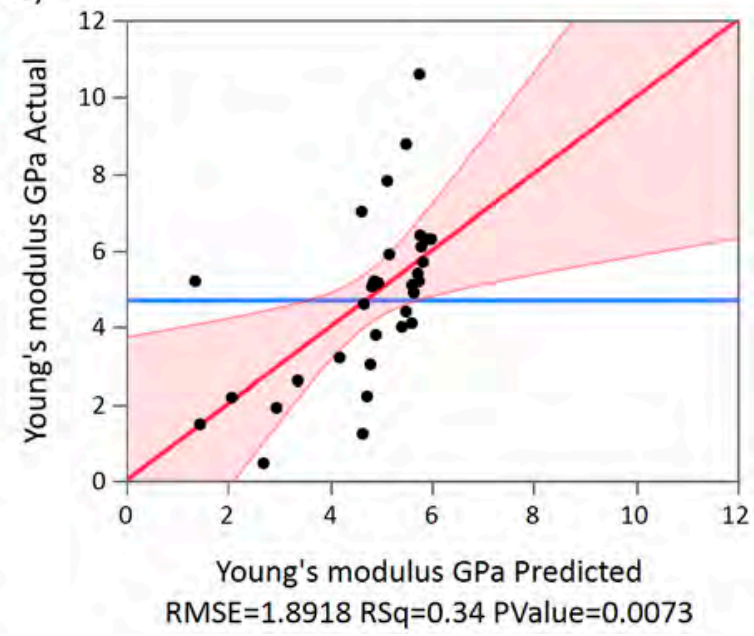

Figure 13. Overall predicted model of elastic modulus actual versus an elastic modulus predicted (a) beam-based scaffolds, and (b) TPMS-based scaffolds.

In the case of the multiple linear regression of TPMS based AMd Ti scaffolds a significant regression equation was also found $(\mathrm{F}(3,28)=4.897, p<0.0073)$, with an $\mathrm{R}^{2}$ adj of 0.273 , as shown in Figure $13 \mathrm{~b}$. The residuals of the multiple linear regression are randomly scattered around the centre line of zero with no obvious pattern. The scaffolds' predicted modulus of elasticity is equal to $0.008-0.002$ (pore size)-2.342 (porosity) +0.002 (pore size* porosity). The TPMS based scaffolds' modulus of elasticity decreased $0.002 \mathrm{MPa}$ for each $\mu \mathrm{m}, 2.342 \mathrm{MPa}$ per $1 \%$ of porosity increment, and $0.002 \mathrm{MPa}$ for the interaction pore size* porosity. Pore size was a significant predictor of TPMS-based scaffolds' modulus of elasticity with a $p$-values $<0.0563$. However, porosity was not a significant predictor with $p$-values $<0.553$ and 0.843 , respectively. Moreover, no interaction between pore size and porosity was found regarding to modulus of the elasticity. 


\subsubsection{Compressive Yield Strength}

For an adequate functioning of any load-bearing implant, it is vital that its design withstand the required forces and loading cycles. Mechanical strength is one of the implant's most crucial features for avoiding implant failure. To withstand the loads of daily activities, load-bearing implants must have at least the same yield strength as the bone that they replace [81]. The yield point of bone represents the threshold from where the structure accumulates irreversible deformation. Unlike bulk metals such as steel, the yield point of bones cannot be clearly distinguished; it is rather associated with a continuous transition zone [160]. Strain beyond the yield point will deform the structure beyond its point of resilience causing material damage, usually occurring as micro-cracks [205]. Bone tissue has evolved to mainly support compressive stress [206,207]. Bone is $30 \%$ weaker under tensile stress, and $65 \%$ weaker under shear stress [208]. Therefore, load-bearing implant scaffolds require a high compressive strength to prevent fractures and improve functional stability [209]. The compressive yield strength of cortical bone varies in the literature. As previously shown in Table 6, the compressive yield strength of cortical bone varies approximately between 90 and $170 \mathrm{MPa}$. To replace like with like, using a biomimetic approach for comparison purposes, a minimum and a maximum compressive yield strength of $90 \mathrm{MPa}$ and $170 \mathrm{MPa}$ were selected as the IQA for fully porous Ti implants.

The systematic search identified that 37 out of 50 studies recorded compressive yield strength, from which a total of 133 experimental results were extracted and compared, as shown in Figures 14 and 15. Figure 14 presents the results of studies using TPMS structures and Figure 15 presents the results of studies using porous beam-based metamaterials. Both comparisons show high numbers of studies resulting in a compressive yield strength below $90 \mathrm{MPa}$. A total of $55.7 \%$ of all results had a compressive yield strength below the defined IQA target and $25 \%$ of the studies achieved a compressive yield strength within the bone region. On the other hand, only $19 \%$ of the extracted experimental results had a strength above the bone region. Such implants would have strengths similar to or higher than cortical bone and are expected to not experience permanent deformation caused by the expected bone compressive loading conditions in the human body.

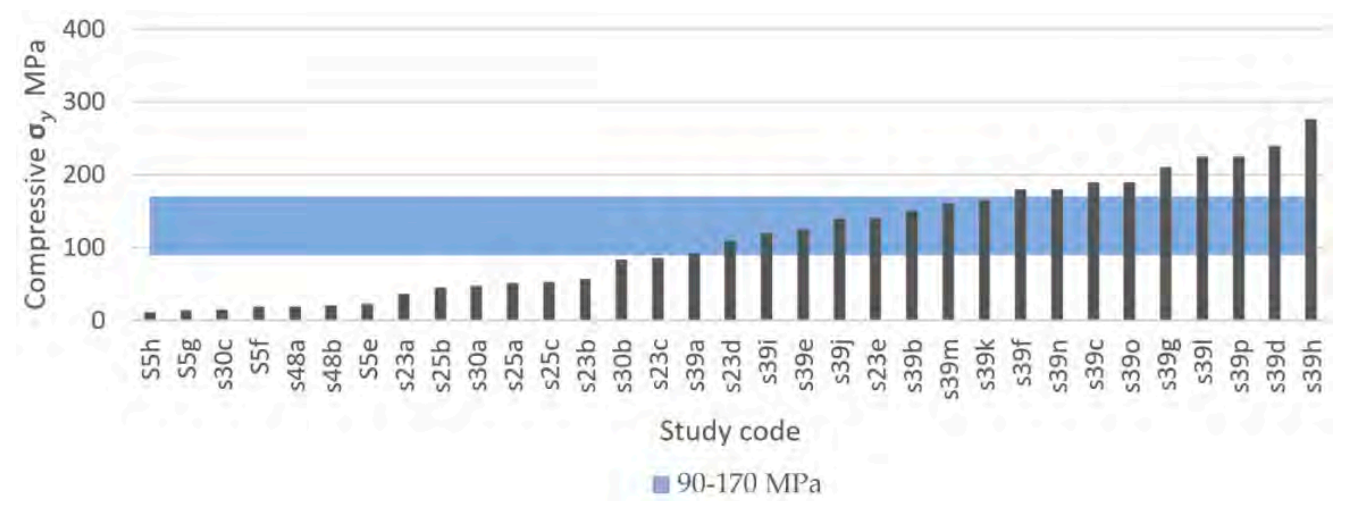

Figure 14. Compressive yield strength of porous metamaterials based on triply periodic minimal surfaces (TPMS) compared with the Ideal Quality Attribute (IQA) target zone. 


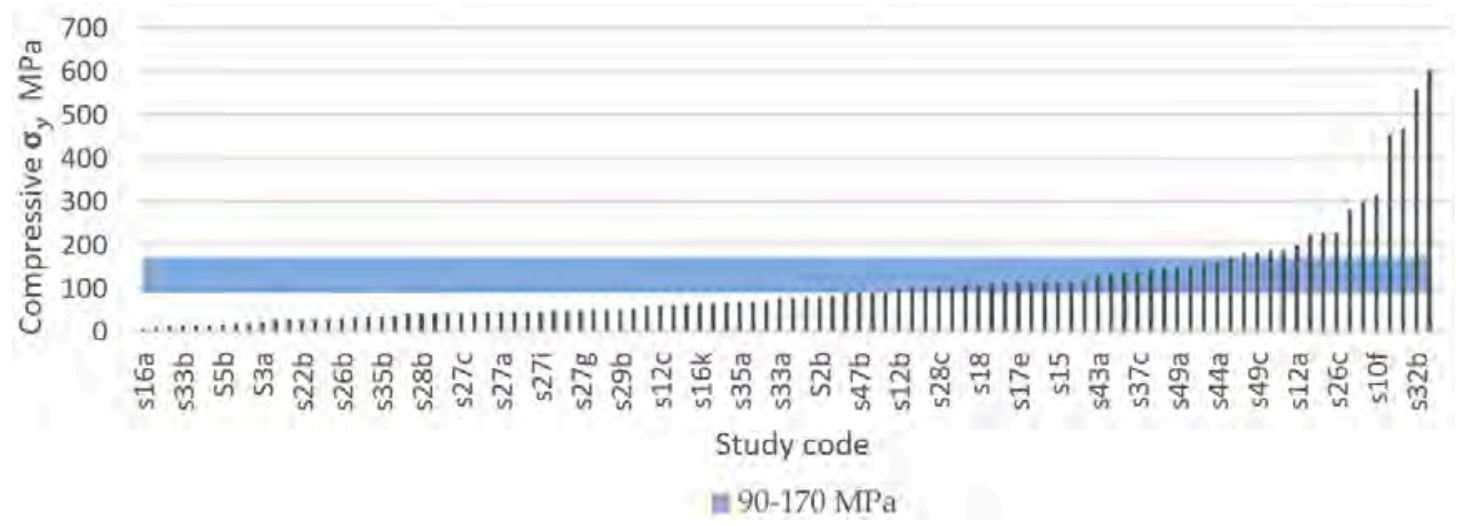

Figure 15. Compressive yield strength of porous beam-based metamaterials compared with the Ideal Quality Attribute (IQA) target zone.

Decreased strength of a porous implant can result from high porosity and large pore sizes, [81,188]. For example, Zhang et al. [113] fabricated porous scaffolds based on the TPMS diamond unit cell with a wide range of compressive yield strengths from $36 \mathrm{MPa}$ to $140 \mathrm{MPa}$ just by varying the scaffolds' porosity and maintaining the pore size constant. The type of unit cell used to design porous scaffolds can also drastically change it mechanical properties. For example, Zhao et al. [116] fabricated four porous scaffolds with the same pore size and similar porosities using two different unit cells (tetrahedron and octahedron). However, the scaffolds based on the octahedron unit cell registered almost double the compressive strength compared with those based on the tetrahedron unit cell [116]. The compressive yield strength of porous metals can also be enhanced by gradually changing the porosity level along the radial direction of the scaffold. This was demonstrated by Zhang et al. [100], who reported functionally graded porous scaffolds based on the diamond unit cell with superior comprehensive mechanical properties to the biomaterials with uniform porous structures.

Using the data obtained through the systematic literature search, we calculated two multiple linear regressions to predict compressive yield strength based on pore size, porosity, and the interaction of size-porosity for beam-based and TPMS-based AMd Ti scaffolds, respectively.

According to our results, a regression equation was found for beam-based AMd Ti scaffolds $(\mathrm{F}(3,75)$ $=31.452, p<0.0001$ ), with an $R^{2}$ adj of 0.539 , as shown in Figure 16a. The residuals of the multiple linear regression are randomly scattered around the centre line of zero, with no obvious pattern. The scaffolds' predicted compressive yield strength is equal to $380.557-0.075$ (pore size)-350.828 (porosity) +0.557 (pore size ${ }^{*}$ porosity), where pore size is coded or measured in $\mu \mathrm{m}$, and porosity is measured as a percentage. The beam-based scaffolds' compressive yield strength decreased $0.075 \mathrm{MPa}$ for each $\mu \mathrm{m}, 350.828 \mathrm{MPa}$ per $1 \%$ of porosity increment, and increased $0.557 \mathrm{MPa}$ for the interaction of pore size*porosity. Both pore size $(p<0.0378)$, porosity $(p<0.001)$, and the interaction between pore size and porosity $(p<0.0048)$ were significant predictors of beam-based scaffolds' compressive yield strength. The interaction between pore size and porosity was found to be significant with a $p$-value $<0.0048$. 
a)

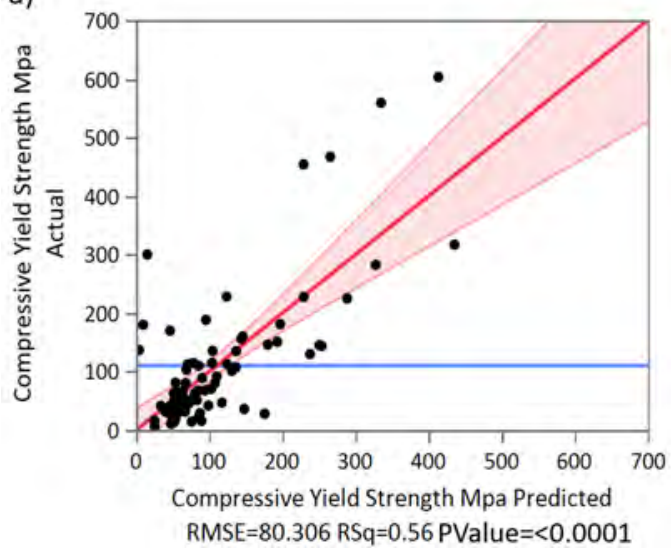

b)

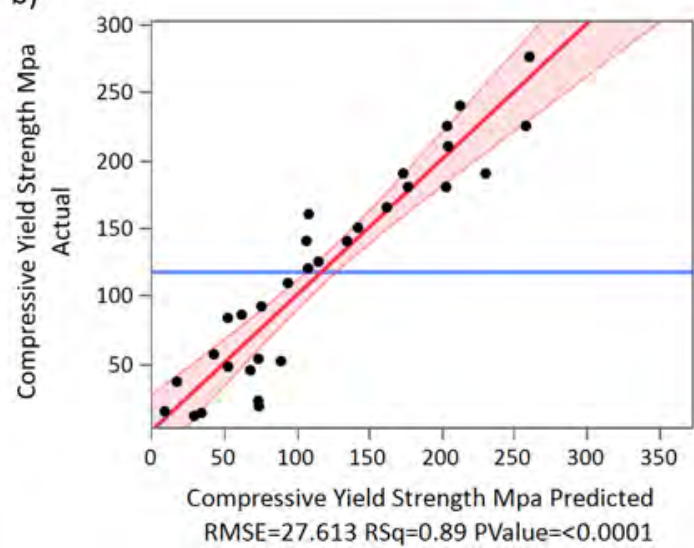

Figure 16. Overall predicted model of compressive yield strength Actual versus compressive yield strength Predicted of (a) beam-based scaffolds, and (b) TPMS-based scaffolds.

Regarding the multiple linear regression of TPMS-based AMd Ti scaffolds, a significant regression equation was also found $(F(3,27)=65.547, p<0.0001)$, with an $R^{2}$ adj of 0.872 , as shown in Figure $16 \mathrm{~b}$. The residuals of the multiple linear regression are randomly scattered around the centre line of zero, with no obvious pattern. The scaffolds' predicted compressive yield strength is equal to $524.780-$ 0.008 (pore size)-625.266 (porosity) +0.183 (pore size*porosity). The TPMS-based scaffolds' compressive yield strength decreased $0.008 \mathrm{MPa}$ for each $\mu \mathrm{m}, 625.266 \mathrm{MPa}$ per each $1 \%$ of porosity increment, and increased $0.183 \mathrm{MPa}$ for the interaction of pore size ${ }^{*}$ porosity. Porosity was a significant predictor of TPMS based scaffolds' compressive yield strength with $p$-values $<0.0001$. However, pore size and the interaction between pore size and porosity were non-significant, with $p$-values $<0.7018$ and 0.3260 , respectively.

\subsubsection{Ultimate Compressive Strength}

If loading surpasses the yield point of bone, it will eventually reach the ultimate point. This point represents the maximum compressive strength that a material can withstand without irreversible strains and damage occurring. Past this point, macrocracks are formed and fracture occurs [160]. Bone implants in load-bearing applications must withstand high stress within the body, to a degree where no permanent deformation occurs during the load that the implant is expected to be exposed to. Hence, controlled ultimate compressive strength is a crucial property to study in bone implant research. Natural bone is estimated to have an ultimate compressive strength of 180-200 MPa [84]. However, results vary in the literature. For example, Calori et al. [8] suggested a more widespread range of 130-290 MPa, whereas Henkel et al. suggested 100-230 MPa [168]. To replace like with like using a biometric approach, bone implants should have an ultimate compressive strength similar to that of bone [8]. Taking into consideration the compressive yield strength suggested previously and the three results presented in Table 5, the proposed IQA region for the ultimate compressive strength is between $180 \mathrm{MPa}$ and $290 \mathrm{MPa}$.

In this systematic search a total of 60 experimental results of ultimate compressive strength from 19 different studies were extracted. Figures 17 and 18 show the ultimate compressive strength of the different studies compared with the defined IQA target of between $180 \mathrm{MPa}$ and 290MPa. Figure 17 corresponds to experimental results of porous scaffolds composed of TPMS unit cells compared with the IQA target. According to Figure 17, only one study with three different experimental results measured the ultimate strength of porous scaffolds based on TPMS unit cells. In this study by Yanez et al. [120], three ultimate compressive strengths of 17, 47.5, and 83.5 MPa were achieved using the gyroid unit cell. Dramatic improvement in the ultimate compressive strength of the scaffold was achieved. This improvement in mechanical properties was possible by slightly changing the gyroid unit cell into an elongated gyroid. However, none of the experimental results obtained by Yanez 
et al. [120] were able to reach the minimum IQA ultimate compressive strength proposed in this study. The low strength of Yanez at al.'s [120] samples can be attributed to their high porosity values which ranged between $75 \%$ and $90 \%$. This increased the stress concentration, reducing the ultimate compressive strength.

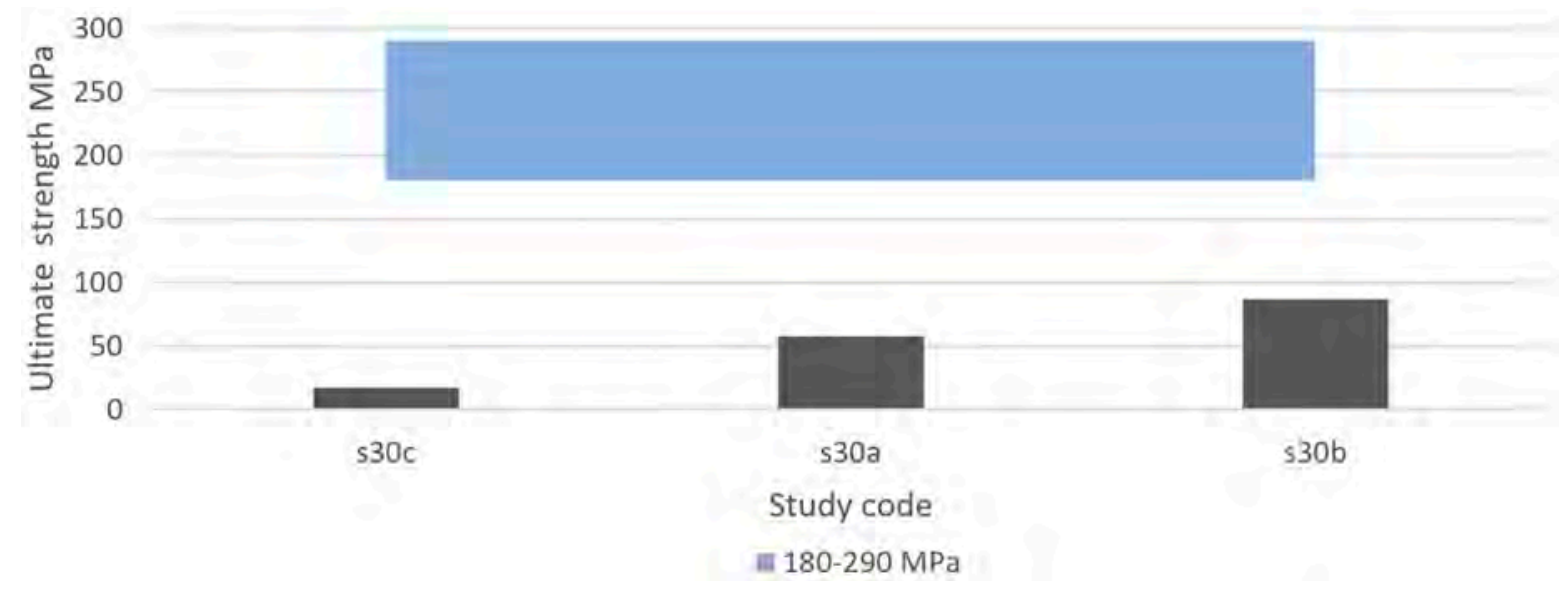

Figure 17. Ultimate compressive strength of porous metamaterials based on triply periodic minimal surfaces (TPMS) compared with the Ideal Quality Attribute (IQA) target zone.

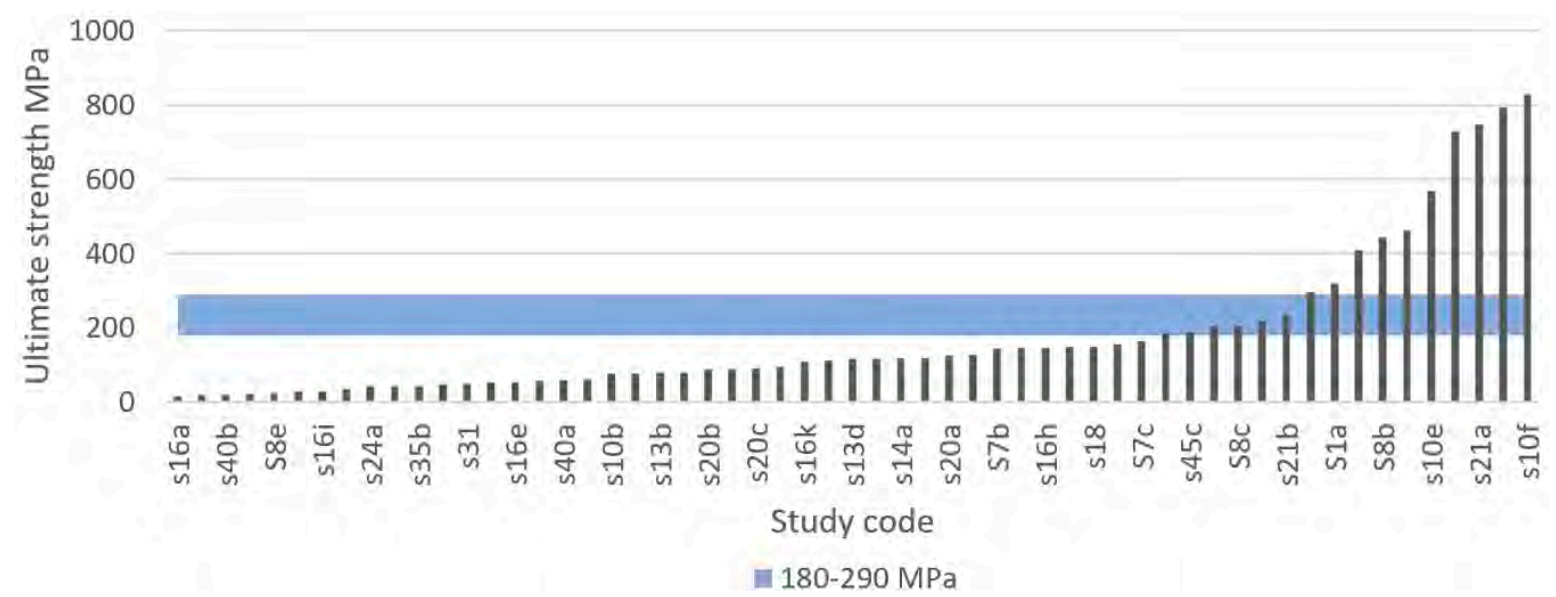

Figure 18. Ultimate compressive strength of porous beam-based metamaterials compared with the Ideal Quality Attribute (IQA) target zone.

Figure 18 is composed of 19 different studies on beam-based unit cells where 57 experimental results are compared with the IQA target. According to Figure 18, 10 experimental results reached higher ultimate compressive strengths than bone. The highest ultimate compressive strength ( $830 \mathrm{MPa})$ recorded was achieved with a scaffold based on the diamond unit cell by Zhang et al. [100]. From all results recorded, a total of $16.7 \%$ achieved an ultimate compressive strength above the proposed IQA ultimate compressive strength; $10 \%$ had similar ultimate compressive strengths to bone; and $73.3 \%$ had lower ultimate compressive strengths than bone. The scaffolds that did not fulfil the required IQA ultimate compressive strength would risk fracturing due to macrocracks occurring during high loads. Porosity within a structure has been proven to decrease the strength of a structure [81,188], which may explain the high number of scaffolds with low ultimate strength.

The goal of designing a porous structure with enough porosity and pore size without diminishing strength is a difficult task, and as researchers aim to create highly porous structures with low elastic modulus, many structures experienced low ultimate strength. Attar et al. [111] manufactured a porous titanium structure by SLM with rectangular pores and $17 \%$ porosity and achieved an ultimate compressive strength of $747 \mathrm{MPa}$. Using the same material, manufacturing method, and unit cell, 
a different structure with $37 \%$ porosity achieved an ultimate strength of $235 \mathrm{MPa}$. In a similar manner, Chen et al. [204] designed three structures of the same material and manufacturing method. Using porosities of 30\%, 40\%, and 50\%, the ultimate compressive strengths recorded were 524, 301.7, and $120.3 \mathrm{MPa}$, respectively, indicating that increased porosity reduces the strength of the structure.

\subsubsection{Fatigue Strength}

During normal daily activities, load-bearing implants experience just a fraction of the material's ultimate stress [209-211]. However, after years of use, the high cyclic loading to which load-bearing implants are subjected eventually leads to the accumulation of small stresses, causing progressive and localised material damage that results in implant failure [212]. For instance, one of the most critical mechanical properties for load-bearing implants is fatigue strength. However, fatigue strength is the most difficult mechanical property to determine [213].

The required fatigue resistance of a load bearing implant and its components mainly depends on their cyclic loading conditions and the required life span. For example, it is estimated that lower limb prostheses are subjected to up to 2 million gait cycles per year [214], and in the case of orthodontic prostheses these can reach up to 300,000 loading cycles per year [213]. Therefore, a large variety of medical standards exist for testing fatigue strength. Some of these fatigue tests differ depending on the type of load applied such as tension-tension, compression-compression, and tension-compression. In the case of load-bearing bones, their loading conditions in real-life activities are complex [135]. However, bone is mainly loaded in compression [206,207]. Therefore, to test the fatigue life of metamaterials for bone implant applications, compression fatigue tests are preferred due to the simplicity of the test setups [215].

Regarding the number of cycles that load bearing implants and their components need to have tested for fatigue strength, all the different medical standards agree that such products need to have a fatigue life within the high-cycle fatigue region $\left(\mathrm{N}>10^{4}\right.$ cycles). For example, the ASTM standard F2777 - 16 recommends testing tibial inserts' endurance and deformation under high flexion with a minimum number of cycles of $2.2 \times 10^{5}$, and in the case of dental implants they are typically tested up to 5 million cycles $[213,216]$. Nevertheless, for a component of a load-bearing implant to have at least 25 years of life span [217], the highest number of cycles that must be tested is $10^{7}$ cycles [213,216]. Taking into consideration current medical standards for load-bearing implants, the high-cycle fatigue region between $10^{4}$ cycles and $10^{7}$ cycles was selected as the IQA fatigue life for porous titanium metamaterials for bone regeneration.

Using the selected high-cycle fatigue region, this systematic literature search identified a total of 13 different studies on fatigue resistance, among which 11 studies performed compression-compression fatigue tests. Then, for comparison purposes, a total of 51 experimental results were extracted and compared. Moreover, to facilitate the comparison of the results of the studies, they were classified according to the type of unit cell used to produce porous structures as beam and TPMS-based as resented in Figures 19-21. According to our results, the TPMS porous structures that withstood the highest stresses at the high-cycle fatigue region were achieved by Bobbert et al. [79]. The primitive TPMS structure presented the highest stress within the high-cycle fatigue region, with $232 \mathrm{MPa}$ at $3 \times 10^{4}$ cycles, as shown in Figure 19. The TPMS porous structures that were able to withstand the second and third highest stresses within the high-cycle fatigue region were the I-WP and diamond structures, with $227 \mathrm{MPa}$ at $3 \times 10^{5}$ cycles and $204 \mathrm{MPa}$ at $3 \times 10^{6}$ cycles as shown in Figures 19 and 20 . Remarkably, the primitive TPMS structure was the only one to pass the $10^{7}$ threshold with $80 \mathrm{MPa}$ at $3 \times 10^{7}$ cycles, as presented in Figure 20 . 


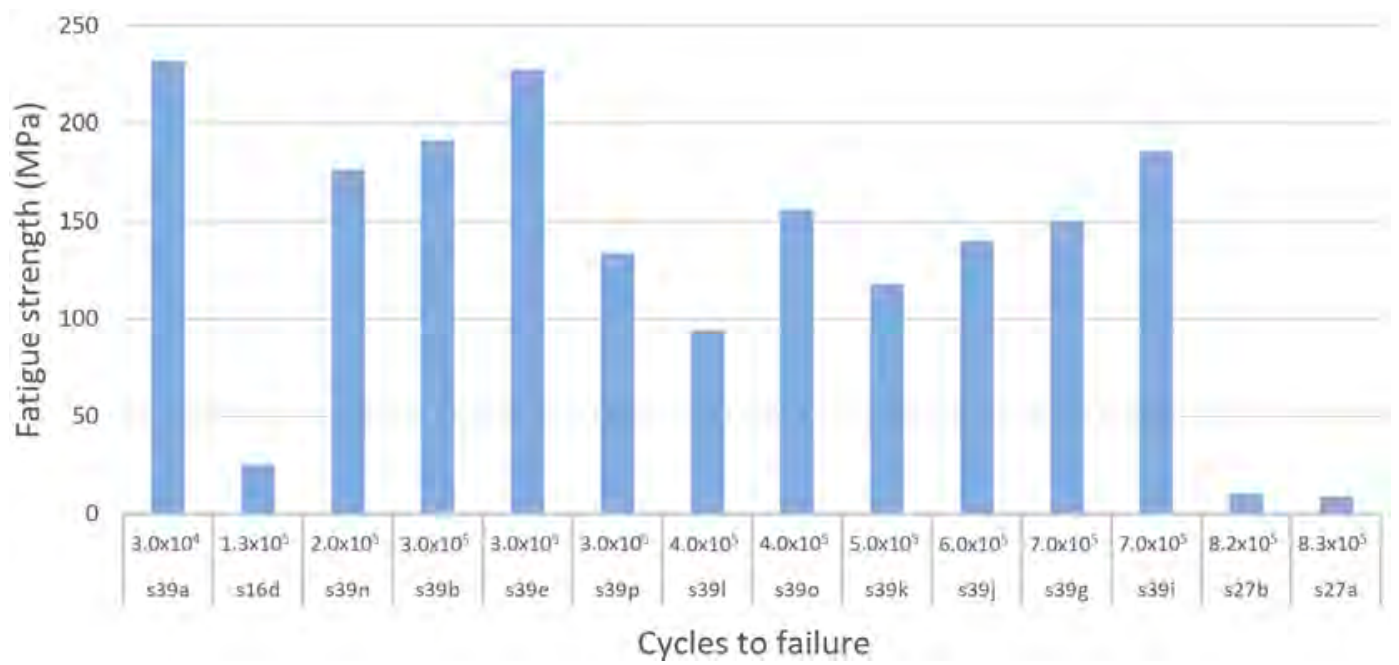

Figure 19. Comparison of the results of different studies on the fatigue strength of porous metamaterials based on triply periodic minimal surfaces (TPMS) within the high-cycle fatigue region between $10^{4}$ and $10^{5}$ cycles.

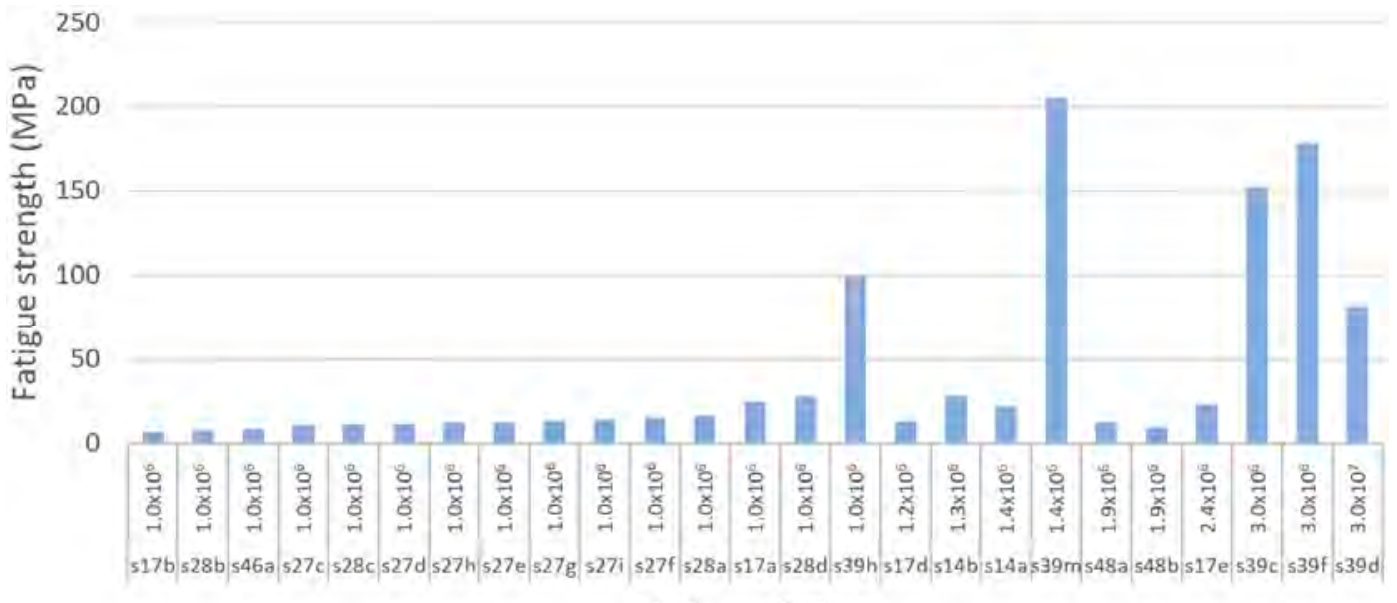

\section{Cycles to failure}

Figure 20. Comparison of the results of different studies on the fatigue strength of porous metamaterials based on triply periodic minimal surfaces (TPMS) within the high-cycle fatigue region between $10^{6}$ and $10^{7}$ cycles.

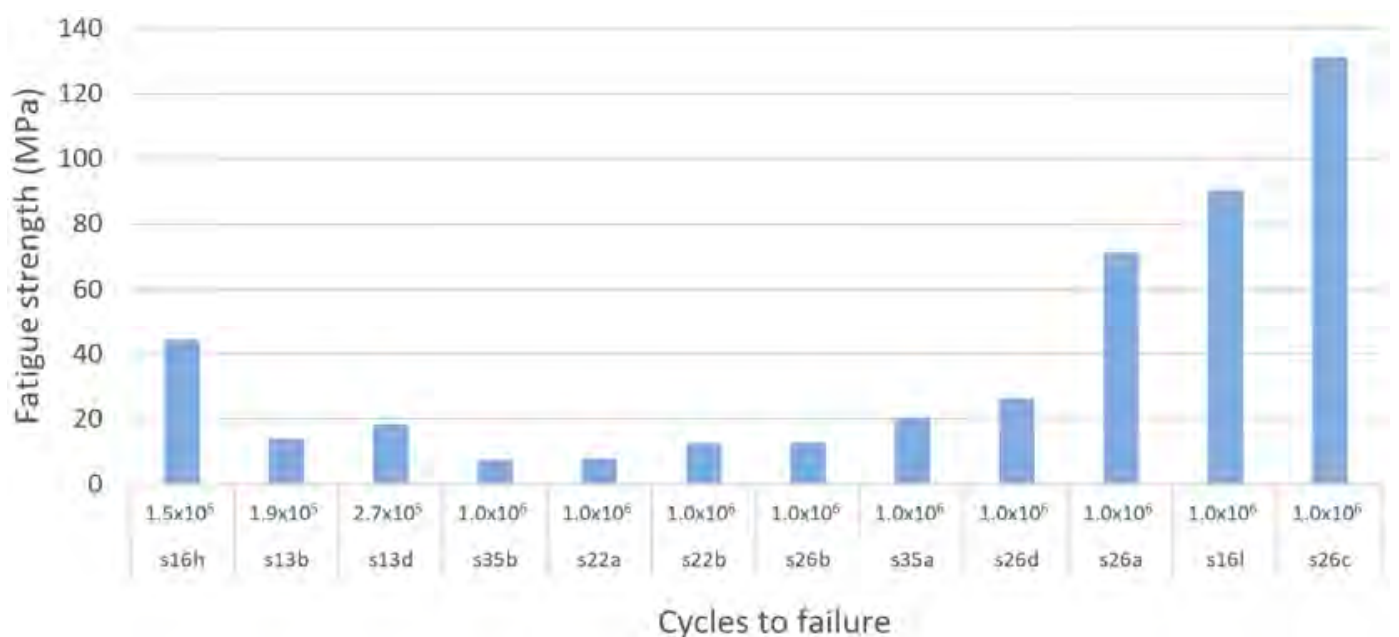

Figure 21. Comparison of the results of different studies on the fatigue strength of porous beam-based metamaterials within the high-cycle fatigue region between $10^{6}$ and $10^{7}$ cycles. 
In the case of beam-based metamaterials the study performed by Zhao et al. [116] achieved the highest fatigue strength with $130 \mathrm{MPa}$ at $10^{6}$ cycles using a lattice structure based on the octahedron unit cell, as shown in Figure 21. In second and third place with the highest fatigue strength are the tetrahedron and the cubic porous lattice structures with $90 \mathrm{MPa}$ at $1 \times 10^{6}$ cycles and $90 \mathrm{MPa}$ at $1 \times 10^{6}$ cycles fabricated by Amin Yavari et al. [106] and Zhao et al. [116], as presented in Figure 21.

According to the results of this systematic search it could be seen that TPMS structures provide superior fatigue strength to porous bio-metamaterials compared with beam-based unit cells. Moreover, in terms of fatigue resistance, it was identified that the primitive, I-WP, and diamond TPMS provided the best performance, whereas the octahedron, cubic, and tetrahedron are the best-performing lattice unit cells. However, it is crucial to note that several factors can affect the fatigue life of additively manufactured Ti metamaterials. Some of these factors are residual stresses and stress concentrators caused by high surface roughness and manufacturing defects [218]. Moreover, the fatigue strength of bulk materials significantly degrades when they are in porous form or when voids and pores are developed during fabrication [219]. In the case of additively manufactured components, it has been proven that their fatigue strength is extremely sensitive to localised and nonuniform heat and uncontrolled cooling cycles during fabrication $[220,221]$.

\subsection{Discussion and Summary of the Findings}

Table 7 presents a summary of proposed IQA target values for porous Ti and Ti alloy bone implants aimed at load-bearing applications. These values are based on scientifically supported values found in human bone research, federal regulations (FDA), and research articles on porous Ti implants manufactured using AM between 2000 and 2020. These properties are part of the first step of the QbD framework of "Define the Quality Target Product Profile." The IQAs are necessary for a systematic and qualitative design approach. These properties will provide benchmark guidance to facilitate future research on porous bone implant design.

Table 7. Summary of Ideal Quality Attributes proposed in this study.

\begin{tabular}{cc}
\hline \multicolumn{2}{c}{ Ideal Quality Attributes } \\
\hline Porosity & $30-70 \%$ \\
Pore size & $100-600 \mu \mathrm{m}$ \\
Elastic modulus & $3-30 \mathrm{GPa}$ \\
Compressive yield strength & $90-170 \mathrm{MPa}$ \\
Ultimate compressive strength & $180-290 \mathrm{MPa}$ \\
Fatigue resistance & $72.6-137 \mathrm{MPa}$ at 106 \\
Interconnectivity & $100 \%$ \\
\hline
\end{tabular}

An IQA target zone for the porosity of porous Ti implants has been proposed as 30-70\% based on results found in research articles as well as in current FDA regulations. We found that $56.6 \%$ of all studies in this review achieved a porosity within this range. AM was found to produce porous structures with highly controlled porosity. Numerous studies as well as FDA regulations have discussed the importance of using porous structures for tissue ingrowth, which have numerous advantages to non-porous implants. Whereas porous coatings are used in some instances, it was observed in this study that many researchers believe in using a fully porous structure to achieve a biomimetic structure mimicking natural bone. All data used extracted in this systematic literature review came from studies that used scaffolds with constant porosity. However whether a repeated lattice structure throughout the entire structure is sufficient or a biomimetic "sponge-like" structure with irregular, elongated pores should be used has not yet been confirmed in research; nevertheless implants using a biomimetic design approach replicating natural bone received attention in recent research [86]. Since bone has a random and stochastic structure with pores of different sizes, a multiscale porous structure with pores of different sizes deserves further research. Multiscale porous scaffold structures have been proven 
to perform better than one-dimensional structures [142]. Nonetheless, to properly compare implants with a multiscale structure, pore distribution and size must be recorded.

In the case of scaffolds' pore size, the IQA was proposed to be $100-600 \mu \mathrm{m}$ based on numerous performed research trials. Whereas the FDA requirement is a pore size between 100-1000 $\mu \mathrm{m}$, a more defined pore size range of $100-600 \mu \mathrm{m}$ is supported by research due to numerous research trials having experienced reduced bone ingrowth in pores larger than $600 \mu \mathrm{m}$. Strut thickness is the thickness of the pore walls within a porous structure. It may have a substantial impact on implant mechanical properties [90] and can serve as a unit cell's characteristic to compare different mechanical properties in relation to it. However, it was found that struct thickness is not commonly reported in the literature.

Research has proven that the elastic modulus of bone changes drastically with age and that patient customisation is a necessity in specific cases. As a result, in this study, an IQA for elastic modulus was proposed to be 3-30 GPa based on values from research studies. According to data analysed in this study a porous structure has a significant influence on mechanical properties in Ti-based implants. Therefore, a porous structure can be altered to provide an elastic modulus comparable to that of natural bone and be adjusted to modify the elastic modulus according to the patient's age and health condition. This will further reduce the risk of stress shielding between the implant and surrounding tissue.

As reported by most studies it was found in the regression analysis that the elastic modulus of Ti and its alloys is directly influenced by the implant porosity, and that by increasing the porosity the elastic modulus is increased and vice versa. A total of $55.5 \%$ of the studies in this review recorded an elastic modulus within this range. Regarding the effect of unit cells on the modulus of elasticity of porous structures, it was found that the studies that used beam-based unit cells covered a wider range of modulus of elasticity values than did those than used TPMS-based unit cells (Figure 22a). Moreover, the studies that used beam-based unit cells also obtained modulus of elasticity values within the whole range of human bone Young's modulus, as shown in Figure 22a.

a)

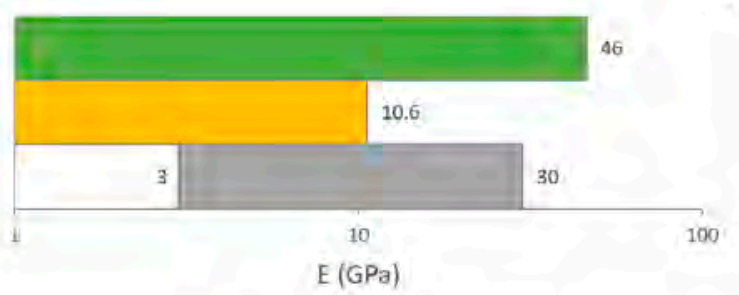

n Beam-based DTPMS m Bone

c)

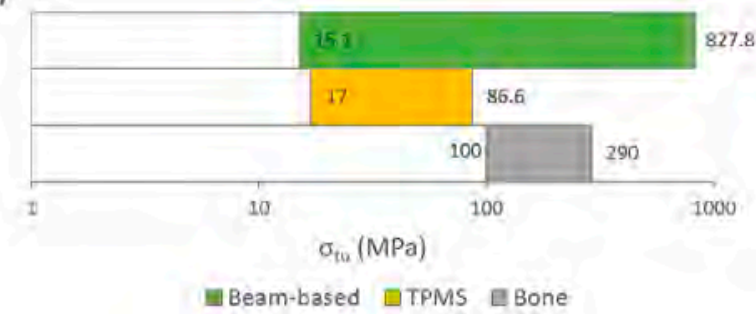

b)

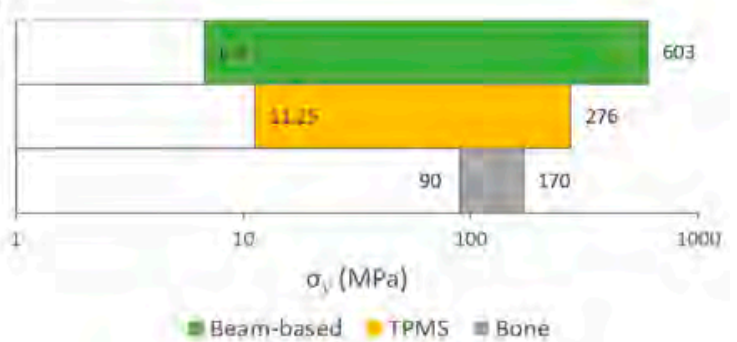

Figure 22. Comparison in logarithmic scale between mechanical properties of bone, beam-based, and triply periodic minimal surfaces (TPMS): (a) modulus of elasticity; (b) compressive yield strength; and (c) ultimate compressive strength.

Compressive yield and ultimate strength were studied. The compressive strength values for cortical bone were found to vary in the literature, which is why a range of values was selected to represent this bone characteristic. The IQA for compressive yield strength was proposed to be a minimum of $90 \mathrm{MPa}$ and the IQA target for ultimate compressive strength a minimum of $180 \mathrm{MPa}$. A total of $44.1 \%$ of the studies achieved a compressive yield strength above $90 \mathrm{MPa}$, whereas only 
$26.7 \%$ achieved an ultimate compressive strength above $180 \mathrm{MPa}$. Both TPMS-based and beam-based scaffolds provided a wide range of compressive yield strengths covering the whole range of human bone compressive yield strength, as presented in Figure 22b. However, according to Figure 22c only beam-based scaffolds provided an adequate range of ultimate compressive yield strength values that include bone properties. The narrow range of ultimate compressive yield strength values of TPMS-based scaffolds can be explained by the lower number of studies that have addressed this mechanical with this type of unit cell. This indicates that a need exists for TPMS-based scaffold research to report the ultimate compressive yield strength.

Just as with the elastic modulus, the strength of implants was found to be directly affected by scaffold porosity. Increased porosity was found to rather dramatically decrease the strength of the implant as demonstrated by the regression model performed with the results of several different studies. Moreover, it was found that large pores are directly related to lowered strength and elastic modulus, and that several studies have struggled to produce highly porous structures with strength higher than or close to natural bone. Therefore, to ensure the adequate strength of implants, pores larger than required $(>600 \mu \mathrm{m})$ and porosity values higher than necessary $(>70 \%)$ are recommended to be avoided as these have been found to likely result in low-strength structures.

\section{Conclusions}

This systematic literature review presented an overview of the reported properties in research studies of fully porous Ti bone implants manufactured with AM received in the last two decades. The study focused on implants made of $\mathrm{Ti}$ and $\mathrm{Ti}$ alloy since they are considered ideal biomaterials for load-bearing applications. This study followed a $\mathrm{QbD}$ approach and includes the first step of the QbD system that defines the QTPP for properties relating to the porous internal architecture of fully porous Ti implants designed for load bearing applications. IQA, part of the QbD system, have been proposed supported by properties of natural human bone, governmental regulations, and scientific research relevant to bone implants. Unit cell geometry, porosity, elastic modulus, compressive yield strength, ultimate compressive yield strength, and compressive fatigue strength were systematically reviewed and benchmarked against the proposed IQA.

This study found that many implant geometrical, mechanical, and dimensional characteristics were directly related to each other. Scaffolds' pore size influences the porosity of the structure, and the porosity alters the elastic modulus as well as the strength of the implant. The unit cell geometry was also found to directly affect the Young's modulus and strength of porous scaffolds, and naturally would also impact the structures' interconnectivity. Moreover, by using ranges rather than set values where possible, such as for elastic modulus, porosity, and pore size, there is a flexibility to the design that allows the implant to be adjusted to its purpose and patient. Such design flexibility is necessary as bone properties vary with patients' age and anatomic site.

Despite the variety of scaffold characteristics reviewed in this study, future systematic literature searches should also focus on other properties, such as fluid dynamics, surface finish (topography), creep, and hardness, as well as surface coatings. Moreover, it should be considered that bone ingrowth may modify implants' mechanical properties; hence, they may be dependent on the level of bone ingrowth. Therefore, it is important to measure the changes in strength and stiffness in metallic bone scaffolds after bone ingrowth has occurred. Since implant location may determine the importance of each implant property, future studies would ideally find IQA for different implant locations within the human body. For example, mechanical features are important to study in load bearing implants, whereas fluid dynamics and vascularisation might be more important features for facial implants that require good aesthetic results and that are placed close to fragile tissue and nerves.

This study was possible due to the abundance of data available in research articles. However, to further develop an effective QbD engineering strategy for the development of specific bone implants it is important to identify the degree of importance of each bone scaffold characteristic according to the implant's future location within the human body. This can be identified by following 
the second step in the QbD system, namely Critical Quality Attributes (CQA), as detailed described in previous work [222]. CQA are product characteristics that must fall within specific limits to comply with the quality standards defined in the QTPP. They can be identified through prior knowledge and experimental data from systematic research based on scientific and risk management rationale that considers regulatory and business requirements [223]. Each step of the QbD system must be further developed to facilitate the strategic, qualitative development of bone implants and increase the rate of successful research studies.

Overall, Ti and Ti alloy porous bone implants are well underway to achieving the ideal properties that will fully allow them to replace natural bone. With the help of the QbD system, consistent and qualitative design of medical implant devices can be achieved.

Author Contributions: Conceptualisation: D.M.-M., Y.D., and R.A.S.; Formal analysis: D.M.-M. and Y.D.; Funding acquisition: R.A.S.; Investigation: D.M.-M. and Y.D.; Methodology: D.M.-M., Y.D., S.S., and R.A.S.; Project administration: D.M.-M. and R.A.S.; Resources: D.M.-M. and Y.D.; Supervision: D.M.-M., S.S., and R.A.S.; Visualisation: D.M.-M. and Y.D.; Writing_original draft: D.M.-M. and Y.D.; Writing—review and editing: D.M.-M., S.S., and R.A.S. All authors have read and agreed to the published version of the manuscript.

Funding: This research received no external funding.

Acknowledgments: This work was supported by Griffith School of Engineering and Built Environment.

Conflicts of Interest: The authors declare no conflict of interest.

\section{References}

1. Cox, S.C.; Thornby, J.A.; Gibbons, G.J.; Williams, M.A.; Mallick, K.K. 3D printing of porous hydroxyapatite scaffolds intended for use in bone tissue engineering applications. Mater. Sci. Eng. C 2015, 47, 237-247. [CrossRef] [PubMed]

2. Reimann, P.; Brucker, M.; Arbab, D.; Lüring, C. Patient satisfaction - A comparison between patient-specific implants and conventional total knee arthroplasty. J. Orthop. 2019, 16, 273-277. [CrossRef]

3. Wafa, H.; Grimer, R.J. Surgical options and outcomes in bone sarcoma. Expert Rev. Anticancer Ther. 2006, 6, 239-248. [CrossRef] [PubMed]

4. US Food and Drug Administration. Understanding Barriers to Medical Device Quality; US Food and Drug Administration: Silver Spring, MD, USA, 2011.

5. Geetha, M.; Singh, A.; Asokamani, R.; Gogia, A. Ti based biomaterials, the ultimate choice for orthopaedic implants-A review. Prog. Mater. Sci. 2009, 54, 397-425. [CrossRef]

6. Maji, P.K.; Banerjee, A.J.; Banerjee, P.S.; Karmakar, S. Additive manufacturing in prosthesis development-a case study. Rapid Prototyp. J. 2014, 20, 480-489. [CrossRef]

7. Katti, K.S. Biomaterials in total joint replacement. Colloids Surf. B Biointerfaces 2004, 39, 133-142. [CrossRef]

8. Calori, G.; Mazza, E.; Colombo, M.; Ripamonti, C. The use of bone-graft substitutes in large bone defects: Any specific needs? Injury 2011, 42, S56-S63. [CrossRef]

9. Griffin, K.S.; Davis, K.M.; McKinley, T.O.; Anglen, J.O.; Chu, T.-M.G.; Boerckel, J.D.; Kacena, M.A. Evolution of bone grafting: Bone grafts and tissue engineering strategies for vascularized bone regeneration. Clin. Rev. Bone Miner. Metab. 2015, 13, 232-244. [CrossRef]

10. Cancedda, R.; Giannoni, P.; Mastrogiacomo, M. A tissue engineering approach to bone repair in large animal models and in clinical practice. Biomaterials 2007, 28, 4240-4250. [CrossRef]

11. Hornicek, F.J.; Gebhardt, M.C.; Tomford, W.W.; Sorger, J.I.; Zavatta, M.; Menzner, J.P.; Mankin, H.J. Factors affecting nonunion of the allograft-host junction. Clin. Orthop. Relat. Res. 2001, 382, 87-98. [CrossRef] [PubMed]

12. Burchardt, H. The biology of bone graft repair. Clin. Orthop. Relat. Res. 1983, 174, 28-34. [CrossRef]

13. Seiler, J., 3rd; Johnson, J. Iliac crest autogenous bone grafting: Donor site complications. J. South. Orthop. Assoc. 1999, 9, 91-97.

14. Sachlos, E.; Czernuszka, J. Making tissue engineering scaffolds work. Review: The application of solid freeform fabrication technology to the production of tissue engineering scaffolds. Eur. Cells Mater. 2003, 5, 39-40. [CrossRef] [PubMed] 
15. Saijo, H.; Igawa, K.; Kanno, Y.; Mori, Y.; Kondo, K.; Shimizu, K.; Suzuki, S.; Chikazu, D.; Iino, M.; Anzai, M. Maxillofacial reconstruction using custom-made artificial bones fabricated by inkjet printing technology. J. Artif. Organs 2009, 12, 200-205. [CrossRef] [PubMed]

16. Lichte, P.; Pape, H.; Pufe, T.; Kobbe, P.; Fischer, H. Scaffolds for bone healing: Concepts, materials and evidence. Injury 2011, 42, 569-573. [CrossRef]

17. Parthasarathy, J. 3D modeling, custom implants and its future perspectives in craniofacial surgery. Ann. Maxillofac. Surg. 2014, 4, 9-18. [CrossRef] [PubMed]

18. Prince, J.D. 3D Printing: An industrial revolution. J. Electron. Resour. Med. Libr. 2014, 11, 39-45. [CrossRef]

19. Ryan, G.E.; Pandit, A.S.; Apatsidis, D.P. Porous titanium scaffolds fabricated using a rapid prototyping and powder metallurgy technique. Biomaterials 2008, 29, 3625-3635. [CrossRef]

20. Barbas, A.; Bonnet, A.-S.; Lipinski, P.; Pesci, R.; Dubois, G. Development and mechanical characterization of porous titanium bone substitutes. J. Mech. Behav. Biomed. Mater. 2012, 9, 34-44. [CrossRef]

21. Wong, K.-C.; Scheinemann, P. Additive manufactured metallic implants for orthopaedic applications. Sci. China Mater. 2018, 61, 440-454. [CrossRef]

22. Martinez-Marquez, D.; Mirnajafizadeh, A.; Carty, C.P.; Stewart, R.A. Facilitating industry translation of custom 3d printed bone prostheses and scaffolds through Quality by Design. Procedia Manuf. 2019, 30, 284-291. [CrossRef]

23. Martinez-Marquez, D.; Jokymaityte, M.; Mirnajafizadeh, A.; Carty, C.P.; Lloyd, D.; Stewart, R.A. Development of 18 quality control gates for additive manufacturing of error free patient-specific implants. Materials 2019, 12, 3110. [CrossRef] [PubMed]

24. Kulkarni, M.; Mazare, A.; Schmuki, P.; Iglič, A. Biomaterial surface modification of titanium and titanium alloys for medical applications. In Nanomedicine; Seifalian, A., de Mel, A., Kalaskar, D.M., Eds.; One Central Press (OCP): Altrincham, UK, 2014; p. 111.

25. Heness, G.; Ben-Nissan, B. Innovative bioceramics. Mater. Forum 2004, 27, 104-114.

26. Singh, M.; Jonnalagadda, S. Advances in bioprinting using additive manufacturing. Eur. J. Pharm. Sci. 2020, 143, 105167. [CrossRef]

27. Donnaloja, F.; Jacchetti, E.; Soncini, M.; Raimondi, M.T.J.P. Natural and Synthetic Polymers for Bone Scaffolds Optimization. Polymers 2020, 12, 905. [CrossRef]

28. Asghari, F.; Samiei, M.; Adibkia, K.; Akbarzadeh, A.; Davaran, S. Biodegradable and biocompatible polymers for tissue engineering application: A review. Artif. Cells Nanomed. Biotechnol. 2017, 45, 185-192. [CrossRef]

29. Rodríguez, G.R.; Patrício, T.; López, J.D. Natural polymers for bone repair. In Bone Repair Biomaterials; Elsevier BV: Amsterdam, The Netherlands, 2019; pp. 199-232.

30. Haugen, H.J.; Lyngstadaas, S.P.; Rossi, F.; Perale, G. Bone grafts: Which is the ideal biomaterial? J. Clin. Periodontol. 2019, 46, 92-102. [CrossRef]

31. Dwivedi, R.; Kumar, S.; Pandey, R.; Mahajan, A.; Nandana, D.; Katti, D.S.; Mehrotra, D. Polycaprolactone as biomaterial for bone scaffolds: Review of literature. JOBCR 2020, 10, 381-388. [CrossRef]

32. Liu, Y.; Lim, J.; Teoh, S.-H. Review: Development of clinically relevant scaffolds for vascularised bone tissue engineering. Biotechnol. Adv. 2013, 31, 688-705. [CrossRef]

33. Bose, S.; Roy, M.; Bandyopadhyay, A. Recent advances in bone tissue engineering scaffolds. Trends Biotechnol. 2012, 30, 546-554. [CrossRef]

34. Huang, B.; Vyas, C.; Roberts, I.; Poutrel, Q.-A.; Chiang, W.-H.; Blaker, J.J.; Huang, Z.; Bártolo, P. Fabrication and characterisation of 3D printed MWCNT composite porous scaffolds for bone regeneration. Mater. Sci. Eng. C 2019, 98, 266-278. [CrossRef] [PubMed]

35. De Moura, N.K.; Martins, E.F.; Oliveira, R.L.M.S.; de Brito Siqueira, I.A.W.; Machado, J.P.B.; Esposito, E.; Amaral, S.S.; de Vasconcellos, L.M.R.; Passador, F.R.; de Sousa Trichês, E. Synergistic effect of adding bioglass and carbon nanotubes on poly (lactic acid) porous membranes for guided bone regeneration. Mater. Sci. Eng. C 2020, 117, 111327. [CrossRef] [PubMed]

36. De Witte, T.M.; Wagner, A.M.; Fratila-Apachitei, L.E.; Zadpoor, A.A.; Peppas, N.A. Immobilization of nanocarriers within a porous chitosan scaffold for the sustained delivery of growth factors in bone tissue engineering applications. J. Biomed. Mater. Res. Part A 2020, 108, 1122-1135. [CrossRef] [PubMed]

37. Swanson, W.B.; Zhang, Z.; Xiu, K.; Gong, T.; Eberle, M.; Wang, Z.; Ma, P.X. Scaffolds with Controlled Release of Pro-Mineralization Exosomes to Promote Craniofacial Bone Healing without Cell Transplantation. Acta Biomater. 2020. [CrossRef] 
38. Ghayor, C.; Weber, F.E. Osteoconductive Microarchitecture of Bone Substitutes for Bone Regeneration Revisited. Front. Physiol. 2018, 9, 960. [CrossRef]

39. Kim, J.-W.; Yang, B.-E.; Hong, S.-J.; Choi, H.-G.; Byeon, S.-J.; Lim, H.-K.; Chung, S.-M.; Lee, J.-H.; Byun, S.-H. Bone Regeneration Capability of 3D Printed Ceramic Scaffolds. Int. J. Mol. Sci. 2020, 21, 4837. [CrossRef]

40. Jeong, J.; Kim, J.H.; Shim, J.H.; Hwang, N.S.; Heo, C.Y. Bioactive calcium phosphate materials and applications in bone regeneration. Biomater. Res. 2019, 23,1-11. [CrossRef]

41. Eliaz, N.; Metoki, N. Calcium Phosphate Bioceramics: A Review of Their History, Structure, Properties, Coating Technologies and Biomedical Applications. Materials 2017, 10, 334. [CrossRef]

42. Dorozhkin, S.V. Calcium orthophosphate deposits: Preparation, properties and biomedical applications. Mater. Sci. Eng. C 2015, 55, 272-326. [CrossRef]

43. Barrère, F.; van Blitterswijk, C.A.; de Groot, K. Bone regeneration: Molecular and cellular interactions with calcium phosphate ceramics. Int. J. Nanomed. 2006, 1, 317-332.

44. Fernandes, H.R.; Gaddam, A.; Rebelo, A.; Brazete, D.; Stan, G.E.; Ferreira, J.M.J.M. Bioactive glasses and glass-ceramics for healthcare applications in bone regeneration and tissue engineering. Materials 2018, 11, 2530. [CrossRef] [PubMed]

45. Seidenstuecker, M.; Kerr, L.; Bernstein, A.; Mayr, H.O.; Suedkamp, N.P.; Gadow, R.; Krieg, P.; Hernandez Latorre, S.; Thomann, R.; Syrowatka, F.J.M. 3D powder printed bioglass and $\beta$-tricalcium phosphate bone scaffolds. Materials 2017, 11, 13. [CrossRef]

46. Ma, Y.; Dai, H.; Huang, X.; Long, Y. 3D printing of bioglass-reinforced $\beta$-TCP porous bioceramic scaffolds. J. Mater. Sci. 2019, 54, 10437-10446. [CrossRef]

47. Mancuso, E.; Bretcanu, O.A.; Marshall, M.; Birch, M.A.; McCaskie, A.W.; Dalgarno, K.W. Novel bioglasses for bone tissue repair and regeneration: Effect of glass design on sintering ability, ion release and biocompatibility. Mater. Des. 2017, 129, 239-248. [CrossRef] [PubMed]

48. Negut, I.; Floroian, L.; Ristoscu, C.; Mihailescu, C.N.; Mirza Rosca, J.C.; Tozar, T.; Badea, M.; Grumezescu, V.; Hapenciuc, C.; Mihailescu, I.N. Functional bioglass-Biopolymer double nanostructure for natural antimicrobial drug extracts delivery. Nanomaterials 2020, 10, 385. [CrossRef] [PubMed]

49. Yang, J. Progress of bioceramic and bioglass bone scaffolds for load-bearing applications. In Orthopedic Biomaterials; Springer: Berlin/Heidelberg, Germany, 2018; pp. 453-486.

50. Rizwan, M.; Hamdi, M.; Basirun, W.J. Bioglass ${ }^{\circledR}$ 45S5-based composites for bone tissue engineering and functional applications. J. Biomed. Mater. Res. Part A 2017, 105, 3197-3223. [CrossRef]

51. Liu, X.; Chu, P.K.; Ding, C. Surface modification of titanium, titanium alloys, and related materials for biomedical applications. Mater. Sci. Eng. R Rep. 2004, 47, 49-121. [CrossRef]

52. Rack, H.; Qazi, J. Titanium alloys for biomedical applications. Mater. Sci. Eng. C 2006, 26, 1269-1277. [CrossRef]

53. Niinomi, M.; Nakai, M.; Hieda, J. Development of new metallic alloys for biomedical applications. Acta Biomater. 2012, 8, 3888-3903. [CrossRef]

54. Vandrovcová, M.; Bacakova, L. Adhesion, growth and differentiation of osteoblasts on surface-modified materials developed for bone implants. Physiol. Res. 2011, 60, 403-417. [CrossRef]

55. Huiskes, R.; Weinans, H.; Van Rietbergen, B. The Relationship Between Stress Shielding and Bone Resorption Around Total Hip Stems and the Effects of Flexible Materials. Clin. Orthop. Relat. Res. 1992, 274, 124-134. [CrossRef]

56. Ryan, G.; Pandit, A.; Apatsidis, D.P. Fabrication methods of porous metals for use in orthopaedic applications. Biomaterials 2006, 27, 2651-2670. [CrossRef]

57. Chen, Q.; Thouas, G.A. Metallic implant biomaterials. Mater. Sci. Eng. R Rep. 2015, 87, 1-57. [CrossRef]

58. Strnad, J.; Strnad, Z.; Šesták, J.; Urban, K.; Povýšil, C. Bio-activated titanium surface utilizable for mimetic bone implantation in dentistry-Part III: Surface characteristics and bone-implant contact formation. J. Phys. Chem. Solids 2007, 68, 841-845. [CrossRef]

59. Zhao, X.; Wang, T.; Qian, S.; Liu, X.; Sun, J.; Li, B. Silicon-doped titanium dioxide nanotubes promoted bone formation on titanium implants. Int. J. Mol. Sci. 2016, 17, 292. [CrossRef] [PubMed]

60. Wiria, F.E.; Maleksaeedi, S.; He, Z. Manufacturing and characterization of porous titanium components. Prog. Cryst. Growth Charact. Mater. 2014, 60, 94-98. [CrossRef]

61. Zhang, L.C.; Klemm, D.; Eckert, J.; Hao, Y.L.; Sercombe, T.B. Manufacture by selective laser melting and mechanical behavior of a biomedical Ti-24Nb-4Zr-8Sn alloy. Scr. Mater. 2011, 65, 21-24. [CrossRef] 
62. Zaharin, H.A.; Rani, A.; Majdi, A.; Azam, F.I.; Ginta, T.L.; Sallih, N.; Ahmad, A.; Yunus, N.A.; Zulkifli, T.Z.A. Effect of unit cell type and pore size on porosity and mechanical behavior of additively manufactured Ti6Al4V scaffolds. Materials 2018, 11, 2402. [CrossRef]

63. Bobyn, J.; Pilliar, R.; Cameron, H.; Weatherly, G.J.C.O.; Research $囚$, R. The optimum pore size for the fixation of porous-surfaced metal implants by the ingrowth of bone. Clin. Orthop. Relat. Res. 1980, 150, 263-270. [CrossRef]

64. John, A.A.; Jaganathan, S.K.; Supriyanto, E.; Manikandan, A. Surface modification of titanium and its alloys for the enhancement of osseointegration in orthopaedics. Curr. Sci. 2016, 111, 1003-1015. [CrossRef]

65. Zhang, L.-C.; Chen, L.-Y.; Wang, L. Surface Modification of Titanium and Titanium Alloys: Technologies, Developments, and Future Interests. Adv. Eng. Mater. 2020, 22, 1901258. [CrossRef]

66. Sasikumar, Y.; Indira, K.; Rajendran, N. Surface Modification Methods for Titanium and its alloys and their corrosion behavior in biological environment: A review. J. Bio. Tribo-Corros. 2019, 5, 36. [CrossRef]

67. Civantos, A.; Martinez-Campos, E.; Ramos, V.; Elvira, C.; Gallardo, A.; Abarrategi, A. Titanium coatings and surface modifications: Toward clinically useful bioactive implants. ACS Biomater. Sci. Eng. 2017, 3, 1245-1261. [CrossRef]

68. Zhang, K.; Fan, Y.; Dunne, N.; Li, X. Effect of microporosity on scaffolds for bone tissue engineering. Regen. Biomater. 2018, 5, 115-124. [CrossRef] [PubMed]

69. Staruch, R.; Griffin, M.F.; Butler, P. Nanoscale Surface Modifications of Orthopaedic Implants: State of the Art and Perspectives. Open Orthop. J. 2016, 10, 920-938. [CrossRef] [PubMed]

70. Zemtsova, E.; Arbenin, A.; Valiev, R.; Smirnov, V. Modern techniques of surface geometry modification for the implants based on titanium and its alloys used for improvement of the biomedical characteristics. In Titanium in Medical and Dental Applications; Elsevier: Amsterdam, The Netherlands, 2018; pp. 115-145.

71. Gulati, K.; Prideaux, M.; Kogawa, M.; Lima-Marques, L.; Atkins, G.J.; Findlay, D.M.; Losic, D. Anodized 3D-printed titanium implants with dual micro- and nano-scale topography promote interaction with human osteoblasts and osteocyte-like cells. J. Tissue Eng. Regen. Med. 2016, 11, 3313-3325. [CrossRef] [PubMed]

72. Zafar, M.S.; Fareed, M.A.; Riaz, S.; Latif, M.; Habib, S.R.; Khurshid, Z. Customized Therapeutic Surface Coatings for Dental Implants. Coatings 2020, 10, 568. [CrossRef]

73. Kunrath, M.F.; Leal, B.F.; Hubler, R.; de Oliveira, S.D.; Teixeira, E.R. Antibacterial potential associated with drug-delivery built $\mathrm{TiO} 2$ nanotubes in biomedical implants. AMB Express 2019, 9, 1-13. [CrossRef] [PubMed]

74. Martinez-Marquez, D.; Mirnajafizadeh, A.; Carty, C.P.; Stewart, R.A. Application of quality by design for 3D printed bone prostheses and scaffolds. PLoS ONE 2018, 13, e0195291. [CrossRef]

75. Kasanen, E.; Lukka, K.; Siitonen, A. The constructive approach in management accounting research. J. Manag. Account. Res. 2003, 5, 243-264.

76. Oyegoke, A. The constructive research approach in project management research. Int. J. Manag. Proj. Bus. 2011, 4, 573-595. [CrossRef]

77. Wen, C.E.; Yamada, Y.; Shimojima, K.; Chino, Y.; Hosokawa, H.; Mabuchi, M. Novel titanium foam for bone tissue engineering. J. Mater. Res. 2002, 17, 2633-2639. [CrossRef]

78. Liberati, A.; Altman, D.G.; Tetzlaff, J.; Mulrow, C.; Gøtzsche, P.C.; Ioannidis, J.P.; Clarke, M.; Devereaux, P.J.; Kleijnen, J.; Moher, D. The PRISMA statement for reporting systematic reviews and meta-analyses of studies that evaluate health care interventions: Explanation and elaboration. J. Clin. Epidemiol. 2009, 62, e1-e34. [CrossRef] [PubMed]

79. Bobbert, F.S.L.; Lietaert, K.; Eftekhari, A.A.; Pouran, B.; Ahmadi, S.M.; Weinans, H.; Zadpoor, A.A. Additively manufactured metallic porous biomaterials based on minimal surfaces: A unique combination of topological, mechanical, and mass transport properties. Acta Biomater. 2017, 53, 572-584. [CrossRef] [PubMed]

80. Wu, S.; Liu, X.; Yeung, K.W.K.; Liu, C.; Yang, X. Biomimetic porous scaffolds for bone tissue engineering. Mater. Sci. Eng. R Rep. 2014, 80, 1-36. [CrossRef]

81. Wang, X.; Xu, S.; Zhou, S.; Xu, W.; Leary, M.; Choong, P.; Qian, M.; Brandt, M.; Xie, Y.M. Topological design and additive manufacturing of porous metals for bone scaffolds and orthopaedic implants: A review. Biomaterials 2016, 83, 127-141. [CrossRef] [PubMed]

82. Heinl, P.; Muller, L.; Korner, C.; Singer, R.F.; Muller, F.A. Cellular Ti-6Al-4V structures with interconnected macro porosity for bone implants fabricated by selective electron beam melting. Acta Biomater. 2008, 4, 1536-1544. [CrossRef] [PubMed] 
83. Brett, E.; Flacco, J.; Blackshear, C.; Longaker, M.T.; Wan, D.C. Biomimetics of Bone Implants: The Regenerative Road. BioRes. Open Access 2017, 6, 1-6. [CrossRef]

84. Wang, X.; Li, Y.; Xiong, J.; Hodgson, P.D.; Wen, C. Porous TiNbZr alloy scaffolds for biomedical applications. Acta Biomater. 2009, 5, 3616-3624. [CrossRef]

85. Bose, S.; Darsell, J.; Hosick, H.L.; Yang, L.; Sarkar, D.; Bandyopadhyay, A. Processing and Characterization of Porous Alumina Scaffolds. J. Mater. Sci. Mater. Med. 2002, 13, 23-28. [CrossRef]

86. Karageorgiou, V.; Kaplan, D. Porosity of 3D biomaterial scaffolds and osteogenesis. Biomaterials 2005, 26, 5474-5491. [CrossRef] [PubMed]

87. Burg, K.J.L.; Porter, S.; Kellam, J.F. Biomaterial developments for bone tissue engineering. Biomaterials 2000, 21, 2347-2359. [CrossRef]

88. Wang, X.; Ni, Q. Determination of cortical bone porosity and pore size distribution using a low field pulsed NMR approach. J. Orthop. Res. 2003, 21, 312-319. [CrossRef]

89. Lee, H.; Jang, T.-S.; Song, J.; Kim, H.-E.; Jung, H.-D. Multi-scale porous Ti6Al4V scaffolds with enhanced strength and biocompatibility formed via dynamic freeze-casting coupled with micro-arc oxidation. Mater. Lett. 2016, 185, 21-24. [CrossRef]

90. Parthasarathy, J.; Starly, B.; Raman, S.; Christensen, A. Mechanical evaluation of porous titanium (Ti6Al4V) structures with electron beam melting (EBM). J. Mech. Behav. Biomed. Mater. 2010, 3, 249-259. [CrossRef]

91. Suska, F.; Kjeller, G.; Tarnow, P.; Hryha, E.; Nyborg, L.; Snis, A.; Palmquist, A. Electron Beam Melting Manufacturing Technology for Individually Manufactured Jaw Prosthesis: A Case Report. J. Oral Maxillofac. Surg. 2016, 74, 1706.e1-1706.e15. [CrossRef]

92. Andreasen, C.M.; Delaisse, J.-M.; van der Eerden, B.C.; van Leeuwen, J.P.; Ding, M.; Andersen, T.L. Understanding age-induced cortical porosity in women: Is a negative BMU balance in quiescent osteons a major contributor? Bone 2018, 117, 70-82. [CrossRef]

93. Morgan, E.F.; Unnikrisnan, G.U.; Hussein, A.I. Bone Mechanical Properties in Healthy and Diseased States. Annu. Rev. Biomed. Eng. 2018, 20, 119-143. [CrossRef]

94. Lopez-Heredia, M.A.; Sohier, J.; Gaillard, C.; Quillard, S.; Dorget, M.; Layrolle, P. Rapid prototyped porous titanium coated with calcium phosphate as a scaffold for bone tissue engineering. Biomaterials 2008, 29, 2608-2615. [CrossRef]

95. Hollander, D.A.; von Walter, M.; Wirtz, T.; Sellei, R.; Schmidt-Rohlfing, B.; Paar, O.; Erli, H.J. Structural, mechanical and in vitro characterization of individually structured Ti-6Al-4V produced by direct laser forming. Biomaterials 2006, 27, 955-963. [CrossRef]

96. Hara, D.; Nakashima, Y.; Sato, T.; Hirata, M.; Kanazawa, M.; Kohno, Y.; Yoshimoto, K.; Yoshihara, Y.; Nakamura, A.; Nakao, Y.; et al. Bone bonding strength of diamond-structured porous titanium-alloy implants manufactured using the electron beam-melting technique. Mater. Sci. Eng. C Mater. Biol. Appl. 2016, 59, 1047-1052. [CrossRef] [PubMed]

97. Wieding, J.; Jonitz, A.; Bader, R. The Effect of Structural Design on Mechanical Properties and Cellular Response of Additive Manufactured Titanium Scaffolds. Materials 2012, 5, 1336-1347. [CrossRef]

98. Xue, W.; Krishna, B.V.; Bandyopadhyay, A.; Bose, S. Processing and biocompatibility evaluation of laser processed porous titanium. Acta Biomater. 2007, 3, 1007-1018. [CrossRef]

99. De Peppo, G.M.; Palmquist, A.; Borchardt, P.; Lennerås, M.; Hyllner, J.; Snis, A.; Lausmaa, J.; Thomsen, P.; Karlsson, C. Free-form-fabricated commercially pure Ti and Ti6Al4V porous scaffolds support the growth of human embryonic stem cell-derived mesodermal progenitors. Sci. World J. 2012, 2012, 1-14. [CrossRef] [PubMed]

100. Zhang, X.-Y.; Fang, G.; Leeflang, S.; Zadpoor, A.A.; Zhou, J. Topological design, permeability and mechanical behavior of additively manufactured functionally graded porous metallic biomaterials. Acta Biomater. 2019, 84, 437-452. [CrossRef] [PubMed]

101. Taniguchi, N.; Fujibayashi, S.; Takemoto, M.; Sasaki, K.; Otsuki, B.; Nakamura, T.; Matsushita, T.; Kokubo, T.; Matsuda, S. Effect of pore size on bone ingrowth into porous titanium implants fabricated by additive manufacturing: An in vivo experiment. Mater. Sci. Eng. C Mater. Biol. Appl. 2016, 59, 690-701. [CrossRef]

102. Zou, C.; Zhang, E.; Li, M.; Zeng, S. Preparation, microstructure and mechanical properties of porous titanium sintered by Ti fibres. J. Mater. Sci. Mater. Med. 2007, 19, 401-405. [CrossRef]

103. Takemoto, M.; Fujibayashi, S.; Neo, M.; Suzuki, J.; Kokubo, T.; Nakamura, T. Mechanical properties and osteoconductivity of porous bioactive titanium. Biomaterials 2005, 26, 6014-6023. [CrossRef] 
104. Van Hooreweder, B.; Apers, Y.; Lietaert, K.; Kruth, J.-P. Improving the fatigue performance of porous metallic biomaterials produced by Selective Laser Melting. Acta Biomater. 2017, 47, 193-202. [CrossRef]

105. Ahmadi, S.M.; Yavari, S.A.; Wauthle, R.; Pouran, B.; Schrooten, J.; Weinans, H.; Zadpoor, A.A. Additively Manufactured Open-Cell Porous Biomaterials Made from Six Different Space-Filling Unit Cells: The Mechanical and Morphological Properties. Materials 2015, 8, 1871-1896. [CrossRef]

106. Amin Yavari, S.; Ahmadi, S.M.; Wauthle, R.; Pouran, B.; Schrooten, J.; Weinans, H.; Zadpoor, A.A. Relationship between unit cell type and porosity and the fatigue behavior of selective laser melted meta-biomaterials. J. Mech. Behav. Biomed. Mater. 2015, 43, 91-100. [CrossRef] [PubMed]

107. Hrabe, N.W.; Heinl, P.; Flinn, B.; Körner, C.; Bordia, R.K. Compression-compression fatigue of selective electron beam melted cellular titanium (Ti-6Al-4V). J. Biomed. Mater. 2011, 99B, 313-320. [CrossRef]

108. Ponader, S.; von Wilmowsky, C.; Widenmayer, M.; Lutz, R.; Heinl, P.; Korner, C.; Singer, R.F.; Nkenke, E.; Neukam, F.W.; Schlegel, K.A. In vivo performance of selective electron beam-melted Ti-6Al-4V structures. J. Biomed. Mater. Res. Part A 2010, 92, 56-62. [CrossRef] [PubMed]

109. Yan, C.; Hao, L.; Hussein, A.; Young, P. Ti-6Al-4V triply periodic minimal surface structures for bone implants fabricated via selective laser melting. J. Mech. Behav. Biomed. Mater. 2015, 51, 61-73. [CrossRef] [PubMed]

110. Wysocki, B.; Idaszek, J.; Szlazak, K.; Strzelczyk, K.; Brynk, T.; Kurzydlowski, K.J.; Swieszkowski, W. Post Processing and Biological Evaluation of the Titanium Scaffolds for Bone Tissue Engineering. Materials 2016, 9, 197. [CrossRef]

111. Attar, H.; Löber, L.; Funk, A.; Calin, M.; Zhang, L.; Prashanth, K.G.; Scudino, S.; Zhang, Y.S.; Eckert, J. Mechanical behavior of porous commercially pure $\mathrm{Ti}$ and $\mathrm{Ti}-\mathrm{TiB}$ composite materials Manufactured by selective laser melting. Mater. Sci. Eng. A 2015, 625, 350-356. [CrossRef]

112. Wauthle, R.; van der Stok, J.; Amin Yavari, S.; Van Humbeeck, J.; Kruth, J.P.; Zadpoor, A.A.; Weinans, H.; Mulier, M.; Schrooten, J. Additively manufactured porous tantalum implants. Acta Biomater. 2015, 14, $217-225$. [CrossRef]

113. Zhang, B.; Pei, X.; Zhou, C.; Fan, Y.; Jiang, Q.; Ronca, A.; D'Amora, U.; Chen, Y.; Li, H.; Sun, Y. The biomimetic design and $3 \mathrm{D}$ printing of customized mechanical properties porous Ti6Al4V scaffold for load-bearing bone reconstruction. Mater. Des. 2018, 152, 30-39. [CrossRef]

114. Kim, T.B.; Yue, S.; Zhang, Z.; Jones, E.; Jones, J.R.; Lee, P.D. Additive manufactured porous titanium structures: Through-process quantification of pore and strut networks. J. Mater. Process. Technol. 2014, 214, 2706-2715. [CrossRef]

115. Ataee, A.; Li, Y.C.; Brandt, M.; Wen, C. Ultrahigh-strength titanium gyroid scaffolds manufactured by selective laser melting (SLM) for bone implant applications. Acta Mater. 2018, 158, 354-368. [CrossRef]

116. Zhao, D.; Huang, Y.; Ao, Y.; Han, C.; Wang, Q.; Li, Y.; Liu, J.; Wei, Q.; Zhang, Z. Effect of pore geometry on the fatigue properties and cell affinity of porous titanium scaffolds fabricated by selective laser melting. J. Mech. Behav. Biomed. Mater. 2018, 88, 478-487. [CrossRef] [PubMed]

117. Ahmadi, S.; Kumar, R.; Borisov, E.; Petrov, R.; Leeflang, S.; Li, Y.; Tümer, N.; Huizenga, R.; Ayas, C.; Zadpoor, A. From microstructural design to surface engineering: A tailored approach for improving fatigue life of additively manufactured meta-biomaterials. Acta Biomater. 2019, 83, 153-166. [CrossRef] [PubMed]

118. Xia, Y.; Feng, C.; Xiong, Y.; Luo, Y.; Li, X. Mechanical properties of porous titanium alloy scaffold fabricated using additive manufacturing technology. Int. J. Appl. Electromagn. Mech. 2019, 59, 1087-1095. [CrossRef]

119. Li, G.; Wang, L.; Pan, W.; Yang, F.; Jiang, W.; Wu, X.; Kong, X.; Dai, K.; Hao, Y. In vitro and in vivo study of additive manufactured porous Ti6Al4V scaffolds for repairing bone defects. Sci. Rep. 2016, 6, 34072. [CrossRef]

120. Yánez, A.; Cuadrado, A.; Martel, O.; Afonso, H.; Monopoli, D. Gyroid porous titanium structures: A versatile solution to be used as scaffolds in bone defect reconstruction. Mater. Des. 2018, 140, 21-29. [CrossRef]

121. Surmeneva, M.; Surmenev, R.; Chudinova, E.; Koptyug, A.; Tkachev, M.S.; Shkarina, S.; Rännar, L.-E. Fabrication of multiple-layered gradient cellular metal scaffold via electron beam melting for segmental bone reconstruction. Mater. Des. 2017, 133. [CrossRef]

122. Zhang, S.; Wei, Q.; Cheng, L.; Li, S.; Shi, Y. Effects of scan line spacing on pore characteristics and mechanical properties of porous Ti6Al4V implants fabricated by selective laser melting. Mater. Des. 2014, 63, 185-193. [CrossRef] 
123. Van der Stok, J.; Van der Jagt, O.P.; Amin Yavari, S.; De Haas, M.F.; Waarsing, J.H.; Jahr, H.; Van Lieshout, E.M.; Patka, P.; Verhaar, J.A.; Zadpoor, A.A.; et al. Selective laser melting-produced porous titanium scaffolds regenerate bone in critical size cortical bone defects. J. Orthop. Res. 2013, 31, 792-799. [CrossRef]

124. Lin, C.Y.; Wirtz, T.; LaMarca, F.; Hollister, S.J. Structural and mechanical evaluations of a topology optimized titanium interbody fusion cage fabricated by selective laser melting process. J. Biomed. Mater. Res. Part A 2007, 83, 272-279. [CrossRef]

125. Yavari, S.A.; Wauthle, R.; van der Stok, J.; Riemslag, A.C.; Janssen, M.; Mulier, M.; Kruth, J.P.; Schrooten, J.; Weinans, H.; Zadpoor, A.A. Fatigue behavior of porous biomaterials manufactured using selective laser melting. Mater. Sci. Eng. C Mater. Biol. Appl. 2013, 33, 4849-4858. [CrossRef]

126. Liu, Y.; Li, S.; Hou, W.; Wang, S.; Hao, Y.L.; Yang, R.; Sercombe, T.; Zhang, L. Electron Beam Melted Beta-Type Ti-24Nb-4Zr-8Sn Porous Structures with High Strength-to-Modulus Ratio. J. Mater. Sci. Technol. 2016, 32, 505-508. [CrossRef]

127. Li, S.J.; Xu, Q.S.; Wang, Z.; Hou, W.T.; Hao, Y.L.; Yang, R.; Murr, L.E. Influence of cell shape on mechanical properties of Ti-6Al-4V meshes fabricated by electron beam melting method. Acta Biomater. 2014, 10, 4537-4547. [CrossRef] [PubMed]

128. Sallica-Leva, E.; Jardini, A.L.; Fogagnolo, J.B. Microstructure and mechanical behavior of porous Ti-6Al-4V parts obtained by selective laser melting. J. Mech. Behav. Biomed. Mater. 2013, 26, 98-108. [CrossRef]

129. Van Bael, S.; Kerckhofs, G.; Moesen, M.; Pyka, G.; Schrooten, J.; Kruth, J.P. Micro-CT-based improvement of geometrical and mechanical controllability of selective laser melted Ti6Al4V porous structures. Mater. Sci. Eng. A 2011, 528, 7423-7431. [CrossRef]

130. Cheng, A.; Humayun, A.; Cohen, D.J.; Boyan, B.D.; Schwartz, Z. Additively manufactured 3D porous Ti-6Al-4V constructs mimic trabecular bone structure and regulate osteoblast proliferation, differentiation and local factor production in a porosity and surface roughness dependent manner. Biofabrication 2014, 6, 045007. [CrossRef] [PubMed]

131. Roy, S.; Khutia, N.; Das, D.; Das, M.; Balla, V.K.; Bandyopadhyay, A.; Chowdhury, A.R. Understanding compressive deformation behavior of porous Ti using finite element analysis. Mater. Sci. Eng. C Mater. Biol. Appl. 2016, 64, 436-443. [CrossRef]

132. Mullen, L.; Stamp, R.C.; Brooks, W.K.; Jones, E.; Sutcliffe, C.J. Selective Laser Melting: A regular unit cell approach for the manufacture of porous, titanium, bone in-growth constructs, suitable for orthopedic applications. J. Biomed. Mater. Res. Part B Appl. Biomater. 2009, 89, 325-334. [CrossRef]

133. Van Grunsven, W.; Hernandez-Nava, E.; Reilly, G.C.; Goodall, R. Fabrication and Mechanical Characterisation of Titanium Lattices with Graded Porosity. Metals 2014, 4, 401-409. [CrossRef]

134. Andani, M.T.; Saedi, S.; Turabi, A.S.; Karamooz-Ravari, M.R.; Haberland, C.; Karaca, H.E.; Elahinia, M. Mechanical and shape memory properties of porous Ni $50.1 \mathrm{Ti} 49.9$ alloys manufactured by selective laser melting. J. Mech. Behav. Biomed. Mater. 2017, 68, 224-231. [CrossRef]

135. Lietaert, K.; Cutolo, A.; Boey, D.; Van Hooreweder, B. Fatigue life of additively manufactured Ti6Al4V scaffolds under tension-tension, tension-compression and compression-compression fatigue load. Sci. Rep. 2018, 8, 1-9. [CrossRef]

136. Barui, S.; Chatterjee, S.; Mandal, S.; Kumar, A.; Basu, B. Microstructure and compression properties of 3D powder printed Ti-6Al-4V scaffolds with designed porosity: Experimental and computational analysis. Mater. Sci. Eng. C Mater. Biol. Appl. 2017, 70, 812-823. [CrossRef]

137. Yang, L.; Yan, C.; Cao, W.; Liu, Z.; Song, B.; Wen, S.; Zhang, C.; Shi, Y.; Yang, S. Compression-compression fatigue behaviour of triply periodic minimal surface porous structures fabricated by selective laser melting. Acta Mater. 2019, 181, 49-66. [CrossRef]

138. Melancon, D.; Bagheri, Z.S.; Johnston, R.B.; Liu, L.; Tanzer, M.; Pasini, D. Mechanical characterization of structurally porous biomaterials built via additive manufacturing: Experiments, predictive models, and design maps for load-bearing bone replacement implants. Acta Biomater. 2017, 63, 350-368. [CrossRef]

139. Eldesouky, I.; Harrysson, O.; West, H.; Elhofy, H. Electron beam melted scaffolds for orthopedic applications. Addit. Manuf. 2017, 17. [CrossRef]

140. Vasireddi, R.; Basu, B. Conceptual design of three-dimensional scaffolds of powder-based materials for Bone Tissue Engineering Applications. Rapid Prototyp. J. 2015, 21. [CrossRef] 
141. Rahyussalim, A.J.; Marsetio, A.F.; Saleh, I.; Kurniawati, T.; Whulanza, Y. The Needs of Current Implant Technology in Orthopaedic Prosthesis Biomaterials Application to Reduce Prosthesis Failure Rate. J. Nanomater. 2016, 2016, 1-9. [CrossRef]

142. Matassi, F.; Botti, A.; Sirleo, L.; Carulli, C.; Innocenti, M. Porous metal for orthopedics implants. Clin. Cases Miner. Bone Metab. 2013, 10, 111-115.

143. Frohlich, M.; Grayson, W.L.; Wan, L.Q.; Marolt, D.; Drobnic, M.; Vunjak-Novakovic, G. Tissue engineered bone grafts: Biological requirements, tissue culture and clinical relevance. Curr. Stem Cell Res. Ther. 2008, 3, 254-264. [CrossRef] [PubMed]

144. Nouri, A.; Hodgson, P.D.; Wen, C.E. Biomimetic Porous Titanium Scaffolds for Orthopaedic and Dental Applications; InTech: London, UK, 2010.

145. Rho, J.-Y.; Kuhn-Spearing, L.; Zioupos, P. Mechanical properties and the hierarchical structure of bone. Med. Eng. Phys. 1998, 20, 92-102. [CrossRef]

146. Currey, J.D. Bones: Structure and Mechanics; Princeton University Press: Princeton, NJ, USA, 2013.

147. Lee, S.; Porter, M.; Wasko, S.; Lau, G.; Chen, P.-Y.; Novitskaya, E.E.; Tomsia, A.P.; Almutairi, A.; Meyers, M.A.; McKittrick, J. Potential Bone Replacement Materials Prepared by Two Methods. MRS Proc. 2012, 1418. [CrossRef]

148. Rodan, G.A.; Raisz, L.G.; Bilezikian, J.P. Principles of Bone Biology; Academic Press: San Diego, CA, USA, 2002; Volume 2.

149. Buenzli, P.; Pivonka, P.; Gardiner, B.; Smith, D.; Dunstan, C.; Mundy, G. Theoretical analysis of the spatio-temporal structure of bone multicellular units. In Proceedings of IOP Conference Series: Materials Science and Engineering; IOP Publishing: Bristol, UK, 2010; Volume 10, p. 012132.

150. Wagermaier, W.; Gupta, H.S.; Gourrier, A.; Burghammer, M.; Roschger, P.; Fratzl, P. Spiral twisting of fiber orientation inside bone lamellae. Biointerphases 2006, 1, 1-5. [CrossRef]

151. Ekwaro-Osire, S.; Wanki, G.; Dias, J.P.; Science, P. Healthcare-Probabilistic Techniques for Bone as a Natural Composite. J. Integr. Des. Process. Sci. 2017, 21,7-22. [CrossRef]

152. Fratzl, P. Collagen: Structure and mechanics, an introduction. In Collagen; Springer: Boston, MA, USA, 2008; pp. 1-13.

153. Arnett, T. Osteoclast Resorption \#3. Available online: https://boneresearchsociety.org/resources/gallery/39/ \#top (accessed on 29 April 2020).

154. Wang, G.; Lu, Z.; Zhao, X.; Kondyurin, A.; Zreiqat, H. Ordered HAp nanoarchitecture formed on HAp-TCP bioceramics by "nanocarving" and mineralization deposition and its potential use for guiding cell behaviors. J. Mater. Chem. B 2013, 1, 2455-2462. [CrossRef]

155. Seeman, E.; Delmas, P.D. Bone quality-the material and structural basis of bone strength and fragility. N. Engl. J. Med. 2006, 354, 2250-2261. [CrossRef]

156. Boyde, A.; Haroon, Y.; Jones, S.; Riggs, C. Three dimensional structure of the distal condyles of the third metacarpal bone of the horse. Equine Vet. J. 1999, 31, 122-129. [CrossRef] [PubMed]

157. Ascenzi, M.-G.; Hetzer, N.; Lomovtsev, A.; Rude, R.; Nattiv, A.; Favia, A. Variation of trabecular architecture in proximal femur of postmenopausal women. J. Biomech. 2011, 44, 248-256. [CrossRef] [PubMed]

158. Boyde, A. Normal Bone. Available online: https://boneresearchsociety.org/resources/gallery/22/\#top (accessed on 29 April 2020).

159. Schwarcz, H.P.; Abueidda, D.; Jasiuk, I. The Ultrastructure of Bone and Its Relevance to Mechanical Properties. Front. Phys. 2017, 5. [CrossRef]

160. Wolfram, U.; Schwiedrzik, J. Post-yield and failure properties of cortical bone. Bonekey Rep. 2016, 5, 829. [CrossRef] [PubMed]

161. Morgan, E.F.; Keaveny, T.M. Dependence of yield strain of human trabecular bone on anatomic site. J. Biomech. 2001, 34, 569-577. [CrossRef]

162. Bayraktar, H.H.; Morgan, E.F.; Niebur, G.L.; Morris, G.E.; Wong, E.K.; Keaveny, T.M. Comparison of the elastic and yield properties of human femoral trabecular and cortical bone tissue. J. Biomech. 2004, 37, 27-35. [CrossRef]

163. Yeni, Y.N.; Fyhrie, D.P. A rate-dependent microcrack-bridging model that can explain the strain rate dependency of cortical bone apparent yield strength. J. Biomech. 2003, 36, 1343-1353. [CrossRef]

164. Ebacher, V.; Wang, R. A Unique Microcracking Process Associated with the Inelastic Deformation of Haversian Bone. Adv. Funct. Mater. 2009, 19, 57-66. [CrossRef] 
165. Dong, X.N.; Acuna, R.L.; Luo, Q.; Wang, X. Orientation dependence of progressive post-yield behavior of human cortical bone in compression. J. Biomech. 2012, 45, 2829-2834. [CrossRef] [PubMed]

166. Leng, H.; Dong, X.N.; Wang, X. Progressive post-yield behavior of human cortical bone in compression for middle-aged and elderly groups. J. Biomech. 2009, 42, 491-497. [CrossRef] [PubMed]

167. Mirzaalimazandarani, M.; Schwiedrzik, J.J.; Thaiwichai, S.; Best, J.P.; Michler, J.; Zysset, P.K.; Wolfram, U. Mechanical properties of cortical bone and their relationships with age, gender, composition and microindentation properties in the elderly. Bone 2016, 93, 196-211. [CrossRef]

168. Henkel, J.; Woodruff, M.A.; Epari, D.R.; Steck, R.; Glatt, V.; Dickinson, I.C.; Choong, P.F.; Schuetz, M.A.; Hutmacher, D.W. Bone Regeneration Based on Tissue Engineering Conceptions - A 21st Century Perspective. Bone Res. 2013, 1, 216-248. [CrossRef] [PubMed]

169. Caparros, C.; Guillem-Marti, J.; Molmeneu, M.; Punset, M.; Calero, J.A.; Gil, F.J. Mechanical properties and in vitro biological response to porous titanium alloys prepared for use in intervertebral implants. J. Mech. Behav. Biomed. Mater. 2014, 39, 79-86. [CrossRef]

170. Dendorfer, S.; Maier, H.J.; Taylor, D.; Hammer, J. Anisotropy of the fatigue behaviour of cancellous bone. J. Biomech. 2008, 41, 636-641. [CrossRef]

171. Zioupos, P.; Gresle, M.; Winwood, K. Fatigue strength of human cortical bone: Age, physical, and material heterogeneity effects. J. Biomed. Mater. Res. Part A 2008, 86A, 627-636. [CrossRef]

172. Zadpoor, A.A. Meta-biomaterials. Biomater. Sci. 2020, 8, 18-38. [CrossRef]

173. Cheah, C.; Chua, C.; Leong, K.; Chua, S. Development of a tissue engineering scaffold structure library for rapid prototyping. Part 1: Investigation and classification. Int. J. Adv. Manuf. Technol. 2003, 21, 291-301. [CrossRef]

174. Sun, W.; Starly, B.; Nam, J.; Darling, A. Bio-CAD modeling and its applications in computer-aided tissue engineering. Comput. Des. 2005, 37, 1097-1114. [CrossRef]

175. An, J.; Teoh, J.E.M.; Suntornnond, R.; Chua, C.K. Design and 3D printing of scaffolds and tissues. Engineering 2015, 1, 261-268. [CrossRef]

176. Chantarapanich, N.; Puttawibul, P.; Sucharitpwatskul, S.; Jeamwatthanachai, P.; Inglam, S.; Sitthiseripratip, K. Scaffold library for tissue engineering: A geometric evaluation. Comput. Math. Methods Med. 2012, 2012, 1-14. [CrossRef] [PubMed]

177. Wettergreen, M.; Bucklen, B.; Starly, B.; Yuksel, E.; Sun, W.; Liebschner, M. Creation of a unit block library of architectures for use in assembled scaffold engineering. Comput. Des. 2005, 37, 1141-1149. [CrossRef]

178. Yoo, D. New paradigms in hierarchical porous scaffold design for tissue engineering. Mater. Sci. Eng. C 2013, 33, 1759-1772. [CrossRef] [PubMed]

179. Feng, J.; Fu, J.; Lin, Z.; Shang, C.; Li, B. A review of the design methods of complex topology structures for 3D printing. Vis. Comput. Ind. Biomed. Art 2018, 1, 1-16. [CrossRef]

180. Rodríguez-Montaño, Ó.L.; Cortés-Rodríguez, C.J.; Naddeo, F.; Uva, A.E.; Fiorentino, M.; Naddeo, A.; Cappetti, N.; Gattullo, M.; Monno, G.; Boccaccio, A. Irregular Load Adapted Scaffold Optimization: A Computational Framework Based on Mechanobiological Criteria. ACS Biomater. Sci. Eng. 2019, 5, 5392-5411. [CrossRef]

181. Wally, Z.J.; Van Grunsven, W.; Claeyssens, F.; Goodall, R.; Reilly, G.C. Porous titanium for dental implant applications. Metals 2015, 5, 1902-1920. [CrossRef]

182. Liu, F.; Zhang, D.Z.; Zhang, P.; Zhao, M.; Jafar, S. Mechanical properties of optimized diamond lattice structure for bone scaffolds fabricated via selective laser melting. Materials 2018, 11, 374. [CrossRef]

183. Ungersböck, S.-E. Advanced Modeling of Strained CMOS Technology; Technical University of Vienna: Vienna, Austria, 2007.

184. Yang, E.; Leary, M.; Lozanovski, B.; Downing, D.; Mazur, M.; Sarker, A.; Khorasani, A.; Jones, A.; Maconachie, T.; Bateman, S. Effect of geometry on the mechanical properties of Ti-6Al-4V Gyroid structures fabricated via SLM: A numerical study. Mater. Des. 2019, 184, 108165. [CrossRef]

185. Kou, X.; Tan, S.T. A simple and effective geometric representation for irregular porous structure modeling. Comput. Des. 2010, 42, 930-941. [CrossRef]

186. Stamp, R.; Fox, P.; O'Neill, W.; Jones, E.; Sutcliffe, C. The development of a scanning strategy for the manufacture of porous biomaterials by selective laser melting. J. Mater. Sci. Mater. Med. 2009, 20, 1839-1848. [CrossRef] 
187. Dorozhkin, S.V. Calcium Orthophosphate-Based Bioceramics. Materials 2013, 6, 3840-3942. [CrossRef] [PubMed]

188. Tang, D.; Tare, R.S.; Yang, L.Y.; Williams, D.F.; Ou, K.L.; Oreffo, R.O. Biofabrication of bone tissue: Approaches, challenges and translation for bone regeneration. Biomaterials 2016, 83, 363-382. [CrossRef] [PubMed]

189. Ghanaati, S.; Barbeck, M.; Orth, C.; Willershausen, I.; Thimm, B.W.; Hoffmann, C.; Rasic, A.; Sader, R.A.; Unger, R.E.; Peters, F.; et al. Influence of beta-tricalcium phosphate granule size and morphology on tissue reaction in vivo. Acta Biomater. 2010, 6, 4476-4487. [CrossRef]

190. Sarhadi, F.; Afarani, M.S.; Mohebbi-Kalhori, D.; Shayesteh, M. Fabrication of alumina porous scaffolds with aligned oriented pores for bone tissue engineering applications. Appl. Phys. A 2016, 122, 1-8. [CrossRef]

191. Schiefer, H.; Bram, M.; Buchkremer, H.P.; Stover, D. Mechanical examinations on dental implants with porous titanium coating. J. Mater. Sci. Mater. Med. 2009, 20, 1763-1770. [CrossRef]

192. Will, J.; Melcher, R.; Treul, C.; Travitzky, N.; Kneser, U.; Polykandriotis, E.; Horch, R.; Greil, P. Porous ceramic bone scaffolds for vascularized bone tissue regeneration. J. Mater. Sci. Mater. Med. 2008, 19, 2781-2790. [CrossRef]

193. Pattanayak, D.K.; Fukuda, A.; Matsushita, T.; Takemoto, M.; Fujibayashi, S.; Sasaki, K.; Nishida, N.; Nakamura, T.; Kokubo, T. Bioactive Ti metal analogous to human cancellous bone: Fabrication by selective laser melting and chemical treatments. Acta Biomater. 2011, 7, 1398-1406. [CrossRef]

194. U.S Food and Drug Administration Department of Health and Human Services FDA, Hip Joint Metal/Polymer/Metal Semi-Constrained Porous-Coated Uncemented Prosthesis. Available online: https: //www.accessdata.fda.gov/scripts/cdrh/cfdocs/cfcfr/CFRSearch.cfm?fr=888.3358 (accessed on 29 April 2020).

195. Roosa, S.M.; Kemppainen, J.M.; Moffitt, E.N.; Krebsbach, P.H.; Hollister, S.J. The pore size of polycaprolactone scaffolds has limited influence on bone regeneration in an in vivo model. J. Biomed. Mater. Res. Part A 2010, 92, 359-368. [CrossRef]

196. Gray, C.; Boyde, A.; Jones, S.J.B. Topographically induced bone formation in vitro: Implications for bone implants and bone grafts. Bone 1996, 18, 115-123. [CrossRef]

197. Oh, I.-H.; Nomura, N.; Masahashi, N.; Hanada, S. Mechanical properties of porous titanium compacts prepared by powder sintering. Scr. Mater. 2003, 49, 1197-1202. [CrossRef]

198. Otsuki, B.; Takemoto, M.; Fujibayashi, S.; Neo, M.; Kokubo, T.; Nakamura, T. Pore throat size and connectivity determine bone and tissue ingrowth into porous implants: Three-dimensional micro-CT based structural analyses of porous bioactive titanium implants. Biomaterials 2006, 27, 5892-5900. [CrossRef]

199. Fukuda, A.; Takemoto, M.; Saito, T.; Fujibayashi, S.; Neo, M.; Pattanayak, D.K.; Matsushita, T.; Sasaki, K.; Nishida, N.; Kokubo, T.; et al. Osteoinduction of porous Ti implants with a channel structure fabricated by selective laser melting. Acta Biomater. 2011, 7, 2327-2336. [CrossRef]

200. Lemos, A.F.; Ferreira, J. Combining foaming and starch consolidation methods to develop macroporous hydroxyapatite implants. In Key Engineering Materials; Trans Tech Publications Ltd.: Freienbach, Switzerland, 2003; pp. 1041-1044.

201. Nyberg, E.L.; Farris, A.L.; Hung, B.P.; Dias, M.; Garcia, J.R.; Dorafshar, A.H.; Grayson, W.L. 3D-Printing Technologies for Craniofacial Rehabilitation, Reconstruction, and Regeneration. Ann. Biomed. Eng. 2017, 45, 45-57. [CrossRef]

202. Dhandayuthapani, B.; Yoshida, Y.; Maekawa, T.; Kumar, S. Polymeric Scaffolds in Tissue Engineering Application: A Review. Int. J. Polym. Sci. 2011, 2011. [CrossRef]

203. Li, J.P.; Li, S.H.; Van Blitterswijk, C.A.; de Groot, K. A novel porous Ti6Al4V: Characterization and cell attachment. J. Biomed. Mater. Res. Part A 2005, 73, 223-233. [CrossRef]

204. Chen, Y.; Frith, J.E.; Dehghan-Manshadi, A.; Attar, H.; Kent, D.; Soro, N.D.M.; Bermingham, M.J.; Dargusch, M.S. Mechanical properties and biocompatibility of porous titanium scaffolds for bone tissue engineering. J. Mech. Behav. Biomed. Mater. 2017, 75, 169-174. [CrossRef]

205. Hart, N.H.; Nimphius, S.; Rantalainen, T.; Ireland, A.; Siafarikas, A.; Newton, R.U. Mechanical basis of bone strength: Influence of bone material, bone structure and muscle action. J. Musculoskelet. Neuronal Interact. 2017, 17, 114-139.

206. Zadpoor, A.A. Mechanics of additively manufactured biomaterials. J. Mech. Behav. Biomed. Mater. 2017, 70, 1-6. [CrossRef] [PubMed]

207. Zadpoor, A.A. Mechanical performance of additively manufactured meta-biomaterials. Acta Biomater. 2019, 85, 41-59. [CrossRef] 
208. Misch, C.E. Stress Treatment Theorem for Implant Dentistry, 3rd ed.; Elsevier Mosby: Chennai, India, 2015; pp. 159-192.

209. Saini, M.; Singh, Y.; Arora, P.; Arora, V.; Jain, K. Implant biomaterials: A comprehensive review. World J. Clin. Cases 2015, 3, 52-57. [CrossRef]

210. Alvarez, K.; Nakajima, H. Metallic scaffolds for bone regeneration. Materials 2009, 2, 790-832. [CrossRef]

211. Brammer, K.S.; Oh, S.; Cobb, C.J.; Bjursten, L.M.; van der Heyde, H.; Jin, S. Improved bone-forming functionality on diameter-controlled TiO 2 nanotube surface. Acta Biomater. 2009, 5, 3215-3223. [CrossRef]

212. Smith, T. The effect of plasma-sprayed coatings on the fatigue of titanium alloy implants. JOM 1994, 46, 54-56. [CrossRef]

213. Zanetti, E.M.; Aldieri, A.; Terzini, M.; Calì, M.; Franceschini, G.; Bignardi, C. Additively manufactured custom load-bearing implantable devices: Grounds for caution. Australas Med. J. 2017, 10, 694. [CrossRef]

214. Silva, M.; Shepherd, E.F.; Jackson, W.O.; Dorey, F.J.; Schmalzried, T.P. Average patient walking activity approaches 2 million cycles per year: Pedometers under-record walking activity. J. Arthroplast. 2002, 17, 693-697. [CrossRef]

215. Ahmadi, S.; Hedayati, R.; Li, Y.; Lietaert, K.; Tümer, N.; Fatemi, A.; Rans, C.; Pouran, B.; Weinans, H.; Zadpoor, A. Fatigue performance of additively manufactured meta-biomaterials: The effects of topology and material type. Acta Biomater. 2018, 65, 292-304. [CrossRef]

216. FDA. Guidance Document for Testing Orthopedic Implants with Modified Metallic Surfaces Apposing Bone or Bone Cement; Branch, O.D., Ed.; U.S. Food and Drug Administration: Rockville, MD, USA, 1994.

217. Aitchison, G.; Hukins, D.; Parry, J.; Shepherd, D.; Trotman, S. A review of the design process for implantable orthopedic medical devices. Open Biomed. Eng. J. 2009, 3, 21-27. [CrossRef]

218. Fratila-Apachitei, L.E.; Leoni, A.; Riemslag, A.; Fratila-Apachitei, L.; Duszczyk, J. Enhanced fatigue performance of porous coated Ti6Al4V biomedical alloy. Appl. Surf. Sci. 2011, 257, 6941-6944. [CrossRef]

219. Gong, H.; Rafi, K.; Gu, H.; Ram, G.J.; Starr, T.; Stucker, B. Influence of defects on mechanical properties of Ti-6Al-4 V components produced by selective laser melting and electron beam melting. Mater. Des. 2015, 86, 545-554. [CrossRef]

220. Liu, H. Numerical Analysis of Thermal Stress and Deformation in Multi-Layer Laser Metal Deposition Process; Missouri University of Science and Technology: Rolla, MO, USA, 2014.

221. Li, S.J.; Murr, L.E.; Cheng, X.Y.; Zhang, Z.B.; Hao, Y.L.; Yang, R.; Medina, F.; Wicker, R.B. Compression fatigue behavior of Ti-6Al-4V mesh arrays fabricated by electron beam melting. Acta Mater. 2012, 60, 793-802. [CrossRef]

222. Martinez-Marquez, D.; Gulati, K.; Carty, C.P.; Stewart, R.A.; Ivanovski, S. Determining the relative importance of titania nanotubes characteristics on bone implant surface performance: A quality by design study with a fuzzy approach. Mater. Sci. Eng. C 2020, 114, 110995. [CrossRef] [PubMed]

223. Yu, L.X. Pharmaceutical quality by design: Product and process development, understanding, and control. Pharm. Res. 2008, 25, 781-791. [CrossRef]

Publisher's Note: MDPI stays neutral with regard to jurisdictional claims in published maps and institutional affiliations.

(C) 2020 by the authors. Licensee MDPI, Basel, Switzerland. This article is an open access article distributed under the terms and conditions of the Creative Commons Attribution (CC BY) license (http://creativecommons.org/licenses/by/4.0/). 